\title{
Data Collection Programs in Support of Endangered Bird Management at Fort Hood, Texas
} by

Steve T. Mackie

Timothy J. Hayden

Supporting the military mission while continuing to protect threatened and endangered (T\&E) species presents a unique challenge to the Army. Land managers need species-specific information to help them make better decisions regarding training exercises, troop and vehicle movements, and other mission requirements. Traditional methods of collecting data in the field and manually entering it into computer databases for analysis lag behind technological capabilities. To address these problems, land managers at Fort Hood, TX, tasked the U.S. Army Construction Engineering Research Laboratories with developing a an efficient program for use by field technicians who collect survey data on endangered birds inhabiting the installation.
This report presents nine programs designed to be run in the field during survey and data collection activities. The programs require an IBM®-compatible computer with at least a 386 processor, $4 \mathrm{MB}$ of RAM, 20MB of available hard disk space, and running Windows $₫ 3.1$ or higher and Excel $\AA$. The programs also use an electronic pen; previous experience with that technology is helpful. 


\section{REPORT DOCUMENTATION PAGE}

Public reporting burden for this collection of information is estimated to average 1 hour per response, including the time for reviewing instr ctions, searching existing data sources, gathering and maintaining the data needed, and completing and reviewing the collection of intormation. Send comments regarding this burden estimate or any other aspect of this collection of information, including suggestions for reducing this burden, to Washington Headquarters Services, Directorate for information Operations and Reports, 1215 Jefferson Davis Highway. Suite 1204, Arlington. VA 22202-4302, and to the Ottice of Management and Budget. Paperwork Reduction Project (0704-0188). Washington, DC 20503.

\begin{tabular}{|l|l|l} 
1. AGENCY USE ONLY (Leave Blank) & 2. REPORT DATE \\
June 1997 & $\begin{array}{c}\text { 3. REPORT TYPE AND DATES COVERED } \\
\text { Final }\end{array}$
\end{tabular}

4. TITLE AND SUBTITLE

Data Collection Programs in Support of Endangered Bird Management at Fort Hood, $\quad$ MIPR

Texas

6. AUTHOR(S)

Steve T. Mackie and Timothy J. Hayden

7. PERFORMING ORGANIZATION NAME(S) AND ADDRESS(ES)

U.S. Army Construction Engineering Research Laboratories (USACERL)

P.O. Box 9005

Champaign, IL 61826-9005

9. SPONSORING / MONITORING AGENCY NAME(S) AND ADDRESS(ES)

Commander, III Corps

329-74 and 319-95

ATTN: AFZF-PW-WNV-NR

Building 1938

Fort Hood, TX 76544

11. SUPPLEMENTARY NOTES

Copies are available from the National Technical Information Service, 5285 Port Royal Road, Springfield, VA 22161.

12a. DISTRIBUTION / AVAILABILITY STATEMENT

12b. DISTRIE UTION CODE

Approved for public release; distribution is unlimited.

13. ABSTRACT (Maximum 200 words)

Supporting the military mission while continuing to protect threatened and endangered (T\&E) species presents a unique challenge to the Army. Land managers need species-specific information to help them make better decisions regarding training exercises, troop and vehicle movements, and other mission requirements. Traditional methods of collecting data in the field and manually entering it into computer databases for analysis lag behind technological capabilities. To address these problems, land managers at Fort Hood, TX, tasked the U.S. Army Construction Engineering K.esearch Laboratories with developing a an efficient program for use by field technicians who collect survey data on endangered birds inhabiting the installation.

This report presents nine programs designed to be run in the field during survey and data collection activities. The programs require an IBM ${ }^{\circledR}$-compatible computer with at least a 386 processor, $4 \mathrm{MB}$ of RAM, 20MB of available hard disk space, and running Windows ${ }^{\circledR} 3.1$ or higher and Excel $®$. The programs also use an electronic pen; previous experience with that technology is helpful.

\begin{tabular}{|c|c|c|}
\hline $\begin{array}{l}\text { 14. SUBJECT TERMS } \\
\text { Endangered species } \\
\text { Computer programs } \\
\text { Ft. Hood, TX }\end{array}$ & \multicolumn{2}{|c|}{ Land management } \\
\hline $\begin{array}{l}\text { 17. SECURITY CLASSIFICATION } \\
\text { OF REPORT } \\
\text { Unclassified }\end{array}$ & $\begin{array}{l}\text { 18. SECURITY CLASSIFICATION } \\
\text { OF THIS PAGE } \\
\text { Unclassified }\end{array}$ & $\begin{array}{l}\text { 19. SECURITY CLASSIFICATION } \\
\text { OF ABSTRACT } \\
\text { Unclassified }\end{array}$ \\
\hline
\end{tabular}




\section{Foreword}

This study was conducted for III Corps Fort Hood under Military Interdepartmental Purchase Requests 329-94 and 319-95 "Monitoring BCVI and GCWA on Fort Hood." The technical monitor was Dennis Herbert, AFZF-PW-ENV-NR.

The work was performed by the Natural Resource Assessment and Management Division (LL-N) of the Land Management Laboratory (LL), U.S. Army Construction Engineering Research Laboratories (USACERL) in cooperation with the Fort Hood Natural Resources Branch. The USACERL principal investigator was Timothy J. Hayden. Several individuals were invaluable in helping design these programs. Howard Weinberg was an integral part of designing the Black-Capped Vireo program and gave many valuable suggestions for the banding and sighting/recaptures program. Maria Tolle, Fort Hood Natural Resources Branch, contributed helpful advice on the point count and Golden-Cheeked Warbler programs. Gil Eckrich, Fort Hood Natural Resources Branch, provided constructive comments on the Brown-Headed Cowbird trapping and non-target species programs. By executing the programs and entering data, Teresa Koloszar, Fort Hood Natural Resources Branch, provided keen insight from a user's perspective. Without the assistance and helpful comments from these people, this work would not have been possible. Dr. David J. Tazik is Acting Chief, CECER-LL-N; Dr. William D. Severinghaus is Operations Chief, CECER-LL. The USACERL technical editor was Gloria J. Wienke, Technical Resources.

Dr. Michael J. O’Connor is Technical Director of USACERL. 


\section{Contents}

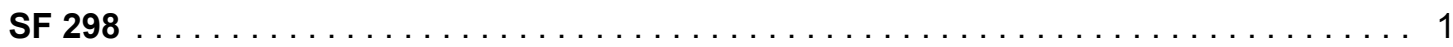

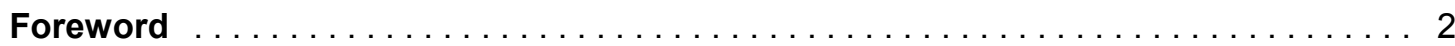

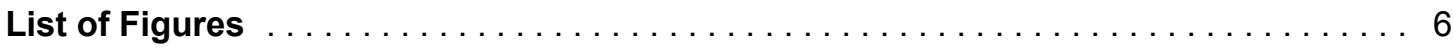

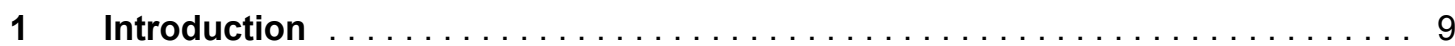

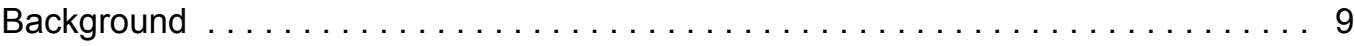

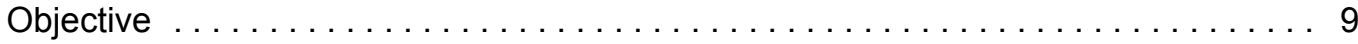

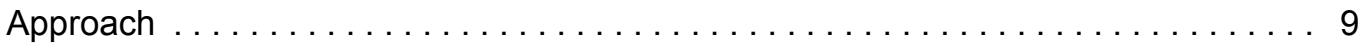

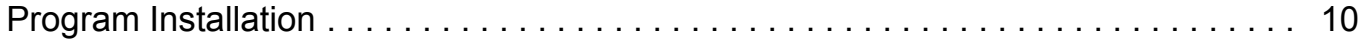

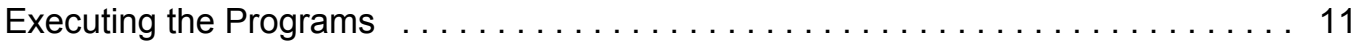

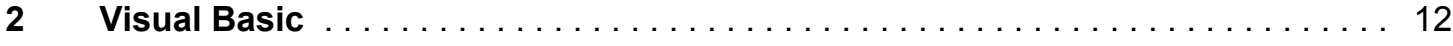

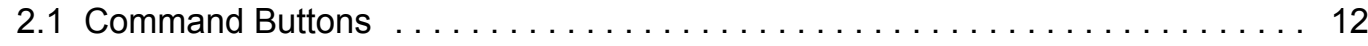

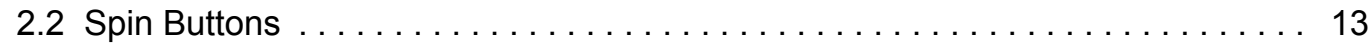

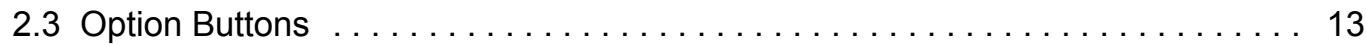

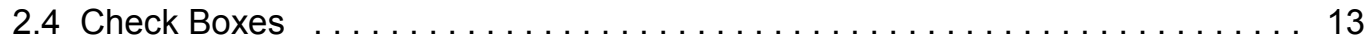

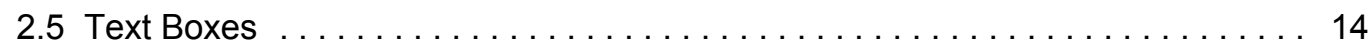

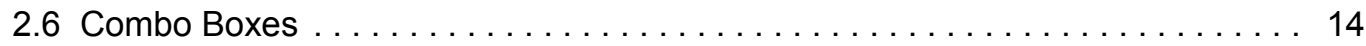

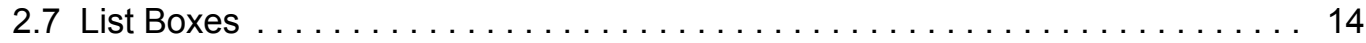

2.8 Data Controls . . . . . . . . . . . . . . . . . . . . . . . . . . 14

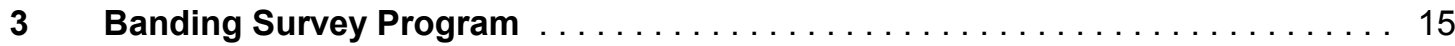

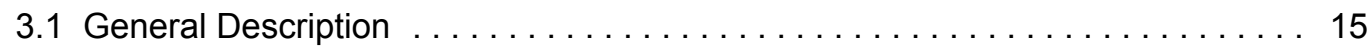

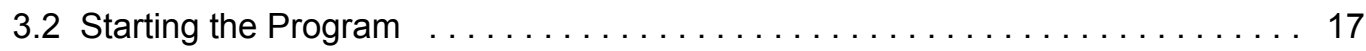

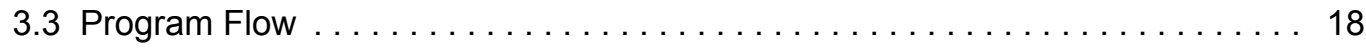

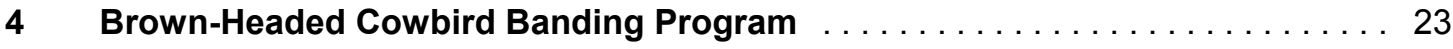

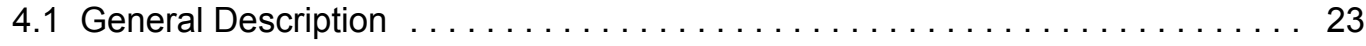

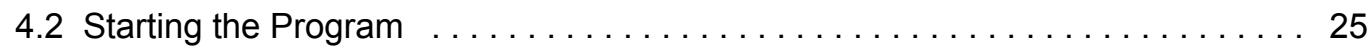

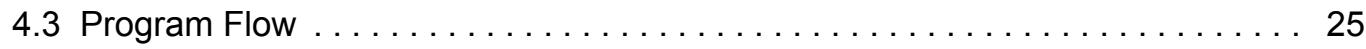

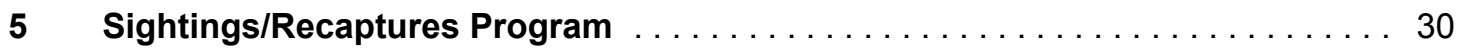

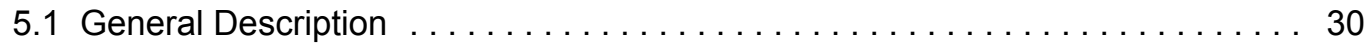

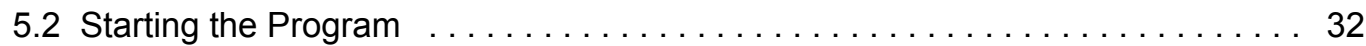

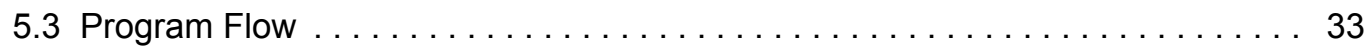




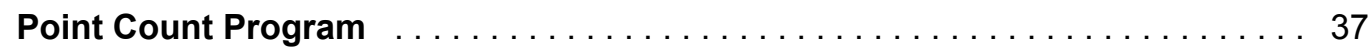

6.1 General Description $\ldots \ldots \ldots \ldots \ldots \ldots \ldots \ldots \ldots \ldots \ldots \ldots \ldots \ldots \ldots \ldots \ldots \ldots \ldots \ldots$

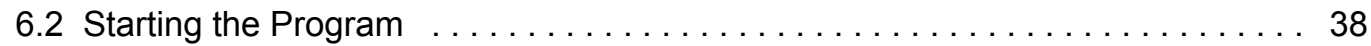

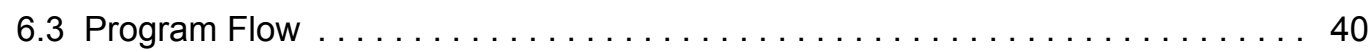

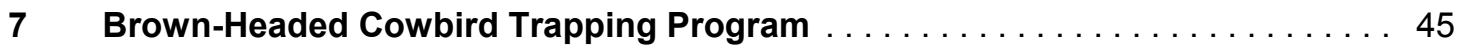

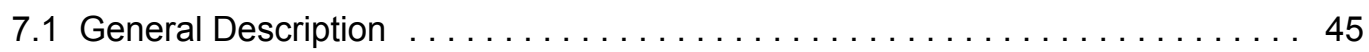

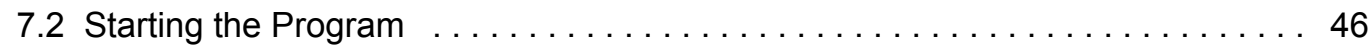

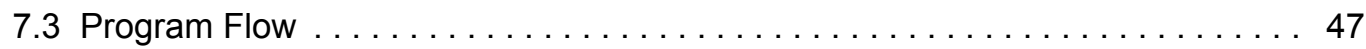

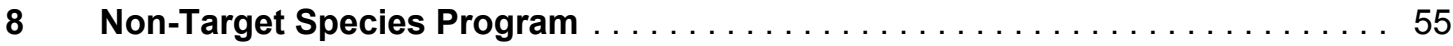

8.1 General Description . . . . . . . . . . . . . . . . . . . . . . 55

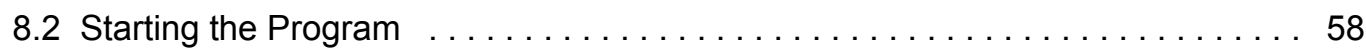

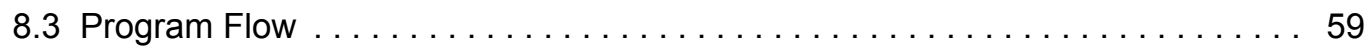

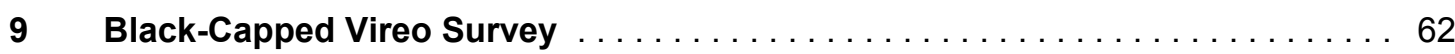

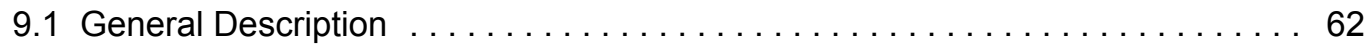

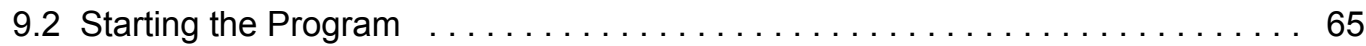

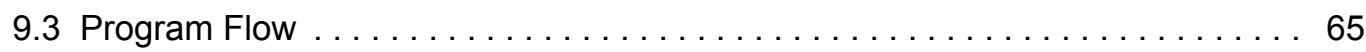

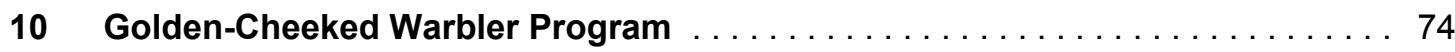

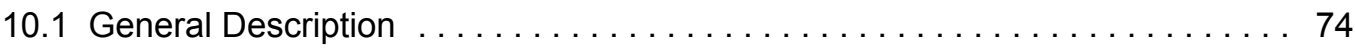

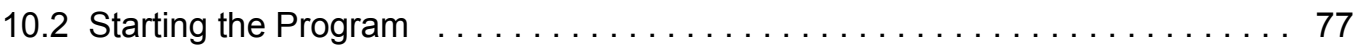

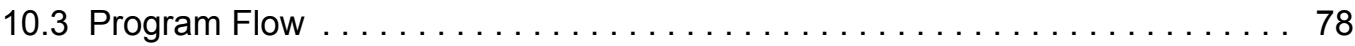

11 Database Backup Program $\ldots \ldots \ldots \ldots \ldots \ldots \ldots \ldots \ldots \ldots \ldots \ldots \ldots \ldots \ldots$

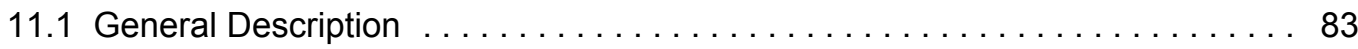

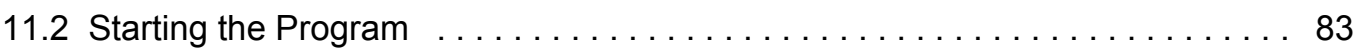

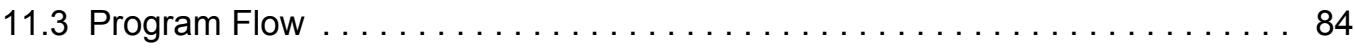

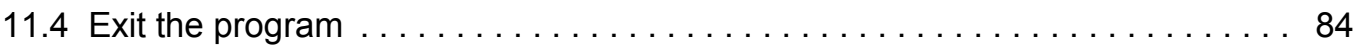

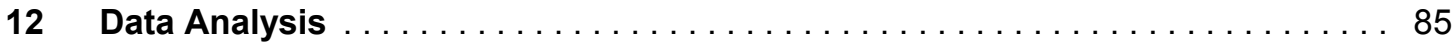

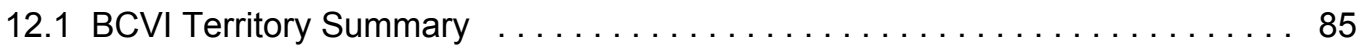

12.2 BCVI Nest Fates and Success Rates $\ldots \ldots \ldots \ldots \ldots \ldots \ldots \ldots \ldots . \ldots \ldots$

12.3 BCVI Nest Fates and Success Rates (monitored $>3$ dates) . . . . . . . . 87

12.4 BCVI Productivity and Pair Success of Successful Territories . . . . . . . . . 87

12.5 BCVI Productivity and Pair Success of Successful Territories

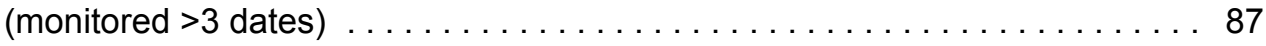

12.6 BCVI Productivity and Pair Success of All Territories . . . . . . . . . . 88

12.7 Age Structures for Banded BCVls $\ldots \ldots \ldots \ldots \ldots \ldots \ldots \ldots \ldots \ldots$

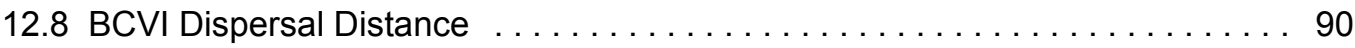

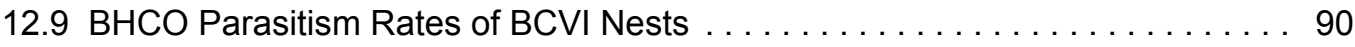

12.10 BHCO and Non-Target Species Trap Deaths ................ 92

12.11 Breakdown of Non-Target Species Deaths . . . . . . . . . . . . 92

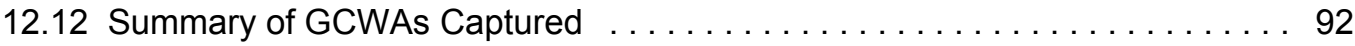

12.13 Male GCWAs Searched for and Found $\ldots \ldots \ldots \ldots \ldots \ldots \ldots \ldots$ 
12.14 GCWAs Returned From Previous Years . . . . . . . . . . . . . . . 93

12.15 GCWA Dispersal Distance . . . . . . . . . . . . . . . . . . 96

12.16 GCWAs Detected on Point Counts $\ldots \ldots \ldots \ldots \ldots \ldots \ldots \ldots \ldots \ldots$ 


\section{List of Figures}

\section{Figures}

\begin{tabular}{|c|c|c|}
\hline 1 & Command buttons & 12 \\
\hline 2 & Spin buttons & 13 \\
\hline 3 & Option buttons & 13 \\
\hline 4 & Check boxes & 13 \\
\hline 5 & Text boxes & 14 \\
\hline 6 & Combo boxes & 14 \\
\hline 7 & List boxes & 14 \\
\hline 8 & Data controls & 14 \\
\hline 9 & Banding Survey data entry form & 17 \\
\hline 10 & Band number selection form & 20 \\
\hline 11 & Banded GCWAs per training area & 21 \\
\hline 12 & BHCO banding data entry form & 25 \\
\hline 13 & BHCO band selection form & 27 \\
\hline 14 & Banded BHCOs per trap & 28 \\
\hline 15 & Sightings/recaptures data entry form & 32 \\
\hline 16 & Sightings/Recaptures band number selection form & 35 \\
\hline 17 & Daily conditions form & 39 \\
\hline 18 & Bird count data entry form & 40 \\
\hline 19 & Bird count selection list box & 43 \\
\hline 20 & Cowbird trapping main menu & 47 \\
\hline 21 & New trap form . & 48 \\
\hline 22 & Cowbird trappings selection list box & 49 \\
\hline 23 & New record form & \\
\hline
\end{tabular}




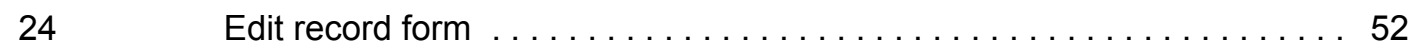

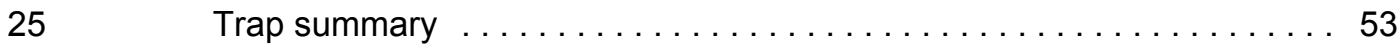

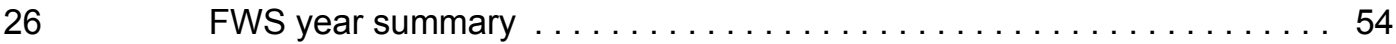

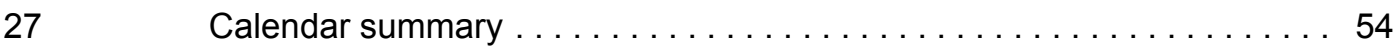

$28 \quad$ Non-target species main menu $\ldots \ldots \ldots \ldots \ldots \ldots \ldots \ldots \ldots$

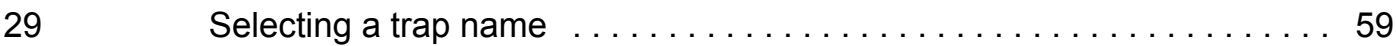

$30 \quad$ Non-targt species data entry form $\ldots \ldots \ldots \ldots \ldots \ldots \ldots \ldots \ldots \ldots \ldots \ldots$

$31 \quad$ Non-target species edit form $\ldots \ldots \ldots \ldots \ldots \ldots \ldots \ldots \ldots \ldots \ldots \ldots \ldots \ldots$

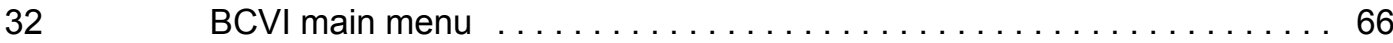

33 BCVI new territory form $\ldots \ldots \ldots \ldots \ldots \ldots \ldots \ldots \ldots \ldots \ldots \ldots \ldots \ldots \ldots \ldots \ldots$

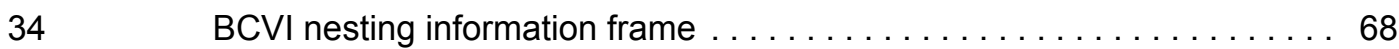

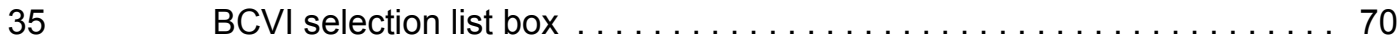

$36 \quad$ BCVI new observation form $\ldots \ldots \ldots \ldots \ldots \ldots \ldots \ldots \ldots \ldots \ldots \ldots \ldots$

$37 \quad$ BCVI summary of observations form $\ldots \ldots \ldots \ldots \ldots \ldots \ldots \ldots \ldots$

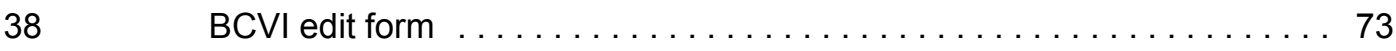

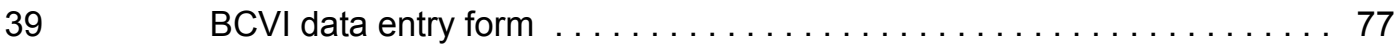

$40 \quad$ Target bird selection form $\ldots \ldots \ldots \ldots \ldots \ldots \ldots \ldots \ldots \ldots$

$41 \quad$ GCWA nesting data frame $\ldots \ldots \ldots \ldots \ldots \ldots \ldots \ldots \ldots \ldots \ldots \ldots \ldots$

$42 \quad$ Database backup form $\ldots \ldots \ldots \ldots \ldots \ldots \ldots \ldots \ldots \ldots \ldots \ldots \ldots$

$43 \quad$ BCVI territory summary $\ldots \ldots \ldots \ldots \ldots \ldots \ldots \ldots \ldots \ldots \ldots$

$44 \quad$ BCVI nest fates and success rates $\ldots \ldots \ldots \ldots \ldots \ldots \ldots$

$45 \quad$ BCVI productivity and pair success $\ldots \ldots \ldots \ldots \ldots \ldots \ldots \ldots \ldots$

$46 \quad$ BCVI productivity and pair success for all BCVI pairs $\ldots \ldots \ldots \ldots 8$

$47 \quad$ Age structures for adult male $\mathrm{BCVI} \ldots \ldots \ldots \ldots \ldots \ldots \ldots$

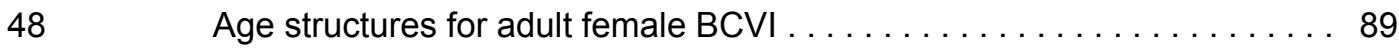

$49 \quad$ Age structures for banded adult BCVI $\ldots \ldots \ldots \ldots \ldots \ldots \ldots \ldots$

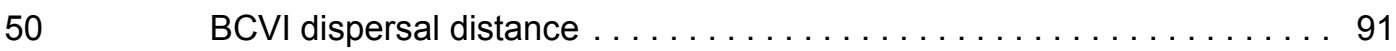

$51 \quad$ BHCO parasitism rates of BCVI $\ldots \ldots \ldots \ldots \ldots \ldots \ldots \ldots \ldots \ldots \ldots$

$52 \quad$ BHCO and non-target species deaths $\ldots \ldots \ldots \ldots \ldots \ldots \ldots \ldots \ldots$ 
$53 \quad$ Breakdown of non-target species deaths $\ldots \ldots \ldots \ldots \ldots \ldots \ldots$

$54 \quad$ Captured GCWAs by sex and age $\ldots \ldots \ldots \ldots \ldots \ldots \ldots \ldots \ldots \ldots \ldots \ldots$

$55 \quad$ Captured GCWAs by sex, region, and training area $\ldots \ldots \ldots \ldots \ldots 94$

$56 \quad$ Male GCWAs by age and training area $\ldots \ldots \ldots \ldots \ldots \ldots \ldots$

$57 \quad$ Male GCWAs searched for and found $\ldots \ldots \ldots \ldots \ldots \ldots \ldots \ldots$

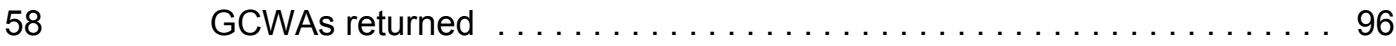

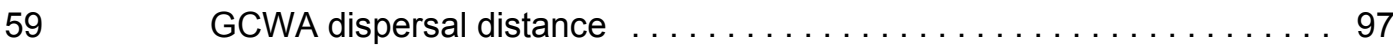

$60 \quad$ Training areas containing GCWAs $\ldots \ldots \ldots \ldots \ldots \ldots \ldots \ldots \ldots$

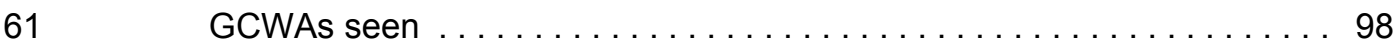

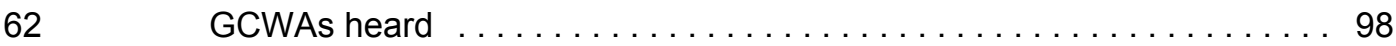

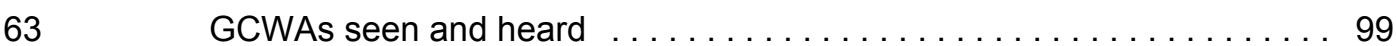




\section{Introduction}

\section{Background}

Supporting the military mission while continuing to protect endangered species presents a unique challenge to the Army. Much of the threatened and endangered (T\&E) species research conducted on installations focuses on assessing and monitoring military activity impacts on T\&E species inhabiting Army lands. The Army is increasingly committing significant resources, both financial and personnel, for research and monitoring $\mathrm{T} \& \mathrm{E}$ species on military lands. These activities require collecting, storing, and monitoring large amounts of data. In the past, data was collected by hand via pen and pad and then stored later back at the office. Data handled this way could end up being inconsistent, undecipherable, and possibly even lost. To address that problem, the U.S. Army Construction Engineering Research Laboratories (USACERL) began to develop and use a variety of state-ofthe-art computer hardware and software capabilities to enhance and efficiently increase field data collection, storage, and manipulation. As part of that overall

process, land managers at Fort Hood, TX, tasked USACERL with developing an efficient program for use by field technicians who collect survey data on endangered birds inhabiting the installation.

\section{Objective}

The objective of this research was to develop computer programs to efficiently collect, store, and retrieve field data on endangered bird species at Fort Hood, TX. The programs were to (1) be easy to use, (2) ensure data accuracy, and (3) save time and money.

\section{Approach}

Initial program design and development was based on field data collected in previous years by Fort Hood natural resources personnel. Program design, layout, and functionality changes were made after consulting with personnel at USACERL 
and Fort Hood. Final refinements were made after field testing the programs during the 1994 breeding season.

The programs include:

Banding Survey Program

Brown-Headed Cowbird Banding Program

Sightings/Recaptures Program

Point Count Program

Brown-Headed Cowbird Trapping Program

Non-Target Species Program

Black-Capped Vireo Program

Golden-Cheeked Warbler Program

Database Backup Program

\section{Program Installation}

The programs should be run on an IBM-compatible computer using Microsoft Windows 3.1 or higher to interface with MS-DOS. The computer should contain at least a 386 processor, $4 \mathrm{MB}$ of RAM and $20 \mathrm{MB}$ of available hard disk space. Microsoft Office with Excel ${ }^{*}$ must be installed on the computer. The user should have a basic working knowledge of Windows and know how to use an electronic mouse. The programs also use an electronic pen; previous experience with that technology is helpful.

The program files are supplied on 3.5-in. diskettes with an installation program included. To install these files, Microsoft Windows must be running on the computer. Follow the steps below.

1. Create a subdirectory called "VB" under the $\mathrm{C}: \backslash$ root directory.

("VB" represents Visual Basic as will be explained in the next chapter.)

2. Insert the program disks into drive A: (or B:).

2. Select "File" from the Program Manager menu.

3. Select "Run" from the pop-up menu.

4. Select "Browse."

5. Go to drive A: (or B:) and double click on the file "setup.exe" and select "OK."

"Windows and Excel are registered trademarks of Microsoft Corporation. 
6. Change the default installation drive from " $\mathrm{C}: \backslash$..." to " $\mathrm{C}: \backslash \mathrm{VB} \backslash$..." where “..." specifies the default program directory. Each program directory will contain the software for each individual program.

7. Select "OK."

8. When installation is complete, a default program group and item will be created. After all programs have been installed, it's a good idea to transfer all program items under one common program group called Fort Hood Bird Survey to reduce clutter on the screen.

9. Transfer the file "vb.ini" from the program directory to the "C: $\backslash \mathrm{VB}$ " subdirectory.

\section{Executing the Programs}

All data collection programs written for Fort Hood should be in the program group titled Fort Hood Bird Survey. Each program is associated with a generic icon that has the program name underneath it. Before starting any program, make sure the file "share.exe" is running from under the $\mathrm{C}: \backslash$ WINDOWS subdirectory. To execute a program, use the mouse to position the cursor over the program and double tap it with the pen. For documentation purposes, every program requires you to enter your initials. As long as you keep running a program, your initials will become part of the records saved to that program's database.

The programs are designed to be run in the field during survey and data collection activities. Data analysis should be conducted in the office so results can be printed. 


\section{Visual Basic}

All programs are written in Microsoft Visual Basic* 3.0 and all records are saved to DBase IV database files. To run these programs effectively, it is important that you acquire a basic knowledge of the components making up Visual Basic's programming language as well as the basic software and data files you'll be using.

In Visual Basic, all items on a form (or window) are called controls. Controls are the interface between the program and the user. Controls gather and manipulate your input as well as format and display output. They perform certain functions based on your response. Of special interest are command buttons, spin buttons, option buttons, check boxes, text boxes, combo boxes, list boxes, and data controls.

\subsection{Command Buttons}

Tapping a command button on the screen with the electronic pen initiates one or more actions and is the most common way for you to interact with the program. When you tap a button, its 3D image will appear to be pushed in and then released. All command buttons have a one- or two-word description written on them. Figure 1 shows an example of several command buttons.

\subsection{Spin Buttons}

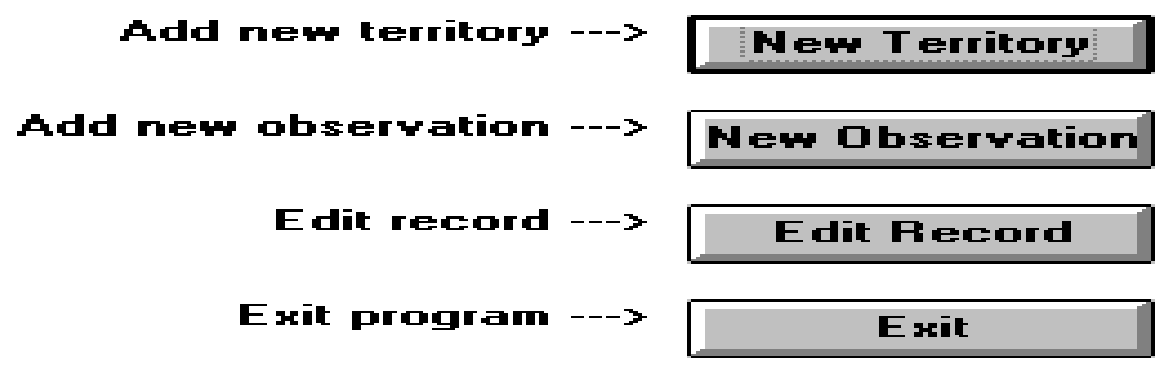

FiğlieualcBmaniarid buttogistered trademark of Microsoft Corporation 
Spin buttons are used in conjunction with text boxes to increment or decrement numbers. When you tap the up arrow, the number will increase. Conversely, when you tap the down arrow, the number decreases. You can also use spin buttons to scroll back and forth through a range of values. Figure 2 shows an example of spin buttons.

\subsection{Option Buttons}

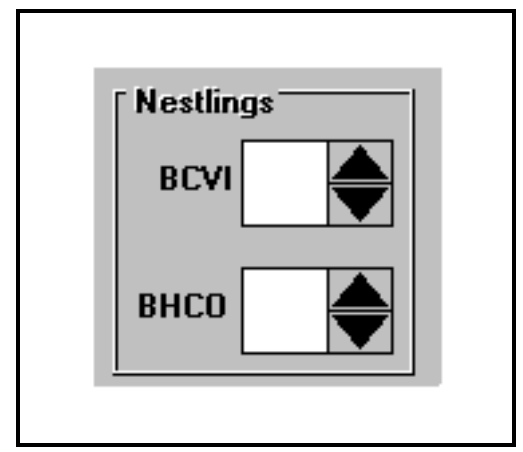

Figure 2. Spin buttons.

The option buttons display an option that can be turned on or off. Usually, option buttons are part of an option group that displays multiple choices from which you can select only one. All others are deselected. Typically, option buttons will be grouped within a boxed frame. To select an option button, tap it with the pen. To deselect it, tap it again. Figure 3 shows a group of option

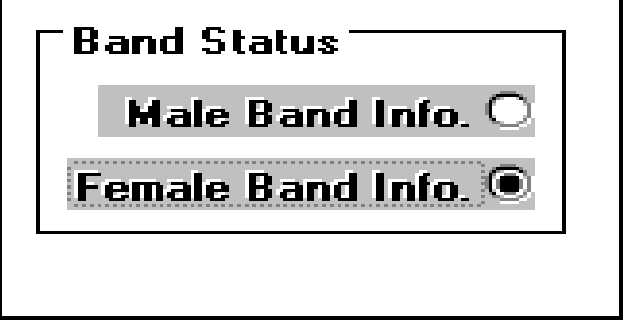

Figure 3. Option buttons. buttons within a frame with Female Band Info. selected.

\subsection{Check Boxes}

Check boxes display an $\mathrm{X}$ when you tap it and remove the $\mathrm{X}$ when you tap it again. Check boxes give you a True/False or Yes/No option. They are used in groups to display multiple choices from which you can select one or more. Check boxes and option buttons function similarly but with one important difference. You can select any number of check boxes on a form at the same time, however you can only select one option button in a group. Figure 4 shows an example of check boxes.

\subsection{Text Boxes}

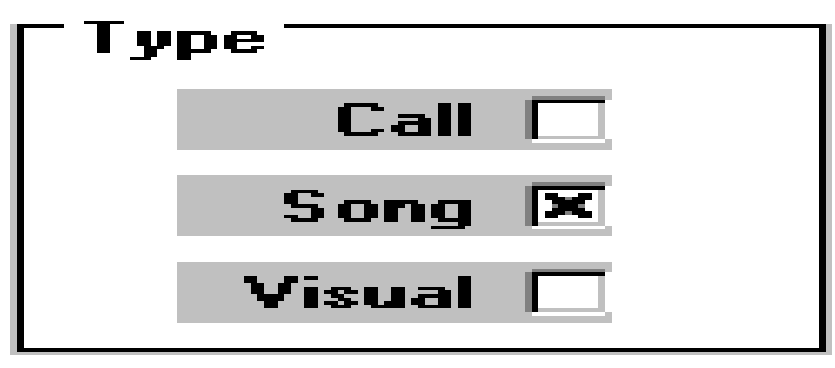

Figure 4. Check boxes. 
The text boxes display information you entered or retrieved from the database. In most cases, text boxes are tied (or linked) to corresponding fields in the database. Information in a text box usually can be edited. Figure 5 shows an example of text boxes.

Date $07 / 17 / 1995$

Dbserver SM

\begin{tabular}{|c|c|c|c|c|c|c|c|}
\hline & & & & & & & \\
\hline $\begin{array}{l}\text { Trap } \\
\text { Name }\end{array}$ & LOC1 & $\begin{array}{c}\text { Training } \\
\text { Area }\end{array}$ & 5 & Easting & 231 & Northing & 546 \\
\hline
\end{tabular}

Figure 5. Text boxes.

\subsection{Combo Boxes}

Combo boxes give you the choice of selecting an item from the list portion of the control or typing in the text box portion. All combo boxes are populated with specific values appropriate for the required data. Figure 6 shows an example of combo boxes.

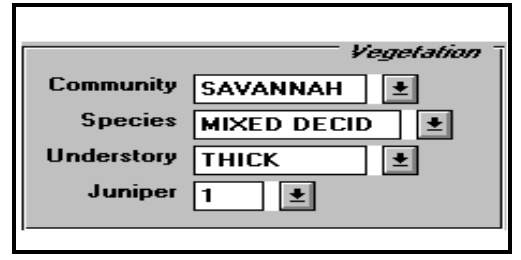

Figure 6. Combo boxes.

\subsection{List Boxes}

List boxes display a list of items from which you can choose one item. If the number of items is greater than the length of the list box, vertical scroll arrows will appear. Figure 7 shows an example of a list boxes.

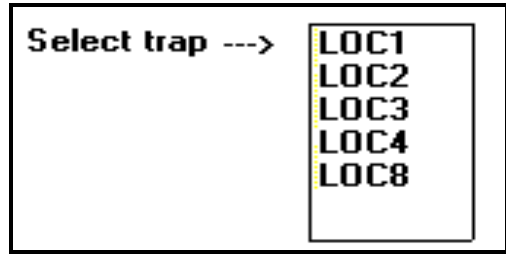

Figure 7. List boxes.

\subsection{Data Controls}

Data controls provides access to data contained in a DBase IV database. They allow you to move from record to record so you can display each one. Every data control contains two sets of left and right arrows. The outer left and right arrows bring you to the first and last records in the database, respectively. The inner left

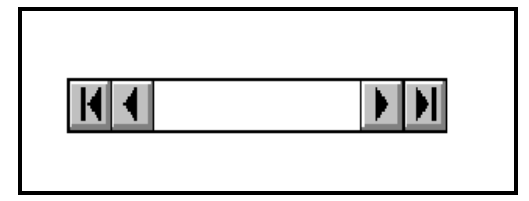

Figure 8. Data controls. and right arrows move you one record before and after the current record, respectively. Figure 8 shows an example of data controls. 


\section{Banding Survey Program}

(BAND_SRV.MAK)

\subsection{General Description}

The Banding Survey Program records banding and measurement data on previously unbanded birds. Although this program is geared towards black-capped vireos and golden-cheeked warblers, it will record information about any bird other than brown-headed cowbirds and loggerhead shrikes, which are recorded in a separate banding database. The records are stored in one of three different DBase IV database files that you select. If you enter records for black-capped vireos, the path name is C: $\backslash V B \backslash B A N D \_S R V \backslash B C V I \_B N D . D B F$. If you enter records for goldencheeked warblers, the path name is $C: \backslash V B \backslash B A N D$ SRV $\backslash$ GCWA_BND.DBF. If you enter records for other birds, the path name is $\mathrm{C}: \backslash \mathrm{VB} \backslash \mathrm{BAND}$ _SRV $\backslash \mathrm{BAND}$ DB.DBF. The field names and descriptions of these files are identical and are given below. Data types and data lengths are given in parentheses.

REC_NUMBER (string) (4) - Number of the record in the database.

DATE (string) (8) - Current date.

OBSERVER (string) (3) - Observer's initials.

BAND_STAT (string) (1) - Status of leg band.

STAT_CODE (string) (3) - Category of banding detail given to a bird.

BAND (string) (4) - Band number prefix.

NUMBER (string) (5) - Band number suffix.

SPECIES (string) (4) - Species code.

SP_NUMBER (string) (4) - A unique 4 digit code representing a bird species. The program will automatically insert this number as part of the record. 
AGE (string) (3) - Age of bird.

AGE_CODE (string) (1) - A one digit code representing a bird's age. The program will automatically insert the correct code into the record based on the entry in the AGE field.

0 - Unknown

1 - AHY (After Hatching Year)

2 - HY (Hatching Year)

4 - L (Local)

5 - SY (Second Year)

6 - ASY (After Second Year)

SEX (string) (1) - Numeric code representing sex of bird.

UP_LEFT (string) (2) - Color code representing the upper left leg band of a banded bird.

LOW_LEFT (string) (2) - Color code representing the lower left leg band of a banded bird.

UP_RIGHT (string) (2) - Color code representing the upper right leg band of a banded bird.

LOW_RIGHT (string) (2) - Color code representing the lower right leg band of a banded bird.

HATCH_ORDR (string) (1) - Hatching order of bird.

REGION (string) (4) - Designated region of Fort Hood. The program will automatically insert the correct region into the record based on the entry in the TR_AREA field.

TR_AREA (string) (4) - Training Area.

TERRITORY (string) (2) - Territory number within a training area.

NEST_NUMBR (string) (1) - Number of nest.

EASTING (string) (6) - UTM Easting coordinate. 
NORTHING (string) (3) - UTM Northing coordinate.

CP (string) (2) - Cloacal protuberance.

BP (string) (2) - Brood patch.

CAP_PLUM (string) (3) - Cap plumage.

WING_LEN (numeric) (8) - Wing length measurement.

TAIL_LEN (numeric) (8) - Tail length measurement.

WEIGHT (numeric) (8) - Weight measurement.

COMMENTS (string) (150) - Any important notes.

\subsection{Starting the Program}

To start the program, double tap the Banding Survey icon with the pen. After typing in your initials and tapping $\mathrm{OK}$, the program will ask for which bird to enter data. The default is "BCVI." To record information for golden-cheeked warbler, write in "GCWA." To record information for any bird other than brownheaded cowbird or loggerhead shrike, write in "OTHER." Tap OK and the data entry form in Figure 9 will appear.

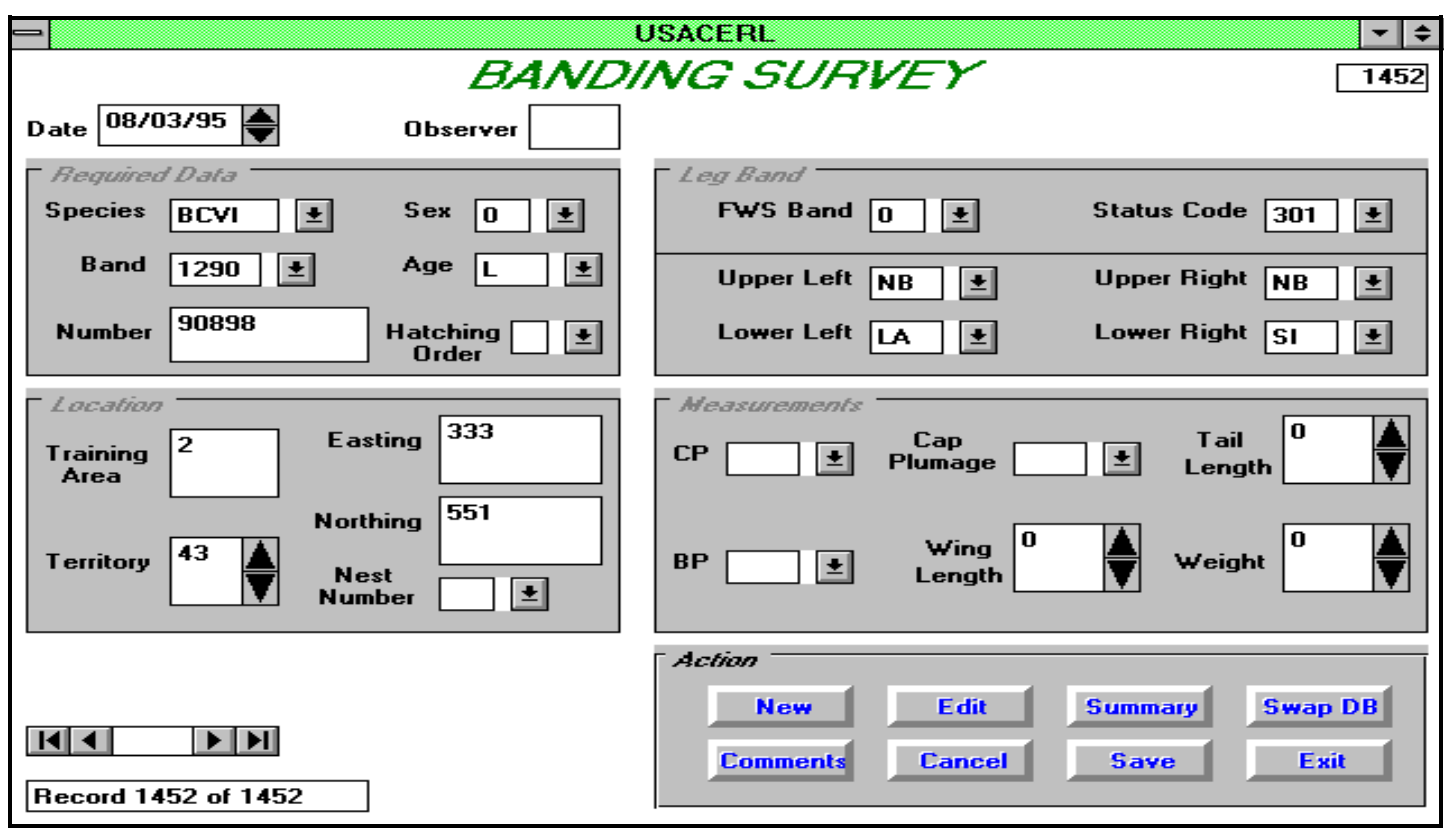

Figure 9. Banding Survey data entry form. 
Once started, the information displayed on the form is the last record in the database. The total number of records in the database is shown at the bottom left corner of the form. The number at the top right corner indicates the number of the individual record in the database. From here, you can add, edit, or view any record in the database.

\subsection{Program Flow}

\section{a. Add a new record}

To add a new record, tap the New button. All fields are cleared out except for observer, record number, FWS band, and status code which are automatically assigned default values. If you're entering data for black-capped vireos or goldencheeked warblers, the program will also insert a species code and assign default wing length, tail length, and weight values. You can change the default observer initials by double tapping on the observer text box and entering new initials.

Of the four frames on the form, only one is enabled or "turned on." The first frame, Required Data, is enabled to remind you that this information must be included on every record. No other frame will be enabled until you enter data for every control in this frame. However, if you need to record a lost or damaged band, feel free to enter the band number along with a band status. The band status field is not disabled.

Date - Double tap the box to insert the current date. Use the spin button to increment/decrement the date.

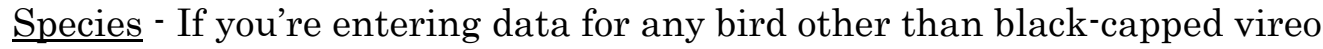
or golden-cheeked warbler, choose a species code from the combo box. If a species doesn't appear on the list, write in the species code. The program will not accept entries for BHCO or LOSH.

Band - Except for the first record, the program will automatically insert a default band prefix if you're entering data for black-capped vireos or goldencheeked warblers. Otherwise, choose a band prefix from the combo box. If a band prefix you want doesn't appear in the list, write it in the box.

Number - Write the band number suffix in the text box. 
$\underline{\text { Sex }}$ - Choose a sex code from the combo box. If you choose "4" (male), the BP combo box field will be disabled. If you choose " 5 " (female), the CP combo box field will be disabled. If you choose "0"(unknown), both boxes will be disabled.

Age - Choose an age code from the combo box. Once you have selected an age code, the remaining frames will be enabled. If you choose "L," the Hatching Order combo box appears. Choose a number representing the hatching order.

FWS Band - Choose an FWS band status code from the combo box or accept the default.

$\underline{\text { Status Code }}$ - Choose a status code from the combo box or accept the default.

Upper Left - Lower Right - Choose a color code for each leg band from the combo boxes.

Training Area - Write the training area in the text box.

Territory - Use the spin button to increment/decrement the territory or write it in the text box.

Easting - Write the easting coordinate in the text box.

Northing - Write the northing coordinate in the text box.

Nest Number - Choose a number from the combo box.

$\underline{\mathrm{CP}}$ - Choose a CP code from the combo box.

$\underline{\mathrm{BP}}$ - Choose a BP code from the combo box.

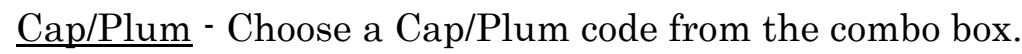

Wing Length - Use the spin button to increment/decrement the default wing length.

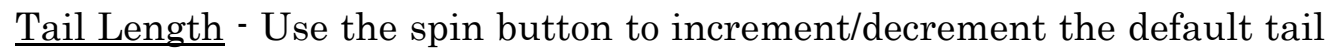
length. 
Weight - Use the spin button to increment/decrement the default weight by 0.1 grams.

Comments - Tap the Comments button. In the white space provided, write in any necessary comments. To eliminate or close the Comments box, double tap it.

b. Edit a record

To edit a record, tap the Edit button. Figure 10 shows the resulting band number selection form:

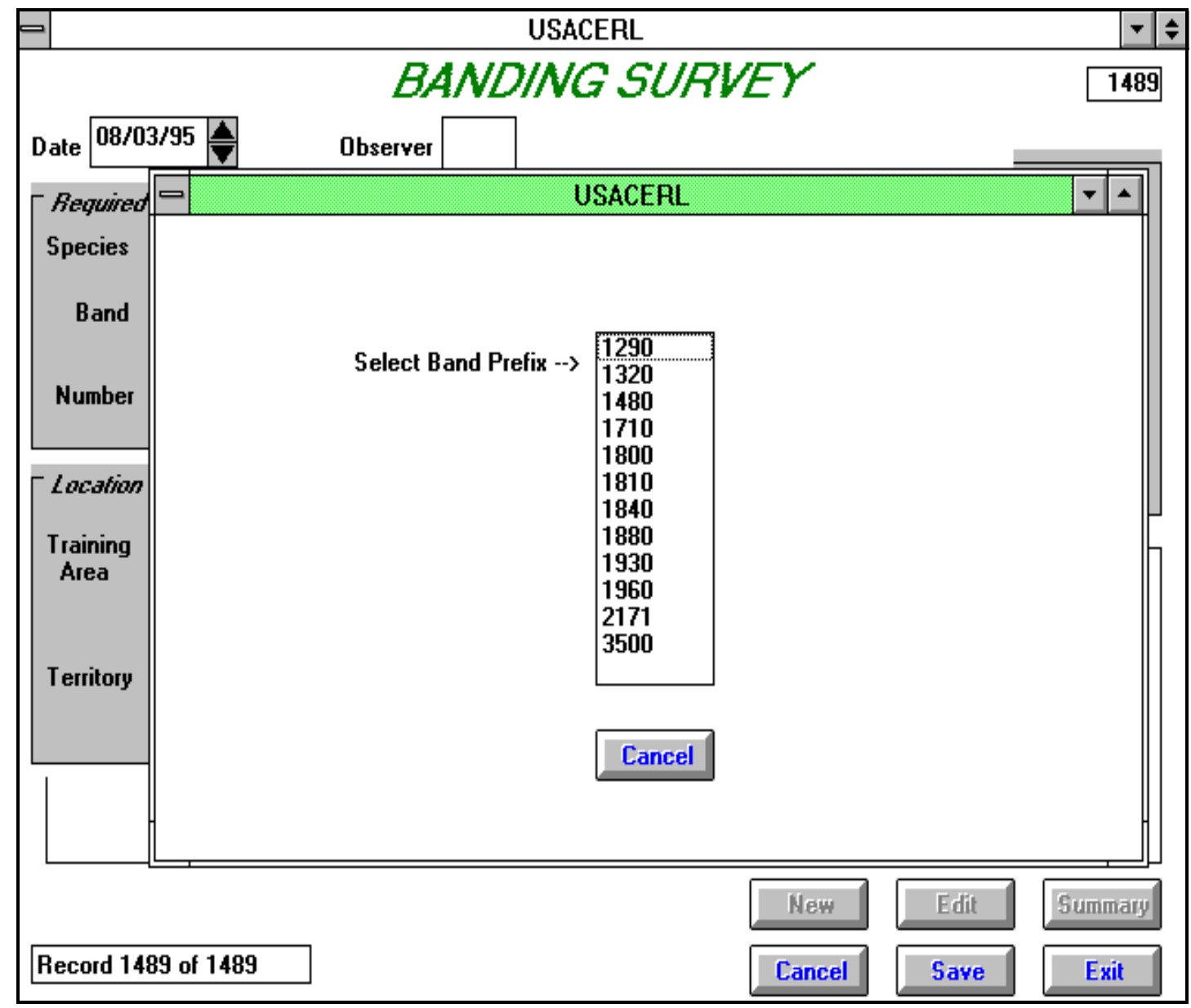

Figure 10. Band number selection form.

Tap the band number prefix you want and a list of band number suffixes will appear in the same box. Tap the band number suffix you want and the data entry form will reappear displaying the record you wish to edit. If you want to forego the edit process, tap Cancel to remove the selection form and return you to the data entry form. 


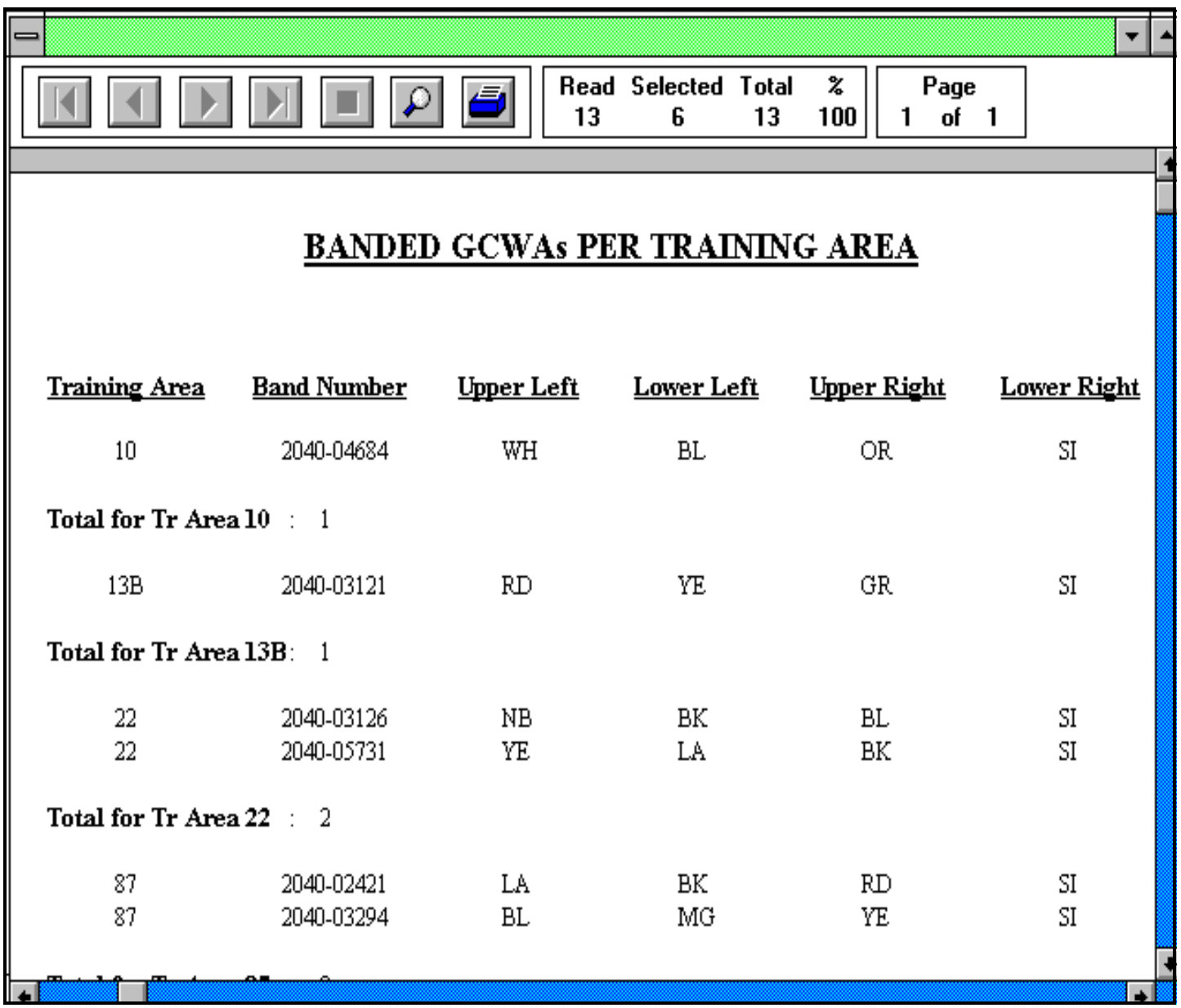

Figure 11. Banded GCWAs per training area.

\section{c. Summary}

To view a list of birds banded within each training area for the database you're working with, tap Summary. Figure 11 shows an example of all GCWAs banded for each training area. To return to the data entry form, tap the control box in the upper left hand corner of the screen. Tap the Close option and the data entry form will reappear.

\section{d. Cancel an action}

Tap Cancel to break out of an action. If you're adding a new record, the fields will clear and the database pointer will point to the last record in the database. If you've edited a record, all changes will be disregarded and you will no longer be in edit mode. The database pointer, however, will still point to the record. If you are scrolling through the database and examining the comments of a particular record, tapping Cancel will make the comments box disappear, double tapping will not. 


\section{e. Save a record}

To save a new record or one that has been edited, tap the Save button. A new record will be appended to the end of the database. An edited record will retain its position in the database.

\section{f. Swap databases}

To switch between databases, tap Swap DB. The program will ask you which bird database you'd like to switch to. Write in BCVI or GCWA or OTHER if you don't want black-capped vireo or golden-cheeked warbler. Tap OK and the program will switch databases accordingly. Keep in mind that you must enter bird data consistent with its own database. For example, only black-capped vireo data can be entered or accessed in the BCVI_BND database and only golden-cheeked warbler data can be entered or accessed in the GCWA_BND database and neither can be accessed in the BAND_DB database.

g. Exit the program

To exit the program, tap Exit. All files are closed. 


\section{Brown-Headed Cowbird Banding Program (BHCO_BND.MAK)}

\subsection{General Description}

The BHCO Banding program functions the same way as the Banding Survey program except that it records banding and location data on unbanded BrownHeaded Cowbirds and Loggerhead Shrikes. The program will not save records on any other birds. The records are stored in a DBase IV database file using the path name: $\mathrm{C}: \backslash V B \backslash B A N D \_S R V \backslash B H C O \_B N D . D B F$. The field names and descriptions of this file are given below. Data types and data lengths are given in parentheses.

REC_NUMBER (string) (4) - Number of the record in the database.

DATE (string) (8) - Current date.

OBSERVER (string) (3) - Observer's initials.

BAND (string) (4) - Band number prefix.

NUMBER (string) (5) - Band number suffix.

BAND_STAT (string) (1) - Status of leg band.

STAT_CODE (string) (3) - Category of banding detail given to a bird.

SPECIES (string) (4) - Species code.

SP_NUMBER (string) (4) - A unique 4 digit code representing a bird species. The program will automatically insert this number into the record based on your entry in the SPECIES field.

AGE_CODE (string) (1) - A one digit code representing a bird's age. The program will automatically insert the correct code into the record based on your entry in the AGE field. 
0 - Unknown

1 - AHY

2 - $\mathrm{HY}$

$4-\mathrm{L}$

$5-\mathrm{SY}$

6 - ASY

AGE (string) (3) - Age of bird.

SEX (string) (1) - Sex of bird.

UP_LEFT (string) (2) - Color code representing the upper left leg band of a banded bird.

LOW_LEFT (string) (2) - Color code representing the lower left leg band of a banded bird.

UP_RIGHT (string) (2) - Color code representing the upper right leg band of a banded bird.

LOW_RIGHT (string) (2) - Color code representing the lower right leg band of a banded bird.

REGION (string) (4) - Designated region of Fort Hood. The program will automatically insert the correct region into the record based on your entry in the TR_AREA field.

TRAP_NAME (string) (4) - Name of trap.

TR_AREA (string) (4) - Training Area.

EASTING (string) (6) - Easting coordinate.

NORTHING (string) (3) - Northing coordinate.

COMMENTS (string) (150) - Any important notes. 


\subsection{Starting the Program}

To start the program, double tap the BHCO_BND icon with the pen. After typing in your initials, the data entry form will appear as in Figure 12.

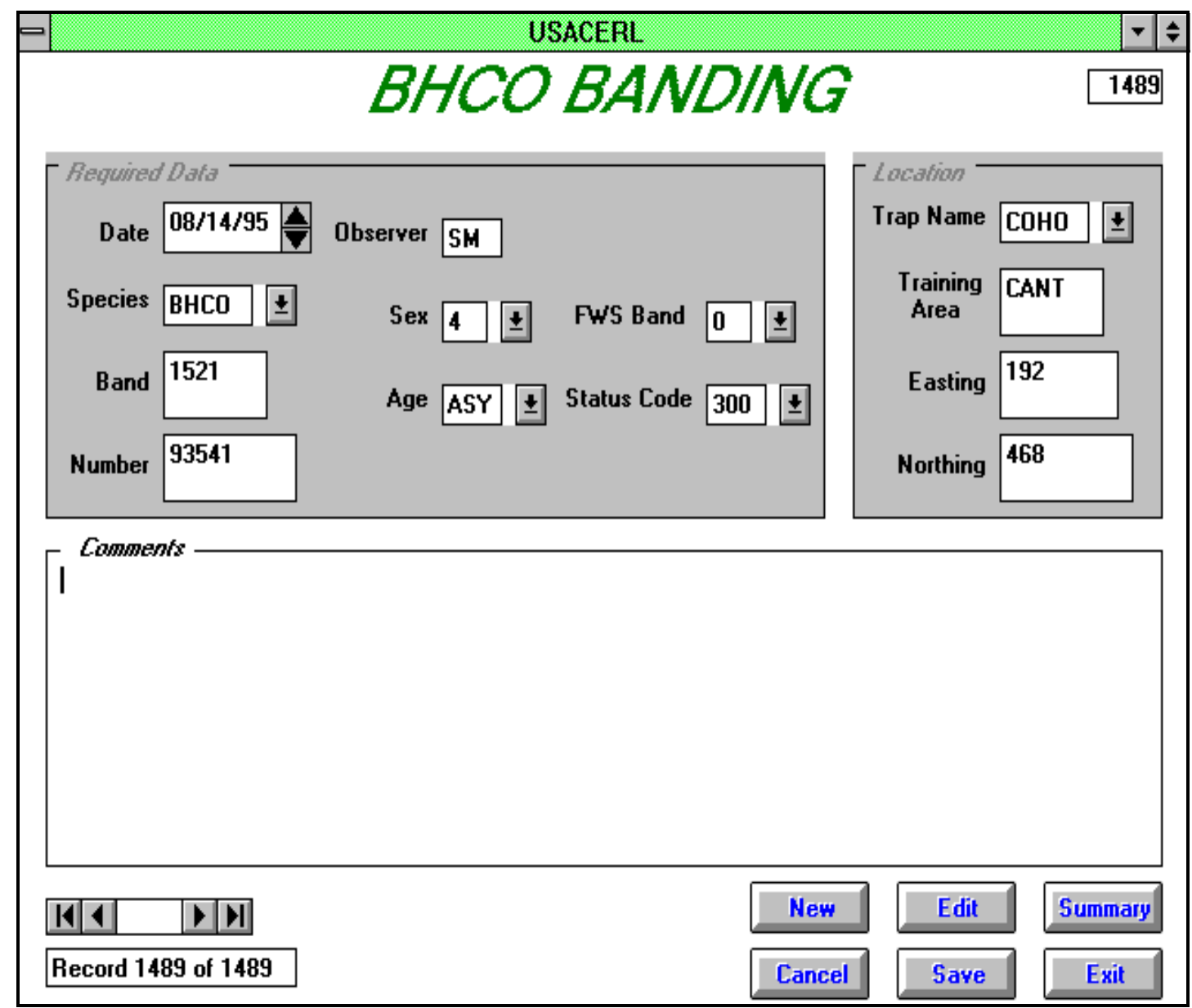

Figure 12. BHCO banding data entry form.

Once started, the information displayed on the form (assuming the database is not empty) is the last record in the database. The total number of records in the database is shown at the bottom left corner of the form. The number at the top right corner indicates the number of the individual record in the database. From here, you can add, edit, or view any record in the database.

\subsection{Program Flow}

a. Add a new record 
To add a new record, tap the New button. All fields are cleared out except for observer, record number, sex, FWS band, and status code, which are all assigned default values. You can change the default observer initials by double tapping on the observer text box. Only one frame on the form, Required Data, is enabled to remind you that this information must be included on every record. The Location frame and Comments box will only be enabled when you enter data for every control in the Required Data frame.

Date - Double tap the box to insert the current date. Use the spin button to increment/decrement the date.

Species - Choose a species code from the combo box. The program will not recognize input you write or type. If you select "BHCO," the program will copy the band number suffix from the last $\mathrm{BHCO}$ record in the database, add one to it, and place the result in the Number text box. It will also copy the trap name, training area, easting, and northing coordinates and insert them into the corresponding text boxes. If you select "LOSH," nothing will be copied.

Band - Write the band number prefix in the text box or accept the default assigned to BHCOs and LOSHs.

Number - Write the band number suffix in the text box or accept the default.

$\underline{\text { Sex }}$ - Choose a sex code from the combo box or accept the default. If you choose " 5 " (female), a frame containing leg band combo boxes will appear. Choose a color for each leg band and double tap the frame when you're done. The frame will disappear.

Age - Choose an age code from the combo box. Once you have selected a code, the Location frame and Comments box will be enabled.

FWS Band - Choose a FWS band status code from the combo box or accept the default.

Status Code - Choose a status code from the combo box or accept the default. If you choose 301,319 , or 325 , a frame containing leg band combo boxes will appear. Choose a color for each leg band and double tap the frame when you're done. The frame will disappear.

Trap Name - Choose a trap name from the combo box or accept the default. 
Training Area - Write the training area in the text box or accept the default.

Easting - Write the easting coordinate in the text box or accept the default.

Northing - Write the northing coordinate in the text box or accept the default.

$\underline{\text { Comments }}$ - Write any additional notes in the text box.

b. Edit a record

To edit a record, tap the Edit button. Figure 13 shows the resulting band number selection form.

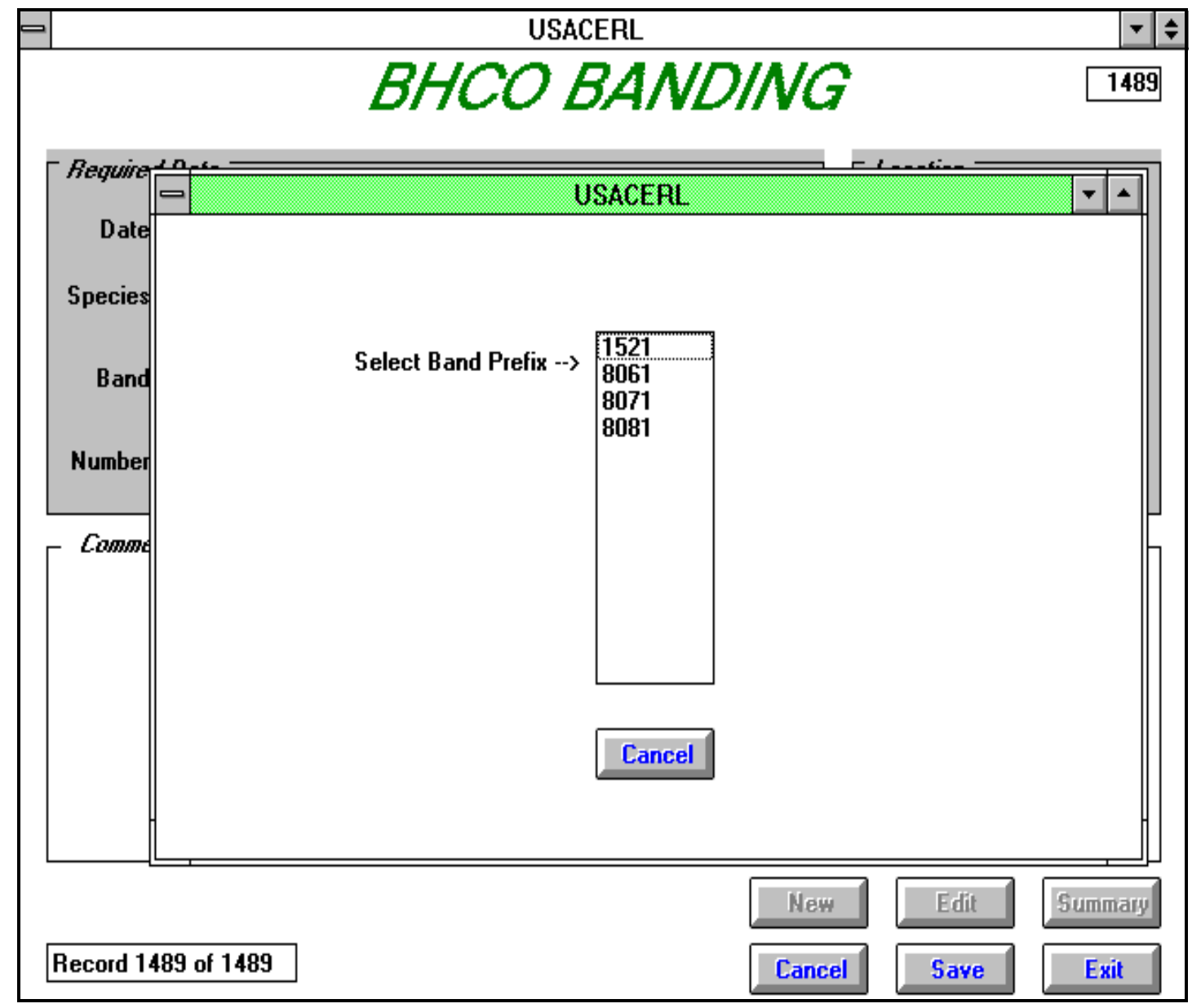

Figure 13. BHCO band selection form.

Tap the band number prefix you want from the list of known prefixes in the database and list of band number suffixes will appear in the same box. Tap the band number suffix you want and the data entry form will reappear displaying the 
record you wish to edit. If you want to forego the edit process, tap Cancel to remove the selection form and bring you back to the data entry form.

\section{c. Summary}

To view a list of all BHCOs banded for each trap, tap Summary. The program generates a list of all trap names as well as band numbers of every BHCO banded. Figure 14 shows an example. To return to the data entry form, tap the control box in the upper left corner of the screen and tap the Close option. The data entry form will reappear.

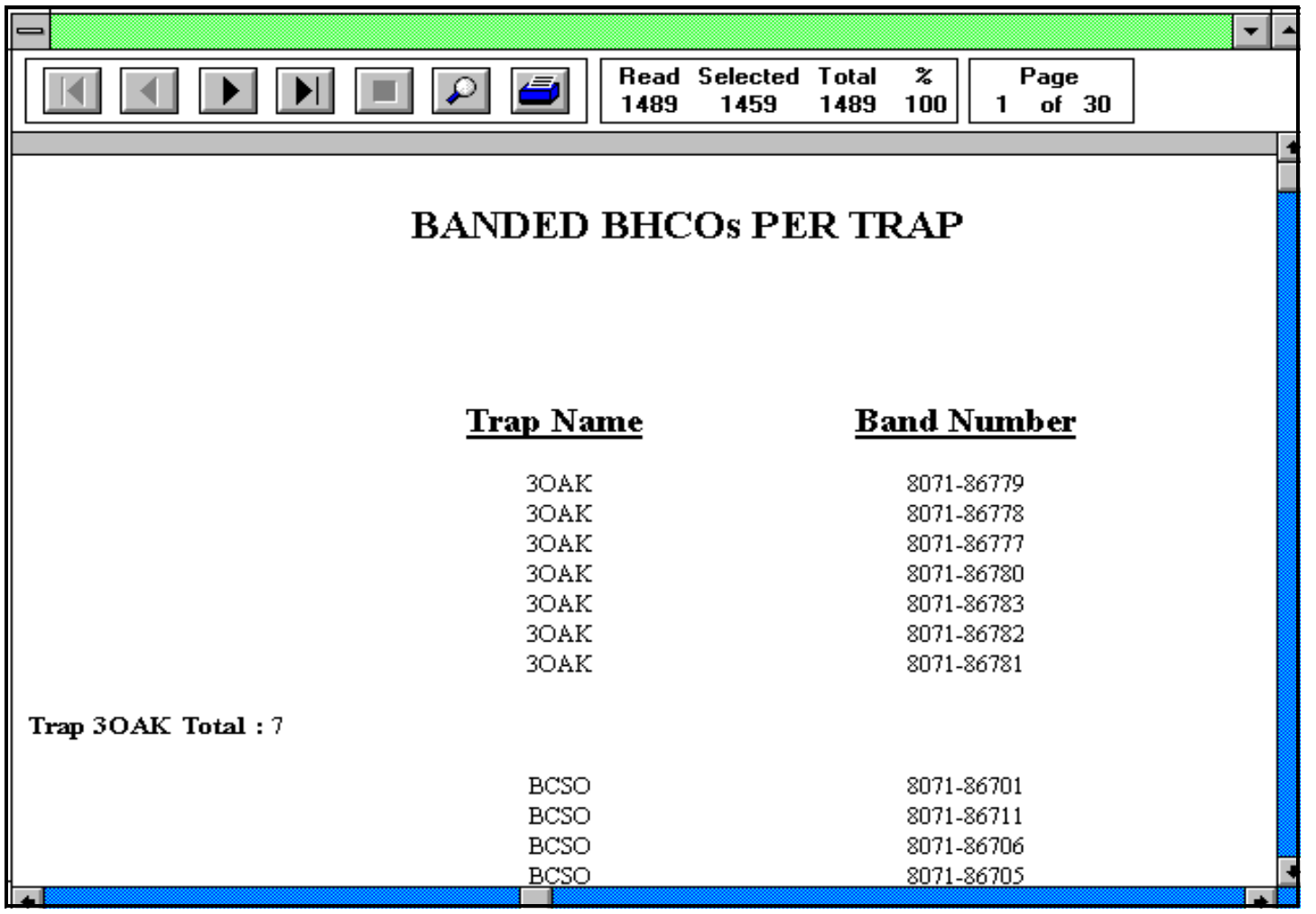

Figure 14. Banded BHCOs per trap.

d. Cancel an action

Tap Cancel to break out of any action. If you're adding a new record, the fields are cleared and the database pointer will point to the last record in the database. If you've edited a record, all changes will be disregarded and you will no longer be in edit mode. However, the database pointer will still point to the record.

e. Save a record 
To save a new record or one that has been edited, tap the Save button. A new record will be appended to the end of the database. An edited record will retain its position in the database.

f. Exit the Program

To exit the program, tap Exit. All files are closed. 


\section{Sightings/Recaptures Program}

(SI_RECAP.MAK)

\subsection{General Description}

The Sightings/Recaptures program records instances of banded black-capped vireos, golden-cheeked warblers, or brown-headed cowbirds returning from previous years. It also records instances where birds are sighted or recaptured in new areas within the same season. The program is structured similar to the Banding Survey program and collects nearly the same data. The records are stored in a DBase IV database file under the path name $\mathbf{C}: \backslash \mathrm{VB} \backslash \mathrm{SI}$ RECAP $\backslash$ SI_RECAP.DBF. The field names and descriptions of this file are given below. Data types and lengths are given in parentheses.

REC_NUMBER (string) (4) - Number of the record in the database.

DATE (string) (8) - Current date.

OBSERVER (string) (3) - Observer's initials.

MULT_SIGHT (string) (4) - Bird sighted and/or recaptured more than once during the current field season. The program will automatically insert "TRUE" if a record for a particular bird already exists in the database.

METHOD (string) (5) - Method of detection.

BAND (string) (4) - Band number prefix.

NUMBER (string) (5) - Band number suffix.

BAND_DATE (string) (8) - Date when bird was originally banded. The program will insert the banding date automatically into the record based on band number or leg band confirmation.

SPECIES (string) (4) - Species code. 
AGE (string) (3) - Age of bird.

BAND_AGE (string) (3) - Age when bird was originally banded. The program will insert the banding age automatically into the record based on band number or leg band confirmation.

SEX (string) (1) - Sex of bird.

UP_LEFT (string) (2) - Color code representing the upper left leg band of a banded bird.

LOW_LEFT (string) (2) - Color code representing the lower left leg band of a banded bird.

UP_RIGHT (string) (2) - Color code representing the upper right leg band of a banded bird.

LOW_RIGHT (string) (2) - Color code representing the lower right leg band of a banded bird.

TR_AREA (string) (4) - Training Area.

EASTING (string) (6) - Easting coordinate.

NORTHING (string) (7) - Northing coordinate.

ORIG_TR_AR (string) (4) - Training area where bird was first banded. The program will automatically insert the training area into the record based on band number or leg band confirmation.

ORIG_EAST (string) (6) - Easting coordinate where bird was originally banded. The program will automatically insert the easting coordinate into the record based on band number or leg band confirmation.

ORIG_NORTH (string) (7) - Northing coordinate where bird was originally banded. The program will automatically insert the northing coordinate into the record based on band number or leg band confirmation.

ACTIVITY (string) (8) - What the bird was doing when sighted or recaptured. 
CP (string) (2) - Cloacal protuberance.

BP (string) (2) - Brood patch.

CAP_PLUM (string) (3) - Cap plumage.

WING_LEN (numeric) (8) - Wing length measurement.

TAIL_LEN (numeric) (8) - Tail length measurement.

WEIGHT (numeric) (8) - Weight measurement.

COMMENTS (string) (100) - Any important notes.

\subsection{Starting the Program}

To start the program, double tap the Si_Recap icon with the pen. After typing your initials, the program will ask you to enter the bird species you'll be working with. Accept "BCVI" as the default or write in "GCWA" or "BHCO" for your choice. Tap OK and the data entry form shown in Figure 15 will appear. 


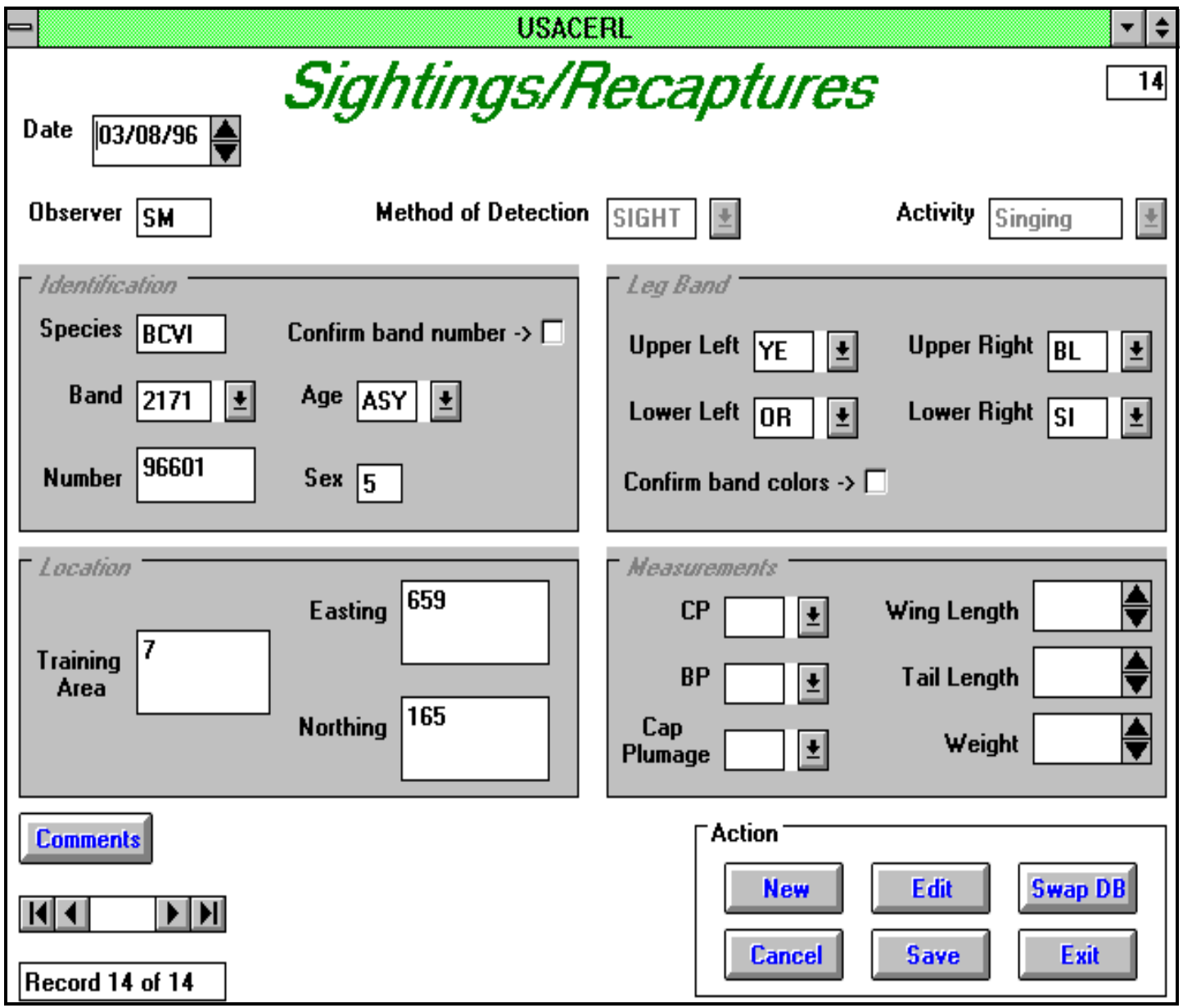

Figure 15. Sightings/recaptures data entry form.

The form looks and acts very much like the Banding Survey program. Once started, the information displayed on the form (assuming the database is not empty) is the last record in the database. The total number of records in the database is shown at the bottom left corner of the form. The number at the top right corner indicates the number of the individual record in the database. From here, you can add, edit, or view any record in the database.

\subsection{Program Flow}

a. Add a new record

To add a new record, tap the New button. All fields are cleared out, but default values for observer, species, and record number are inserted. 
Date -Double tap the box to insert the current date. Use the spin button to increment/decrement the date.

Method of Detection - This combo box purposely flashes on and off to remind you to make a selection for this field. To stop the flashing, select a choice from the combo box. Choosing "SIGHT" will swap the leg band and identification frames to facilitate data entry as well as disable the Measurements frame since no measurements can be taken on a sighted bird. Choosing "RECAP" will enable the Measurements frame and set the default values for wing length, tail length, and weight.

Activity - Choose an activity from the combo box.

Band - Choose a band prefix from the combo box. If a band prefix you want doesn't appear in the list, write it in the box.

Number - Write the band suffix in the text box.

Confirm Band Number? - If you're sure of the band number, check this box. The program will automatically search the appropriate database file for that band number and retrieve the sex and leg band colors. The CP combo box will automatically be disabled if the sex is female and the BP combo box will be disabled if the sex is male. Banding date, banding age, original training area, and UTM coordinates will be added when you save the record.

Upper Left - Lower Right - Choose a color code for each leg band from the combo box, if necessary.

Confirm Band Colors? - If you know all four band colors, but don't know the band number, check this box. The program will automatically search the appropriate database file for those band colors and retrieve the sex and band number. Banding date, banding age, original training area, and UTM coordinates will be added when you save the record.

$\underline{\text { Age }}$ - Choose an age code from the combo box.

Training Area - Write the training area in the text box.

Easting - Write the easting coordinate in the text box.

Northing - Write the northing coordinate in the text box. 
$\underline{\mathrm{CP}}$ - Choose a CP code from the combo box.

$\underline{B P}$ - Choose a BP code from the combo box.

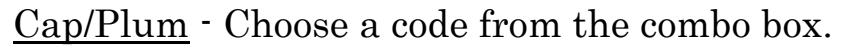

Wing Length - Use the spin button to increment/decrement the default wing length.

Tail Length - Use the spin button to increment/decrement the default tail length.

Weight - Use the spin button to increment/decrement the default weight by 0.1 grams.

Comments - Tap the Comments button. In the white space provided, write in whatever comments are necessary. To eliminate the Comments box, double tap it.

b. Edit a record

To edit a record, tap the Edit button. Figure 16 shows the resulting band number selection form. 


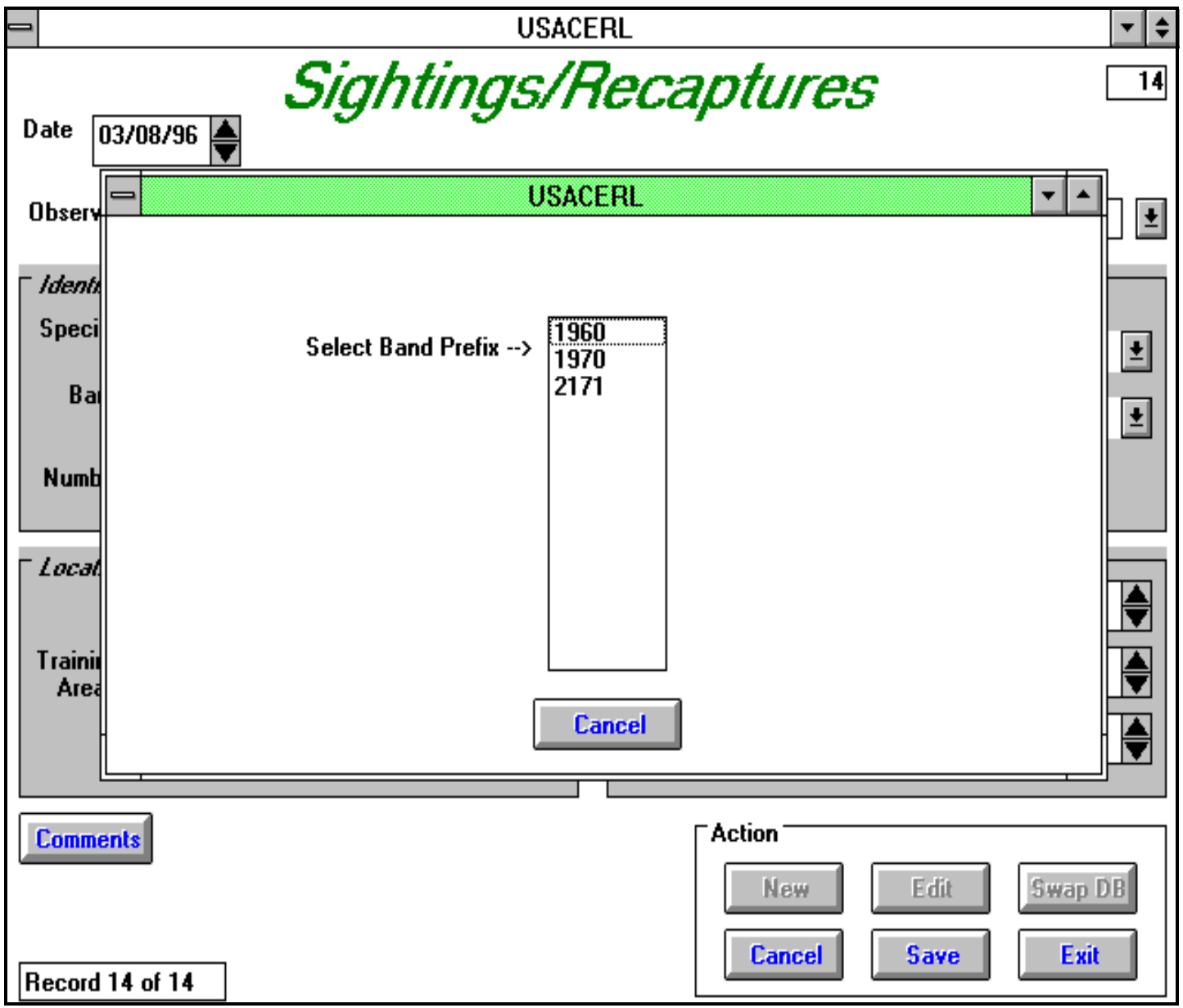

Figure 16. Sightings/Recaptures band number selection form.

This form looks and acts exactly the same as the band selection form in the Banding Survey program. If you want to forego the edit process, tap Cancel to remove the selection form and return to the original form. Otherwise, tap the band number prefix you want and a list of band number suffixes will appear in the same box. Tap the band number suffix you want and the original form will reappear displaying the last record matching that band number. You now have access to the entire set of records matching that band number. Use the FIND buttons to view and/or edit those records.

c. Cancel an action

Tap Cancel to break out of any action. If you're adding a new record and tap Cancel , the fields are cleared and the database pointer will point to the last record in the database. If you've made changes to a record and tap Cancel, all changes will be disregarded. You will no longer be in edit mode, but the database pointer will still point to the record. 
If you are scrolling through the database and examining the comments of a particular record, tapping Cancel will make the comments screen disappear, double tapping will not.

d. Save a record

To save a new record or one that has been edited, tap the Save button. The record will be automatically saved to the database. A new record will be appended to the end of the database. An edited record will retain its position in the database.

e. Swap databases

Tap Swap DB when you need to enter data for another species. The program will ask you which species database you'd like to switch to. Write in "GCWA" for goldencheeked warbler, "BHCO" for brown-headed cowbird or accept "BCVI" as the default. Tap OK and the program will switch databases accordingly. Be aware that switching databases only changes the underlying database the program accesses when retrieving banding information. It does not switch the SI RECAP.DBF file.

f. Exit the Program

To exit the program, tap Exit. All files are closed. 


\title{
6 Point Count Program
}

\author{
(BIRD_CNT.MAK)
}

\subsection{General Description}

The Point Count program records data (i.e., location, bird observations) while conducting point counts. At each designated point, after the count has started, the computer will beep when the allotted 10 minute time limit is over. The program will accommodate new routes, new points, and new observations. The records are stored in a DBase IV database file under the path name $\mathrm{C}: \backslash \mathrm{VB} \backslash \mathrm{BIRD} \_\mathrm{CNT} \backslash \mathrm{BIRD}$ CNT.DBF. The field names and descriptions of this file are given below. Data types and field lengths are given in parentheses.

REC_NUMBER (string) (4) - Number of the record in database.

DATE (string) (8) - Current date.

OBSERVER (string) (3) - Observer's initials.

SUNRISE (string) (5) - Time of sunrise.

TEMP (string) (3) - Current temperature.

WIND_SPEED (string) (5) - Range of wind speed.

WIND_DIR (string) (2) - Wind direction.

CLOUD (string) (3) - Cloud cover.

ROUTE (string) (2) - Route number.

POINT_NUM (string) (2) - Point number.

TR_AREA (string) (4) - Training area.

EASTING (string) (6) - Easting coordinate. 
NORTHING (string) (7) - Northing coordinate.

TYPE (string) (10) - Community type.

UNDERSTORY (string) (8) - Understory thickness.

TREE_SPEC (string) (15) - Most common tree species.

JUNIPER (string) (1) - Juniper class.

START_TIME (string) (10) - Start time for 10-minute time limit.

OBS_TIME (string) (10) - Start time for observing a bird.

SPECIES (string) (4) - Species code.

SEX (string) (1) - Sex of bird.

CALL (true/false) (1) - Was a call heard?

SONG (true/false) (1) - Was a song heard?

SONG_TYPE (string) (4) - Type of song.

VISUAL (true/false) (1) - Was bird seen?

DIRECTION (string) (3) - Azimuthal direction.

EST_DIST (numeric) (8) - Estimated distance away from observer.

FLEDGLINGS (numeric) (8) - Number of fledglings.

COMMENTS (string) (150) - Any important notes.

\subsection{Starting the Program}

To start the program, double tap the Bird_Cnt icon with the pen. The daily conditions form shown in Figure 17 will appear. 


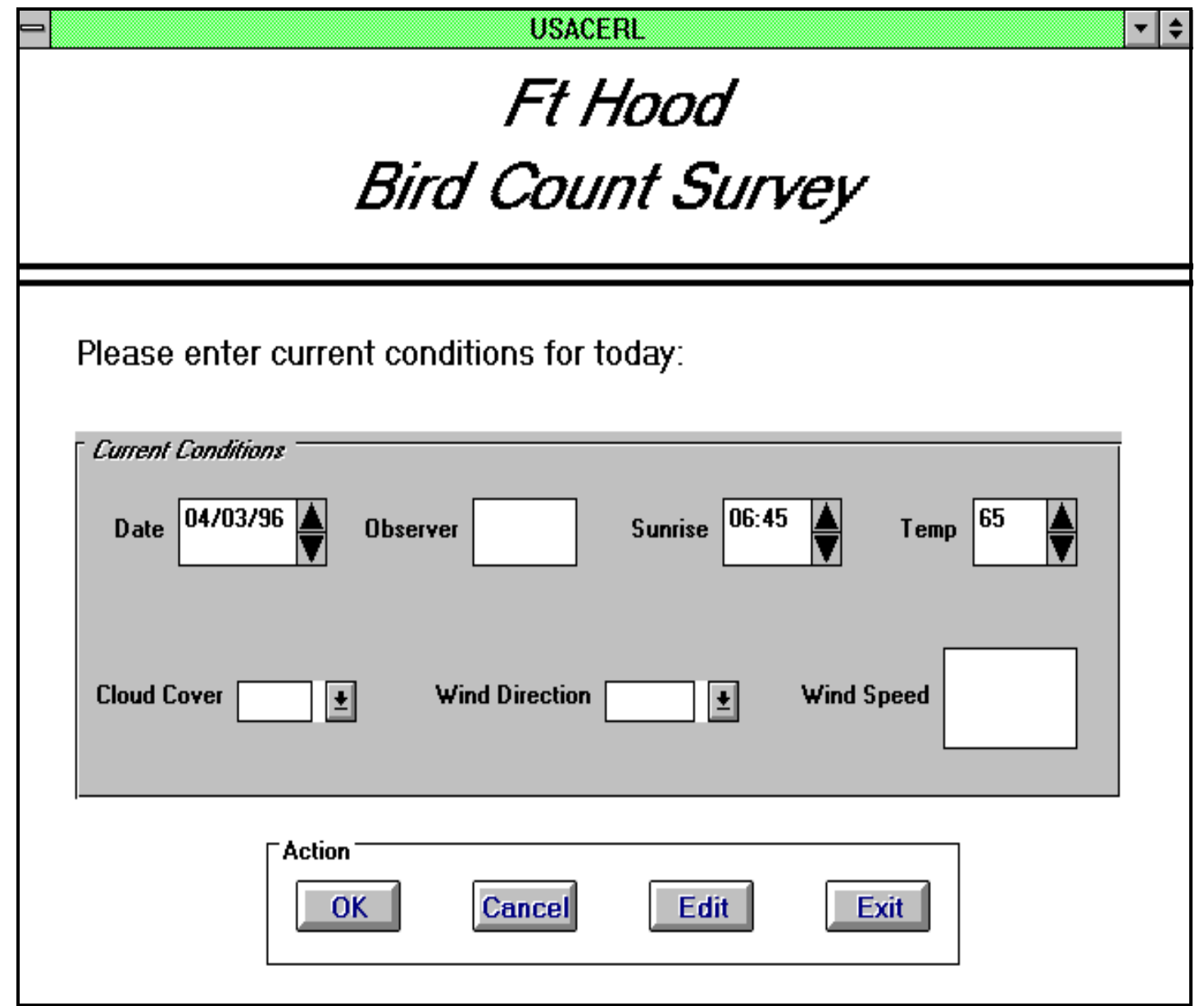

Figure 17. Daily conditions form.

You need to enter data in this form only at the beginning of the point count. Since these data are entered only once, it is very important to complete all the fields. The data will automatically be added to each record saved to the database. Each field in this initial form is addressed below.

Date - Accept the current date or use the spin button to increment/ decrement the date.

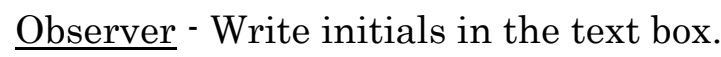

$\underline{\text { Sunrise }}$ - Accept the default sunrise time or use the spin button to increment/decrement the time.

$\underline{\text { Temp }}$ - Accept the default temperature or use the spin button to increment/decrement the temperature.

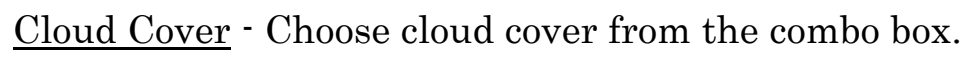


Wind Direction - Choose any wind direction from the combo box. If you select a blank space, the program will automatically insert zero for Wind Speed.

Wind Speed - Write wind speed range (i.e., 10-15) in text box.

If you wish to exit the program, tap Exit. If you're satisfied with the data you have entered, tap OK and the data entry form in Figure 18 will appear. Field data collection can then begin.

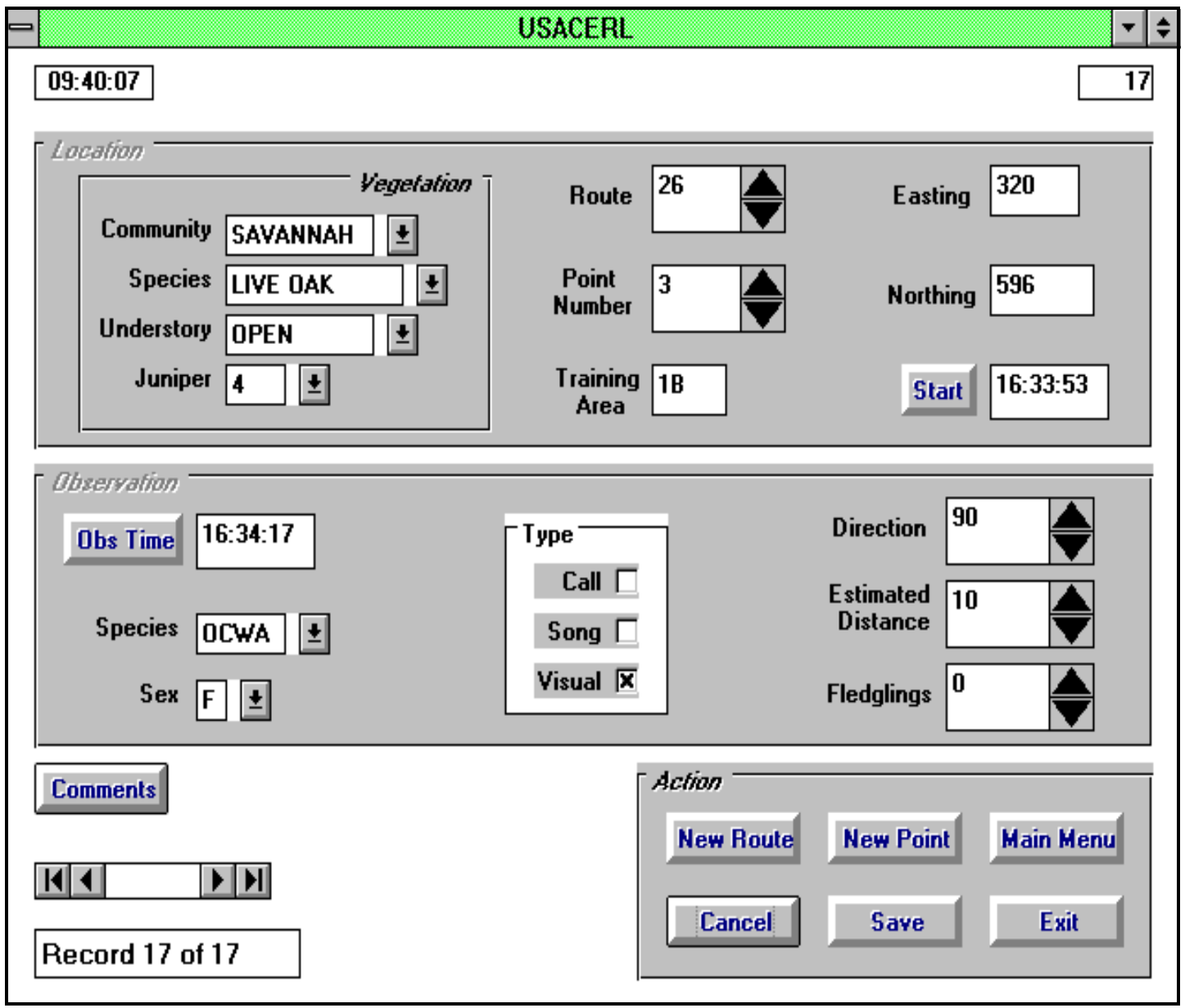

Figure 18. Bird count data entry form.

The information displayed on the form (assuming the database is not empty) is the last record in the database. The total number of records in the database is shown at the lower left corner of the form. The number at the upper right corner indicates the number of the individual record in the database. 


\subsection{Program Flow}

\section{a. Start new route}

To start a new route, tap the New Route button. All fields are cleared out, but the program inserts a value for the next record number.

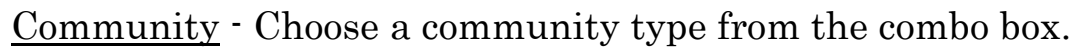

Species - Choose the dominant tree species from the combo box.

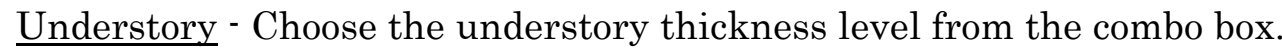

Juniper - Choose a juniper class from the combo box.

$\underline{\text { Route }}$ - Use the spin button to increment/decrement the route number or write it in the text box.

Point Number - Use the spin button to increment/decrement the point number or write it in the text box.

Training Area - Tap the text box. By tapping the box, the program will search a location file for a corresponding training area, easting, and northing coordinate matching the route and point number. These values will be placed in the appropriate text boxes.

Easting - No need for action. Data automatically inserted.

Northing - No need for action. Data automatically inserted.

Start - Tap the Start button to begin the 10 minute time limit.

Observation Time - Tap the Obs Time button to record the time you observed a bird.

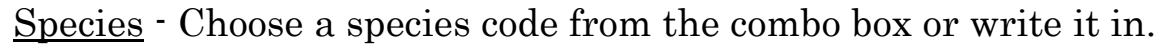

$\underline{\text { Sex }}$ - Choose a sex code from the combo box.

Call - Tap the box if you heard a bird call. 
Song - Tap the box if you heard a bird singing. If the observed bird is a GCWA, choose a song name from the list box.

Visual - Tap the box if you saw the bird.

Direction - Use the spin button to increment/decrement the azimuthal direction by 5 degrees or write it in the text box.

Estimated Distance - Use the spin button to increment/decrement the distance by 5 degrees or write it in the text box.

Fledglings - Use the spin button to increment/decrement the number of fledglings or write it in the text box.

Comments - Tap the Comments button. In the white space provided, write whatever comments are necessary. To eliminate the Comments box, double tap it.

\section{b. Start new point number}

To record a new point number, you must already have a route established, otherwise an error will occur. Tap the New Point button and all fields are cleared out except for route number. That value is carried forward from the initial new route entry. Continue entering data following the same guidelines as new route number.

c. Start new observation

To record a new observation, you must already have a route and point number established. When these conditions are met, the New Obs button will replace the Obs Time button. Tap it and all fields in the Observation frame will clear except the observed time text box, which displays the beginning observation time. All values in the Location frame are carried forward from the last entry. Continue entering data following the same guidelines as new route number.

\section{d. Edit a record}

To edit a record, make sure all fields on the daily conditions form contain values and then tap Edit. Figure 19 shows the resulting selection list box. 


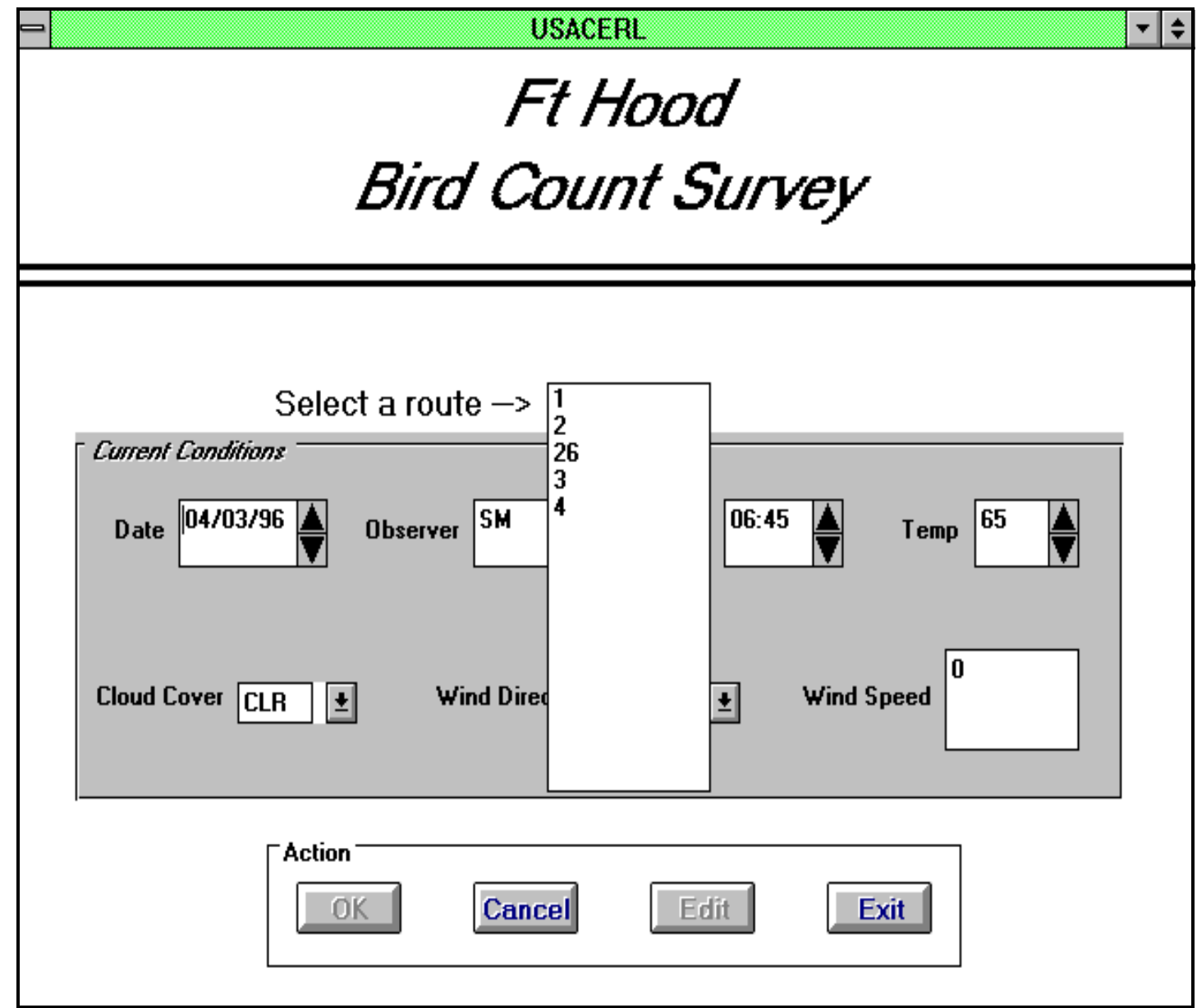

Figure 19. Bird count selection list box.

If you want to forego the edit process, tap the Cancel button. Otherwise, tap the route you want and an associated list of point numbers will appear in the same box. Tap the point number you want and the data entry form will reappear displaying the last record matching that route and point number. You now have access to the entire set of records matching that route and point number. Use the FIND buttons to view and/or edit those records.

\section{e. Cancel an action}

Tap Cancel to break out of any action. If you're adding a new route, point, or observation, the fields will clear and the database pointer will point to the last record in the database. Be careful using this button. Tapping Cancel requires you to re-establish a route before you can add a new point or observation. If you've made changes to a record and tap Cancel, all changes will be disregarded and you 
will no longer be in edit mode. The database pointer will still point to the same record.

If you're scrolling through the database and examining the comments of a particular record, tapping Cancel will make the comments box disappear, double tapping the box will not.

f. Save a record

To save a new record or one that has been edited, tap the Save button. The record will be automatically saved to the database. A new record will be appended to the end of the database. An edited record will retain its position in the database.

g. Exit the program

To exit the program, tap Exit. All files are closed. 


\section{Brown-Headed Cowbird Trapping Program (BHCO_TRP.MAK)}

\subsection{General Description}

The Cowbird Trapping program collects data on trapped cowbirds. It accumulates the number of dead and released cowbirds as well as non-target species. Additional features include calendar and FWS yearly total print outs and monthly trap totals including trapping efficiency. To print a copy of the totals, you must have a printer (such as the Fujitsu DL2400) connected to the computer using a parallel cable. The records are stored in a DBase IV database file under the path name $\mathrm{C}: \backslash \mathrm{VB} \backslash \mathrm{BHCO}$ _TRP $\backslash$ BHCO_TRP.DBF. The field names and descriptions of this file are given below. Data types and lengths are given in parentheses.

REC_NUMBER (string) (4) - Number of the record in database.

DATE (date/time) (8) - Current date.

MONTH (string) (2) - Current month.

DAY (string) (2) - Current day.

YEAR (string) (2) - Current year.

OBSERVER (string) (3) - Observer's initials.

TRAP_NAME (string) (4) - Name of trap.

TRAP_TYPE (string) (10) - Type of trap.

TRAP_STAT (string) (6) - Trap status.

REGION (string) (4) - Designated region of Fort Hood.

TR_AREA (string) (4) - Training area. 
EASTING (string) (6) - Easting coordinate.

NORTHING (string) (7) - Northing coordinate.

M_ADDED (numeric) (8) - Number of male cowbirds added to a trap.

F_ADDED (numeric) (8) - Number of female cowbirds added to a trap.

I_ADDED (numeric) (8) - Number of immature cowbirds added to a trap.

M_KILLED (numeric) (8) - Number of male cowbirds killed.

F_KILLED (numeric) (8) - Number of female cowbirds killed.

I_KILLED (numeric) (8) - Number of immature cowbirds killed.

M_RELEASED (numeric) (8) - Number of male cowbirds released.

F_RELEASED (numeric) (8) - Number of female cowbirds released.

I_RELEASED (numeric) (8) - Number of immature cowbirds released.

M_TOTAL (numeric) (8) - Number of male cowbirds killed and released.

F_TOTAL (numeric) (8) - Number of female cowbirds killed and released.

I_TOTAL (numeric) (8) - Number of immature cowbirds killed and released.

N_TRG_REL (numeric) (8) - Number of non-target species released.

N_TRG_DEAD (numeric) (8) - Number of non-target species dead.

COMMENTS (string) (100) - Any important notes.

\subsection{Starting the Program}

To start the program, double tap the BHCO icon with the pen. After writing your initials in the box, the main menu form in Figure 20 will appear. This menu is divided into two boxes: one box for summarizing data and a second box for adding and editing records. 


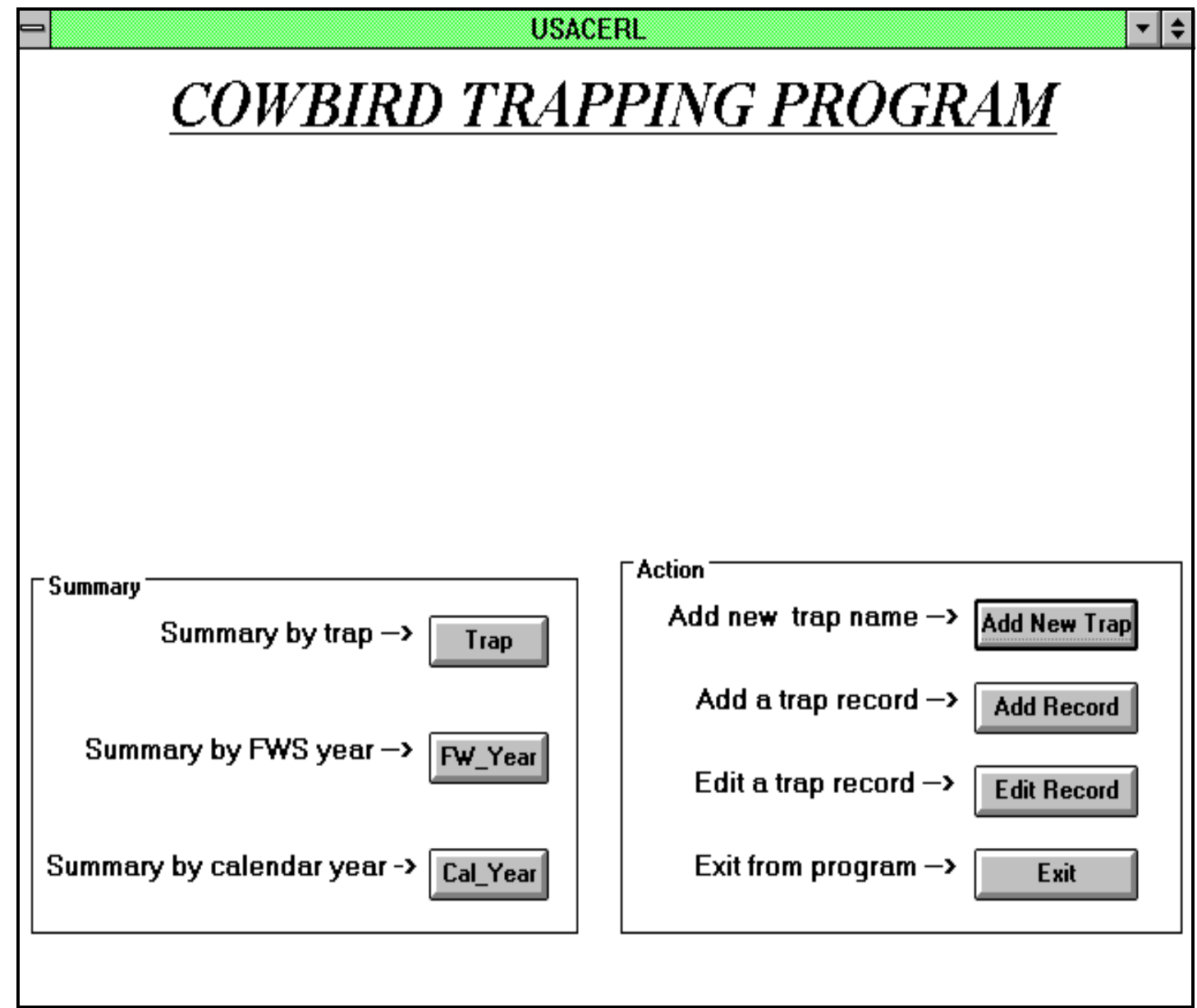

Figure 20. Cowbird trapping main menu.

\subsection{Program Flow}

\section{a. Add a new trap}

To add a new trap to the database, tap the Add New Trap button. The main menu form will disappear and the new trap form shown in Figure 21 will appear.

All fields are cleared out, but the program will insert default values for current date, observer initials, and record number. You can increment or decrement the current date by tapping the spin button.

Trap Name - Write the name of the trap in the text box.

Type - Choose a type of trap from the combo box.

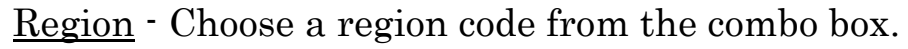




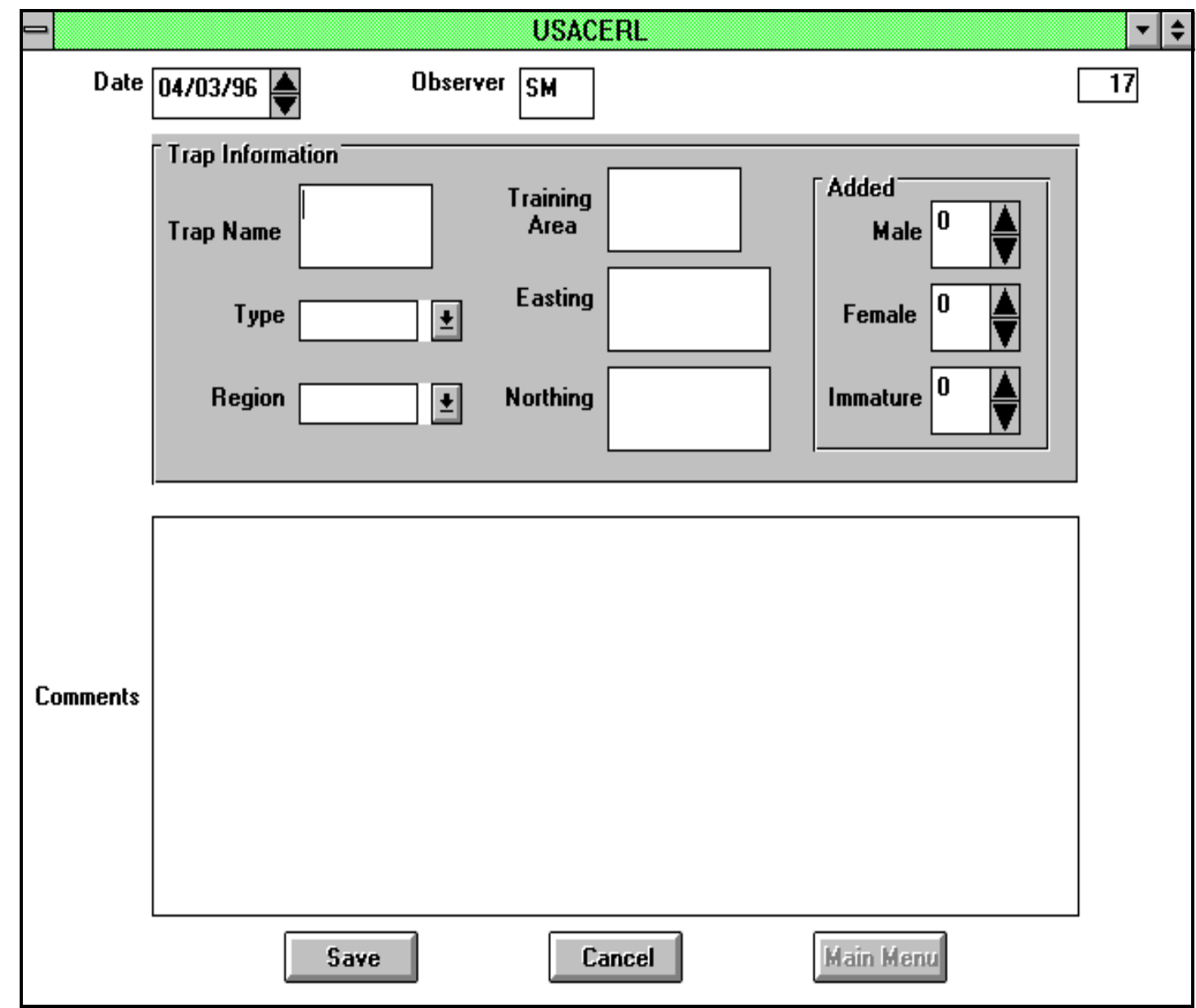

Figure 21. New trap form.

Training Area - Write the training area in the text box.

Easting - Write the easting coordinate in the text box.

Northing - Write the northing coordinate in the text box.

Males Added - Use the spin button to increment/decrement the number of males added or write it in the text box.

Females Added - Use the spin button to increment/decrement the number of females added or write it in the text box.

Immatures Added - Use the spin button to increment/decrement the number of immatures added or write it in the text box. 
$\underline{\text { Comments }}$ - Write any pertinent comments in the text box.

Tap the Save button to save the record to the database. The program will automatically check to see if the trap name already exists in the database. If it does, a warning message will appear on the screen. You can ignore the message and continue, or accept it and re-enter a different trap name. Tap the Cancel button to clear out all the fields and start over. Tap the Main Menu button to remove the new trap form and return to the main menu.

b. Add a new record

To record a new observation, tap the Add Record button. A list box will appear on the form containing all trap names in the database. Figure 22 shows an example.

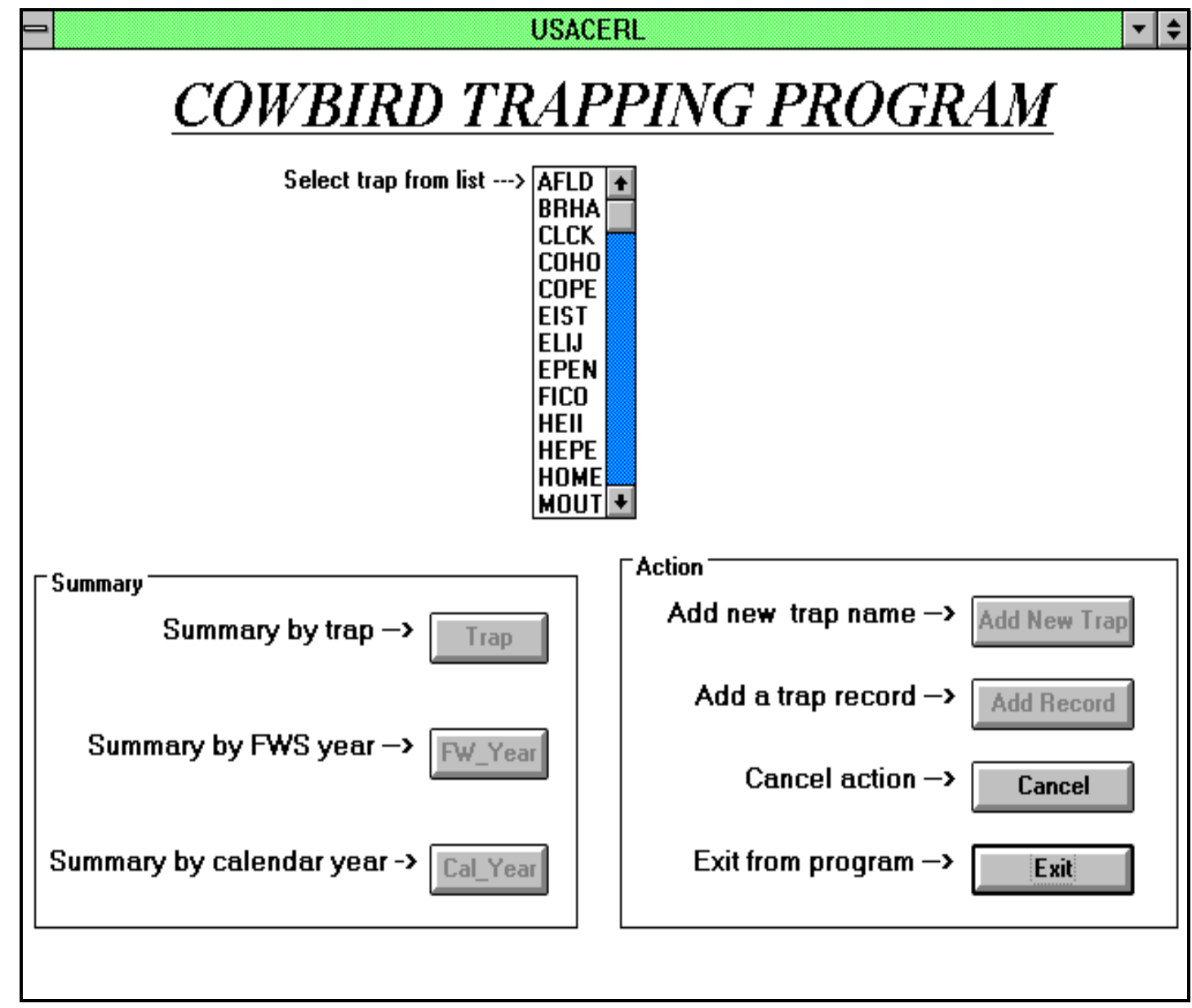

Figure 22. Cowbird trappings selection list box. 


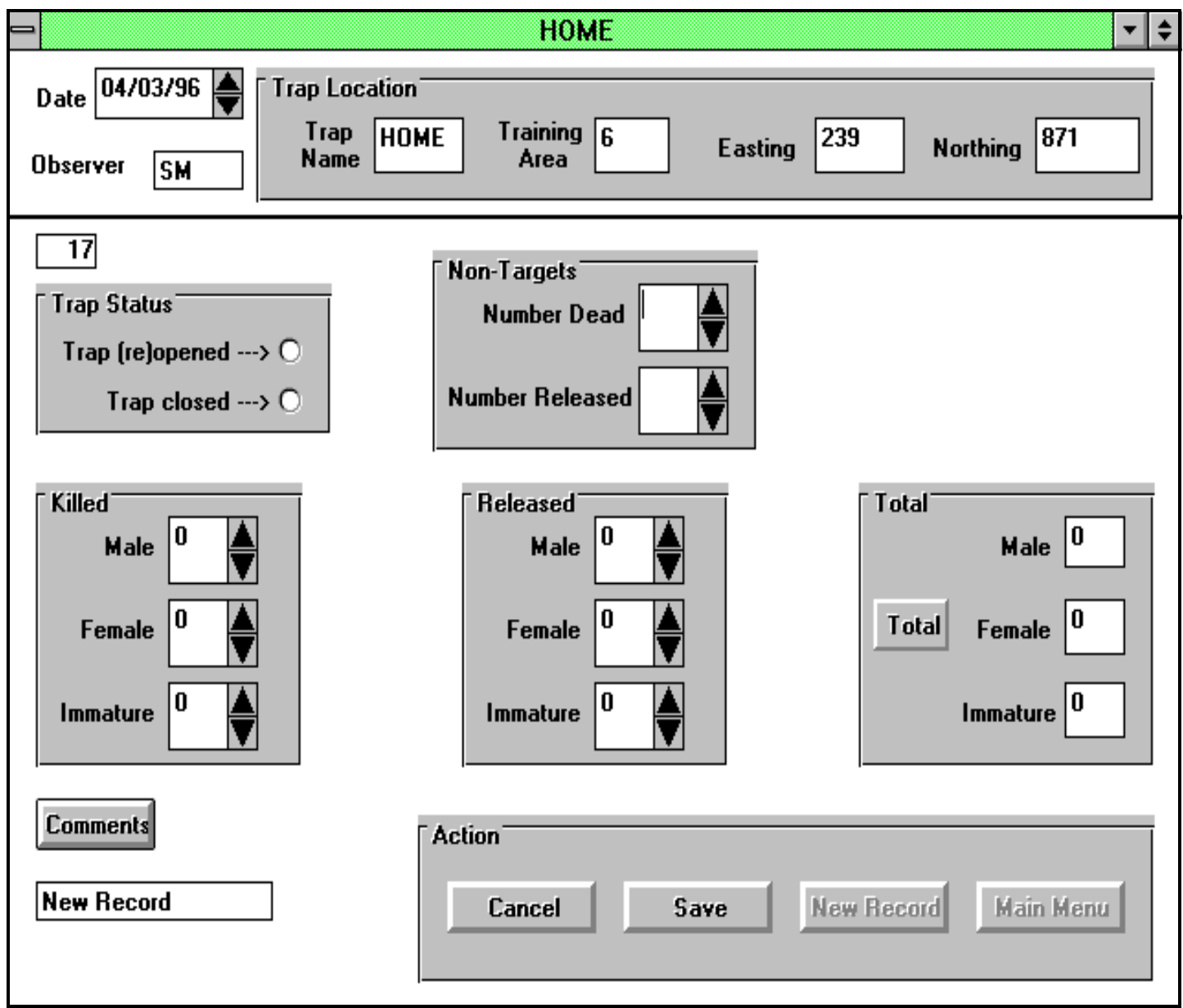

Figure 23. New record form.

Tap the trap name you want and the main menu form will be removed while the new record form will appear. To cancel your request, tap the Cancel button. Figure 23 shows the resulting new record form.

The top part of the form shows the Trap Location frame, which contains location information that wouldn't normally change. It is shown for reference. Date, observer, and record number fields have default values automatically inserted. You need to enter data only in the lower portion of the form.

Trap re-opened/closed - Because these two option buttons are grouped into one frame, only one may be selected, not both. Select either one only when necessary. If you select "Trap re-opened," all frames in the lower portion disappear and the Added frame takes their place. Use the spin button to increment the number of males, females, and immatures added to the trap.

Number Released - Use the spin button to increment/decrement the number of non-target species released or write it in the text box. 
Number Dead - Use the spin button to increment/decrement the number of non-target species dead or write it in the text box.

Males Killed - Use the spin button to increment/decrement the number of males killed or write it in the text box.

Females Killed - Use the spin button to increment/decrement the number of females killed or write it in the text box.

Immatures Killed - Use the spin button to increment/decrement the number of immatures killed or write it in the text box.

Males Released - Use the spin button to increment/decrement the number of males released or write it in the text box.

Females Released - Use the spin button to increment/decrement the number of females released or write it in the text box.

Immatures Released - Use the spin button to increment/decrement the number of immatures released or write it in the text box.

Total - Tap the Total button to sum up the number of male, female, and immature cowbirds killed and released.

Comments - Tap the Comments button. In the white space provided, write any pertinent comments. To eliminate the Comments box, double tap it.

Tap the Save button to save the record to the database. Tap the Cancel button to clear out all fields and remain at the last database record. To add another record, tap the New Rec button. In doing so, a list box will appear containing all trap names. Choose a trap name to enter another record. Tap the Main Menu button to remove the new record form and return to the main menu.

c. Edit a record

To edit a record, tap the Edit button. The same list box containing all trap names in the database appears exactly as adding a new record. Refer to Figure 22 for that example. If you want to forego the edit process, tap the Cancel button. Otherwise, tap the trap name you want and the edit record form will appear 


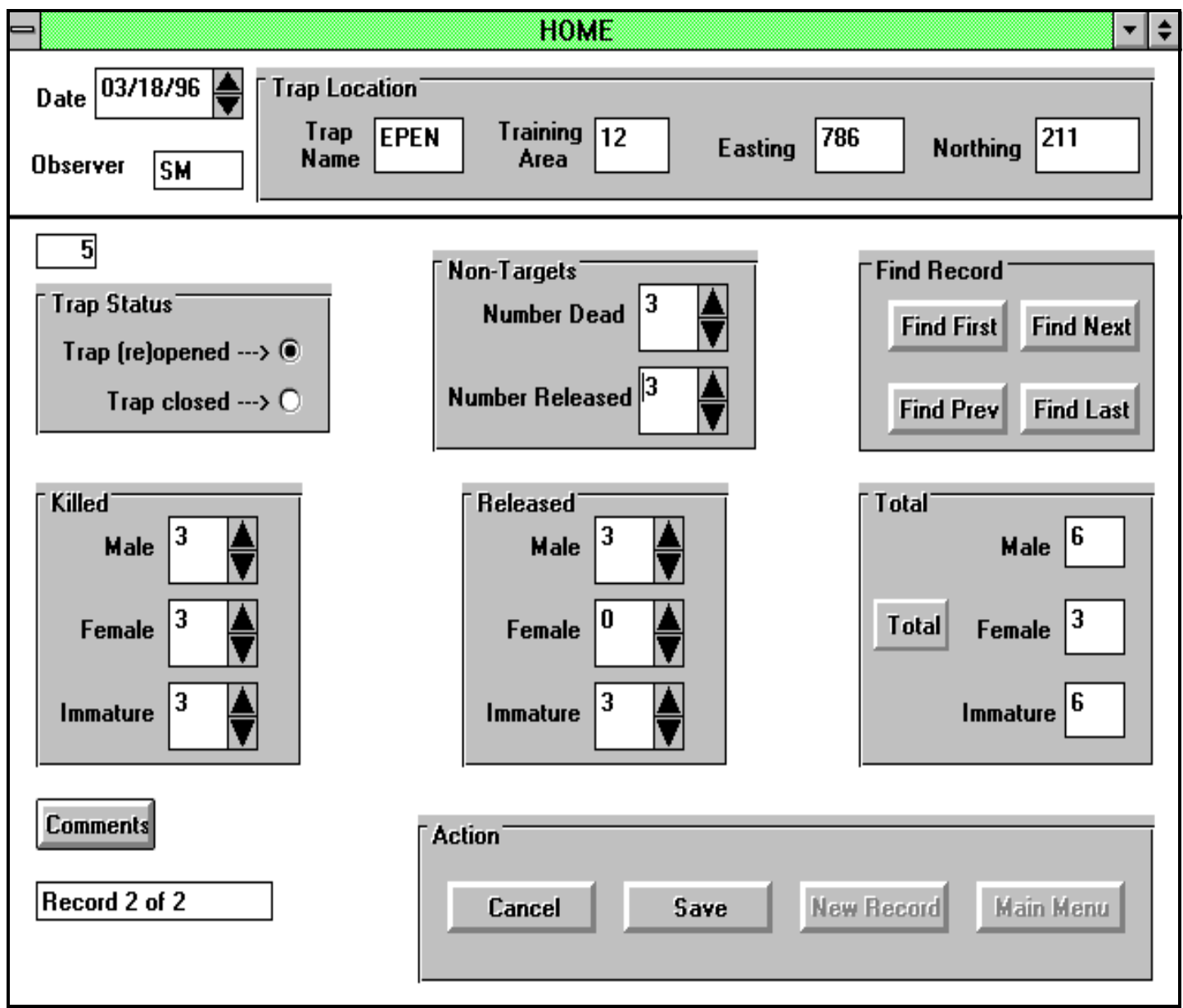

Figure 24. Edit record form.

displaying the last record matching that trap name. You now have access to all records matching that trap name. Figure 24 shows the resulting edit record form.

The text box in the upper left shows the individual record number in the database. The text box in the lower left corner shows how many records belong to the selected trap name. The edit record form functions the same way as the new record form and looks the same, except the edit record form has a frame containing FIND buttons. Use the FIND buttons to view and/or edit those records.

Except for the location frame in the top part of the form, all data fields are available to edit. Tap Save to save your changes to the database. Tap Cancel to nullify any changes made. After tapping either button, you can scroll through the database and view any record. Tap New Record to add a new record to the database. Tap Main Menu to remove the edit record form and return the main menu form.

d. Summary by Trap 
To get any trap summary, including trapping efficiency, tap the Trap button. The same list box containing all trap names in the database will appear exactly as adding a new record or editing an existing record. Refer to Figure 22 for that example. Tap the trap name you want and the program will ask you for a start date. Write in the starting date for the summary. The program will then ask you for a stop date. The default will be the last day of the starting month. Write in a different date if you want to change it. Choose the default or write in a different date to display a summary of killed and released cowbirds with an overall trapping efficiency for that time period. Tap Cancel to cancel your request. Figure 25 shows an example.

To print a copy of this table, tap the Print button. To remove this table and return to the main menu, tap Main Menu. 


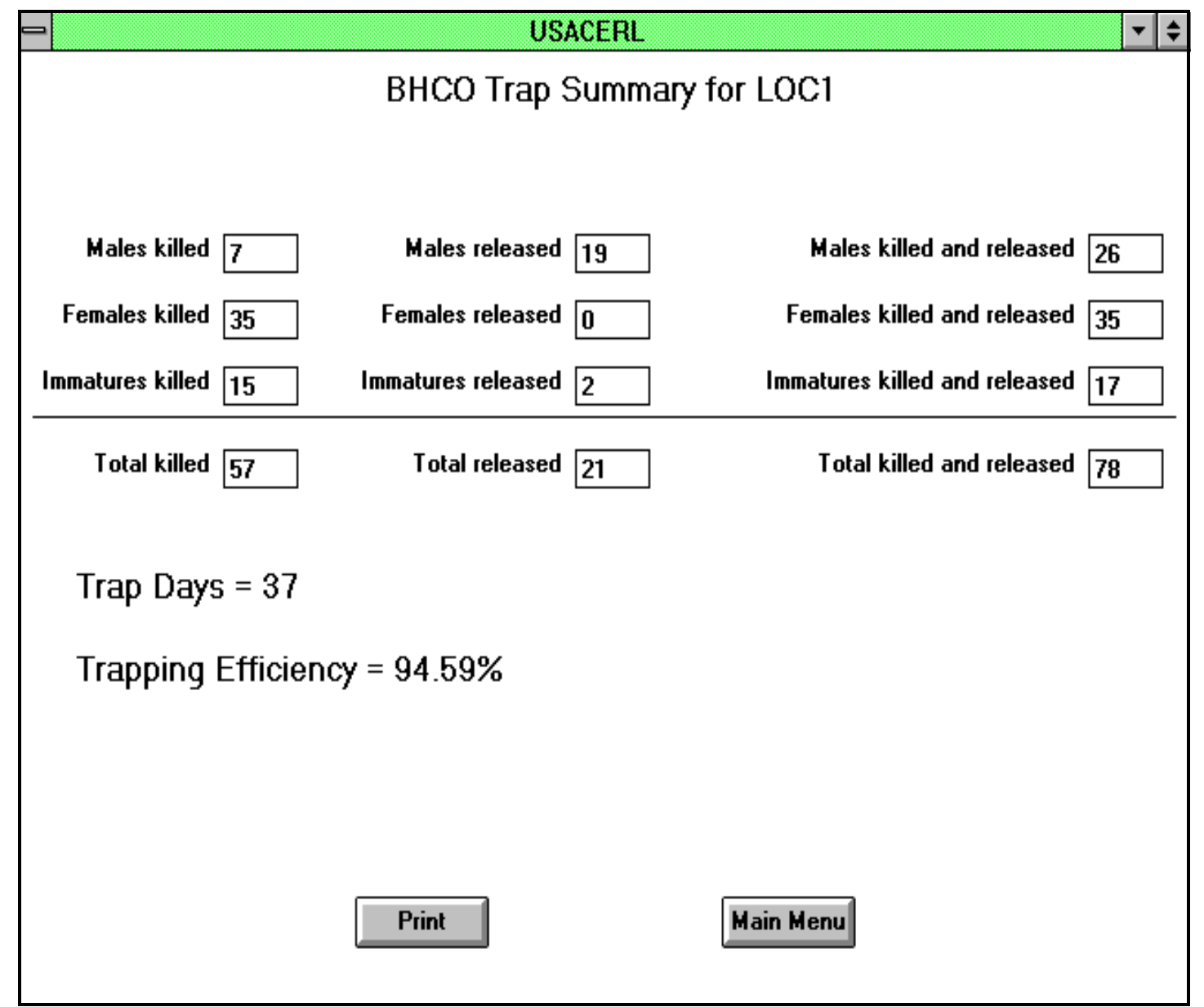

Figure 25. Trap summary.

e. Summary by Year

If you want a collective summary of all traps over a given year, the cowbird trapping program gives you two choices: FWS year or calendar year. FWS year prints a combined trap summary from December to the following November. To view it, tap FW_Year . Calendar year prints a combined summary of traps from January to December. To view that, tap Cal_Year. No matter which you choose, each will prompt you for a particular year. The default will always be the current year. Choosing the default or writing in a different year will bring up the summary table for that particular year. Figures 26 and 27 show an example of each.

To print a copy of any of these tables, make sure the printer is turned on and tap the Print button. To remove or get out of any table and return to the main menu, tap Main Menu.

f. Exit the Program 


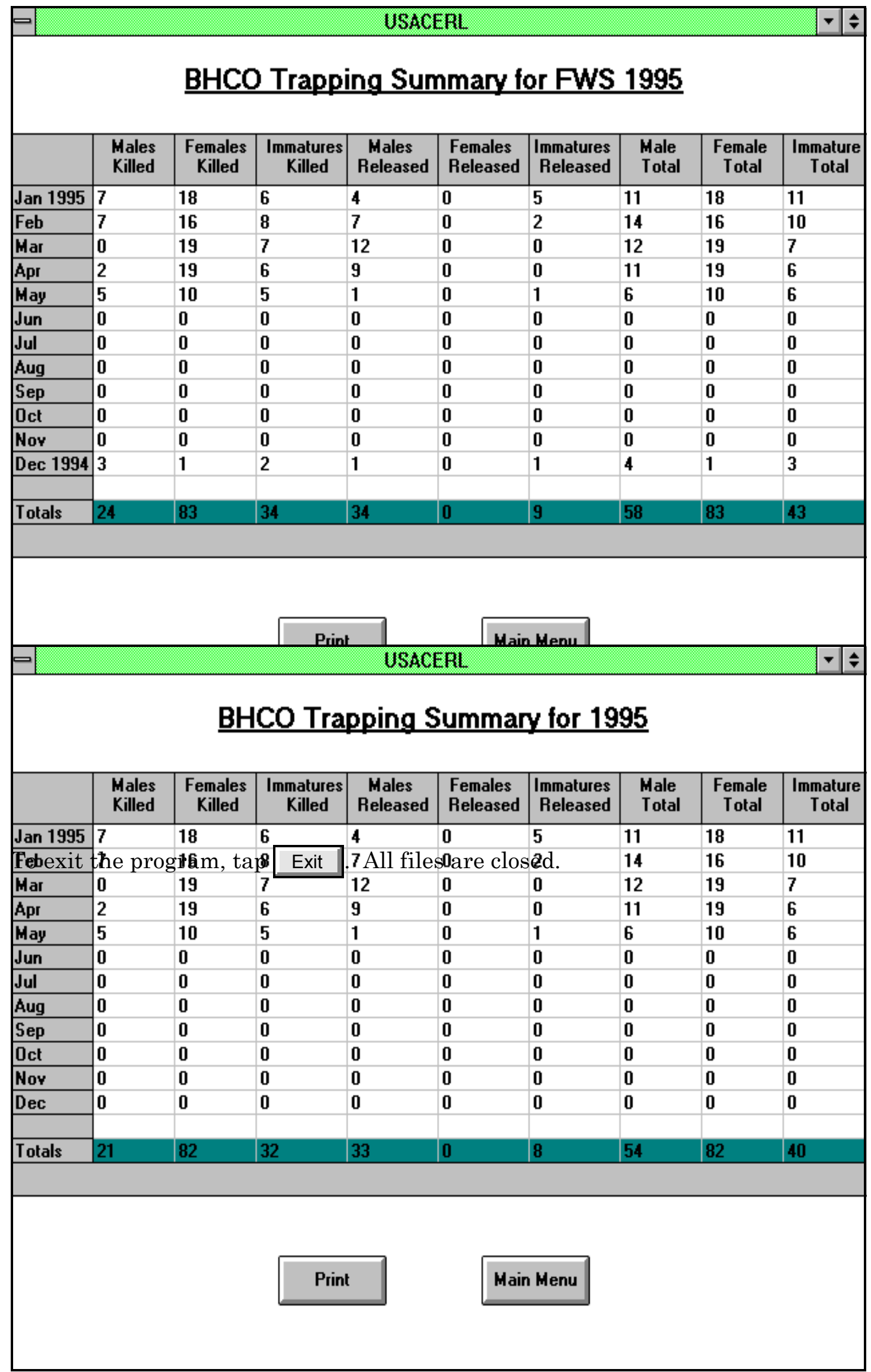

Figure 27. Calendar summary. 


\section{Non-Target Species Program} (NON_TARG.MAK)

\subsection{General Description}

The non-target species program is an offshoot of the cowbird trapping program. The non-target species program accumulates the number of non-target birds killed in and released from cowbird traps. It also records what species they were. The records are stored in a DBase IV database file under the path name $\mathrm{C}: \backslash \mathrm{VB} \backslash \mathrm{NON}$ TARG $\backslash N O N \_T A R G . D B F$. The field names and descriptions of this file are given below. Data types and lengths are given in parentheses.

REC_NUMBER (string) (4) - Number of the record in database.

DATE (string) (8) - Current date.

OBSERVER (string) (3) - Observer's initials.

TRAP_NAME (string) (4) - Name of trap.

AMKE_REL (numeric) (8) - Number of American Kestrels released.

BEWR_REL (numeric) (8) - Number of Bewick's Wrens released.

BLJA_REL (numeric) (8) - Number of Blue Jays released.

BRBL_REL (numeric) (8) - Number of Brewer's Blackbirds released.

BROC_REL (numeric) (8) - Number of Bronzed Cowbirds released.

CASP_REL (numeric) (8) - Number of Cassin's Sparrows released.

COGR_REL (numeric) (8) - Number of Common Grackles released.

DOWO_REL (numeric) (8) - Number of Downy Woodpeckers released. 
EABL_REL (numeric) (8) - Number of Eastern Bluebirds released.

EAPH_REL (numeric) (8) - Number of Eastern Phoebes released.

FISP_REL (numeric) (8) - Number of Field Sparrows released.

HASP_REL (numeric) (8) - Number of Harris' Sparrows released.

HOFI_REL (numeric) (8) - Number of House Finches released.

LASP_REL (numeric) (8) - Number of Lark Sparrows released.

LOSH_REL (numeric) (8) - Number of Loggerhead Shrikes released.

MODO_REL (numeric) (8) - Number of Mourning Doves released.

NOCA_REL (numeric) (8) - Number of Northern Cardinals released.

NOMO_REL (numeric) (8) - Number of Northern Mockingbirds released.

RBWO_REL (numeric) (8) - Number of Red-Bellied Woodpeckers released.

RCSP_REL (numeric) (8) - Number of Rufous-Crowned Sparrows released.

RWBL_REL (numeric) (8) - Number of Red-Winged Blackbirds released.

SHCO_REL (numeric) (8) - Number of Shiny Cowbirds released.

SSHA_REL (numeric) (8) - Number of Sharp-Shinned Hawks released.

STFL_REL (numeric) (8) - Number of Scissor-Tailed Flycatchers released.

WCSP_REL (numeric) (8) - Number of White-Crowned Sparrows released.

WEKI_REL (numeric) (8) - Number of Western Kingbirds released.

YHBL_REL (numeric) (8) - Number of Yellow-Headed Blackbirds released.

AMKE_DEAD (numeric) (8) - Number of American Kestrels dead.

BEWR_DEAD (numeric) (8) - Number of Bewick's Wrens dead. 
BLJA_DEAD (numeric) (8) - Number of Blue Jays dead.

BRBL_DEAD (numeric) (8) - Number of Brewer's Blackbirds dead.

BROC_DEAD (numeric) (8) - Number of Bronzed Cowbirds dead.

CASP_DEAD (numeric) (8) - Number of Cassin's Sparrows dead.

COGR_DEAD (numeric) (8) - Number of Common Grackles dead.

DOWO_DEAD (numeric) (8) - Number of Downy Woodpeckers dead.

EABL_DEAD (numeric) (8) - Number of Eastern Bluebirds dead.

EAPH_DEAD (numeric) (8) - Number of Eastern Phoebes dead.

FISP_DEAD (numeric) (8) - Number of Field Sparrows dead.

HASP_DEAD (numeric) (8) - Number of Harris' Sparrows dead.

HOFI_DEAD (numeric) (8) - Number of House Finches dead.

LASP_DEAD (numeric) (8) - Number of Lark Sparrows dead.

LOSH_DEAD (numeric) (8) - Number of Loggerhead Shrikes dead.

MODO_DEAD (numeric) (8) - Number of Mourning Doves dead.

NOCA_DEAD (numeric) (8) - Number of Northern Cardinals dead.

NOMO_DEAD (numeric) (8) - Number of Northern Mockingbirds dead.

RBWO_DEAD (numeric) (8) - Number of Red-Bellied Woodpeckers dead.

RCSP_DEAD (numeric) (8) - Number of Rufous-Crowned Sparrows dead.

RWBL_DEAD (numeric) (8) - Number of Red-Winged Blackbirds dead.

SHCO_DEAD (numeric) (8) - Number of Shiny Cowbirds dead.

SSHA_DEAD (numeric) (8) - Number of Sharp-Shinned Hawks dead. 
STFC_DEAD (numeric) (8) - Number of Scissor-Tailed Flycatchers dead.

WCSP_DEAD (numeric) (8) - Number of White-Crowned Sparrows dead.

WEKI_DEAD (numeric) (8) - Number of Western Kingbirds dead.

YHBL_DEAD (numeric) (8) - Number of Yellow-Headed Blackbirds dead.

COMMENTS (string) (150) - Any important notes.

\subsection{Starting the Program}

To start the program, double tap the Non_Targ icon with the pen. After writing your initials in the box, the main menu form in Figure 28 will appear.

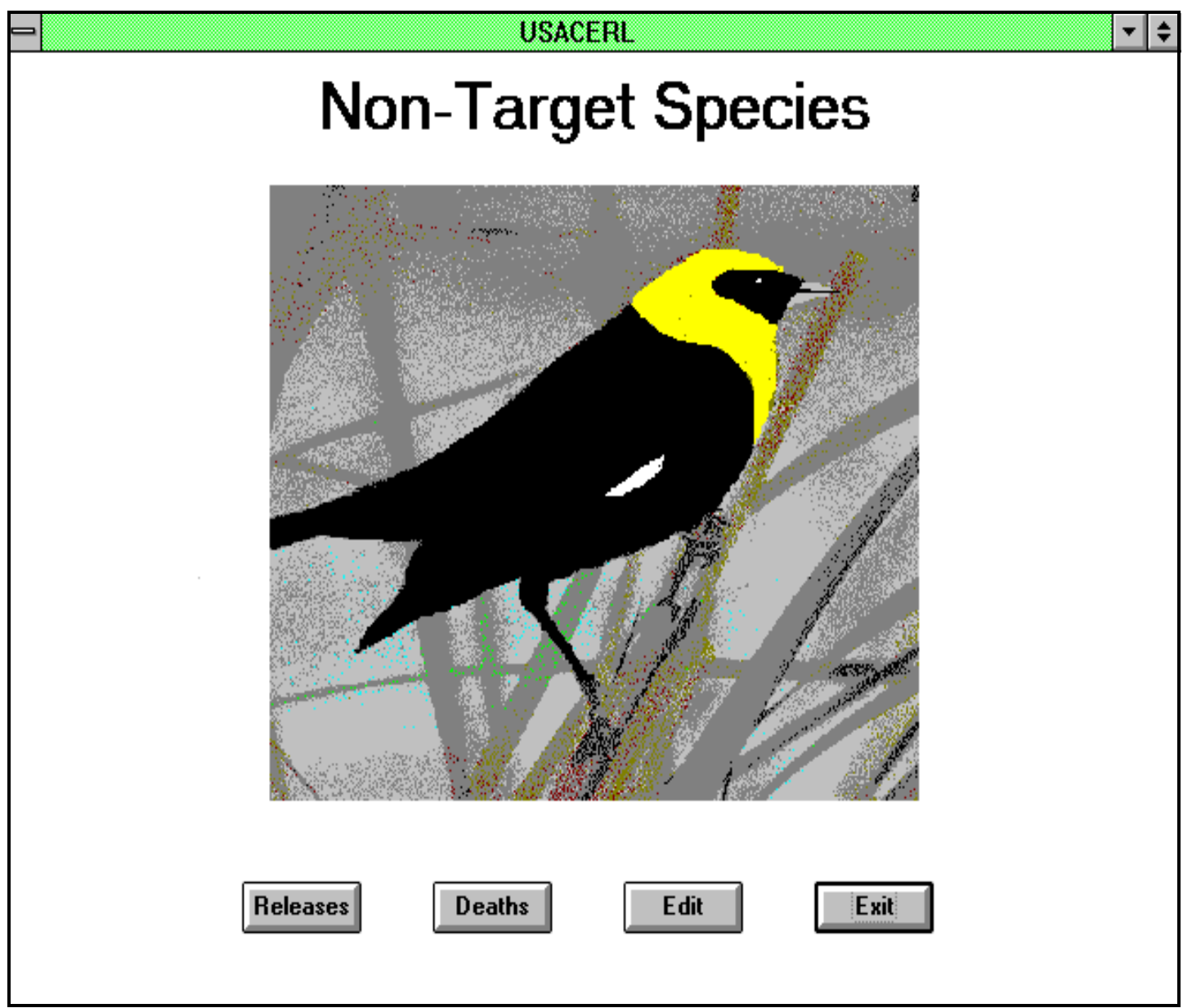

Figure 28. Non-target species main menu. 


\subsection{Program Flow}

\section{a. Add a Non-Target Species}

To record non-target releases and/or non-target deaths, tap either the Releases or Deaths button. A box will appear prompting you to enter the current date. Accept the default current date or write in a different date and tap OK. If you wish to cancel your request, tap Cancel. After tapping OK, a list box containing all cowbird trap names will appear as shown in Figure 29.

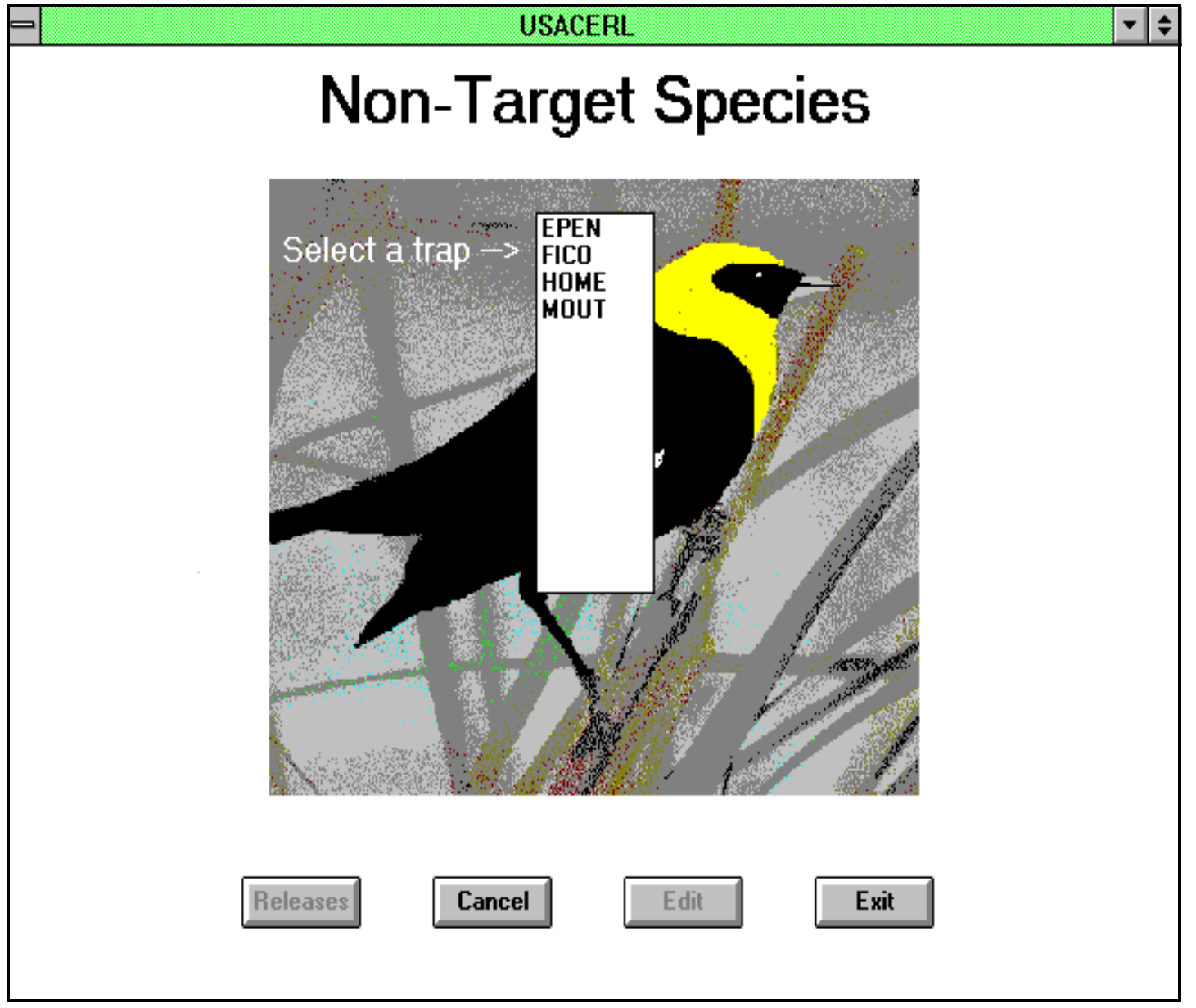

Figure 29. Selecting a trap name.

Tap Cancel to cancel your request or tap the trap name you want and the data entry form will appear. Figure 30 shows an example of the data entry form.

Both releases and deaths use the same data entry form. For all data fields, use the spin buttons to increment/decrement the counter or write the number in the text 


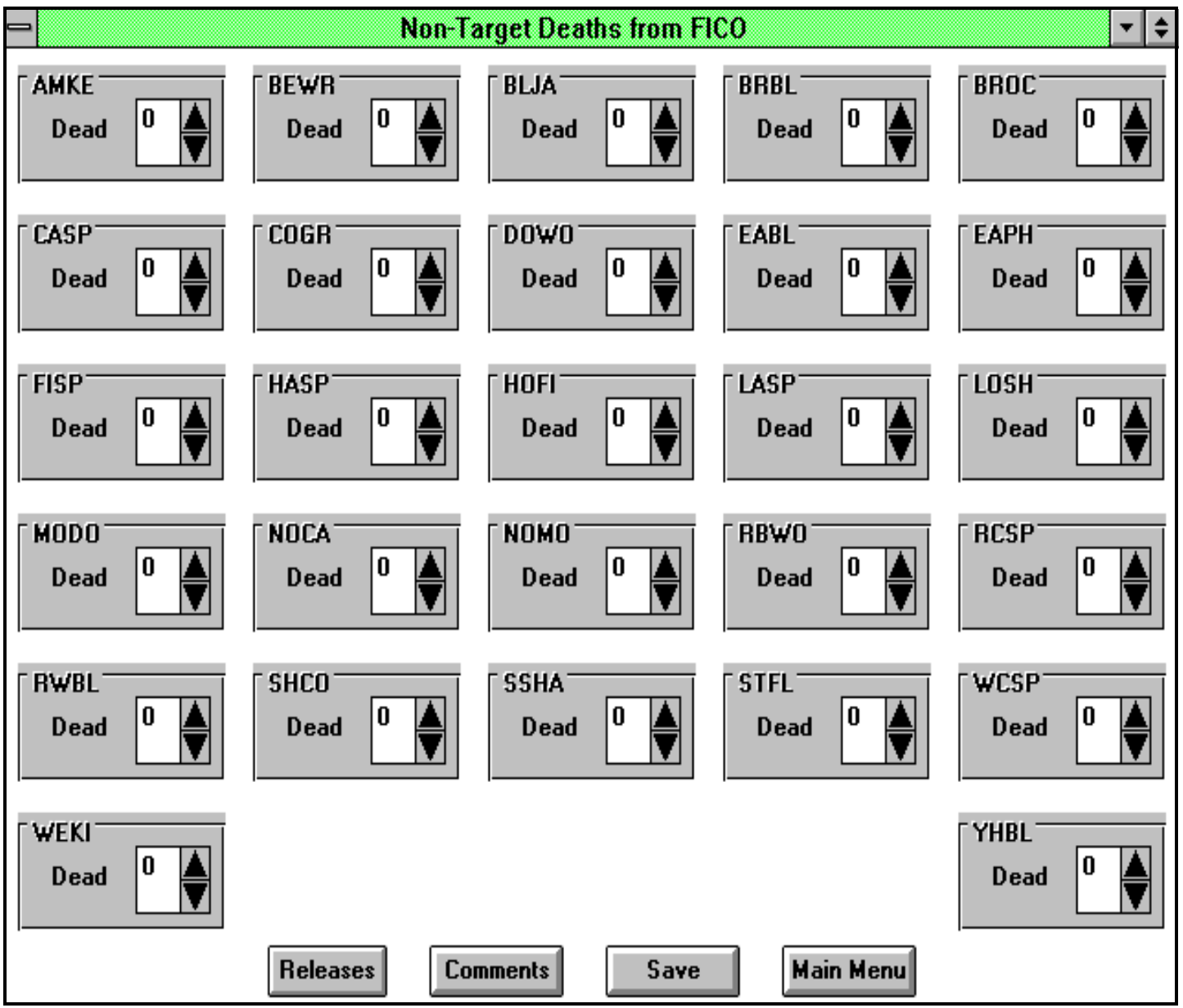

Figure 30. Non-targt species data entry form.

box. If you're done entering data for released birds and want to enter data for nontarget deaths, tap the Deaths button. If you're done entering data for dead birds and want to enter data for non-target releases, tap the Releases button. Tapping either button will only change the field names and the title bar, but everything else stays the same. As such, the procedure for entering data is the same. Tap the Comments button to write any pertinent comments in the white space provided.

When all data have been entered, tap Save to save the record to the database. Both non-target releases and deaths will be saved. Tapping Main Menu will remove the data entry form and return you to the main menu.

\section{b. Edit a record}

To edit a record, tap the Edit button. A list box containing all trap names in the non-target database will appear. Select the trap you wish to edit and the program will ask if you want to edit non-target deaths. Tap Yes if you want to edit non- 


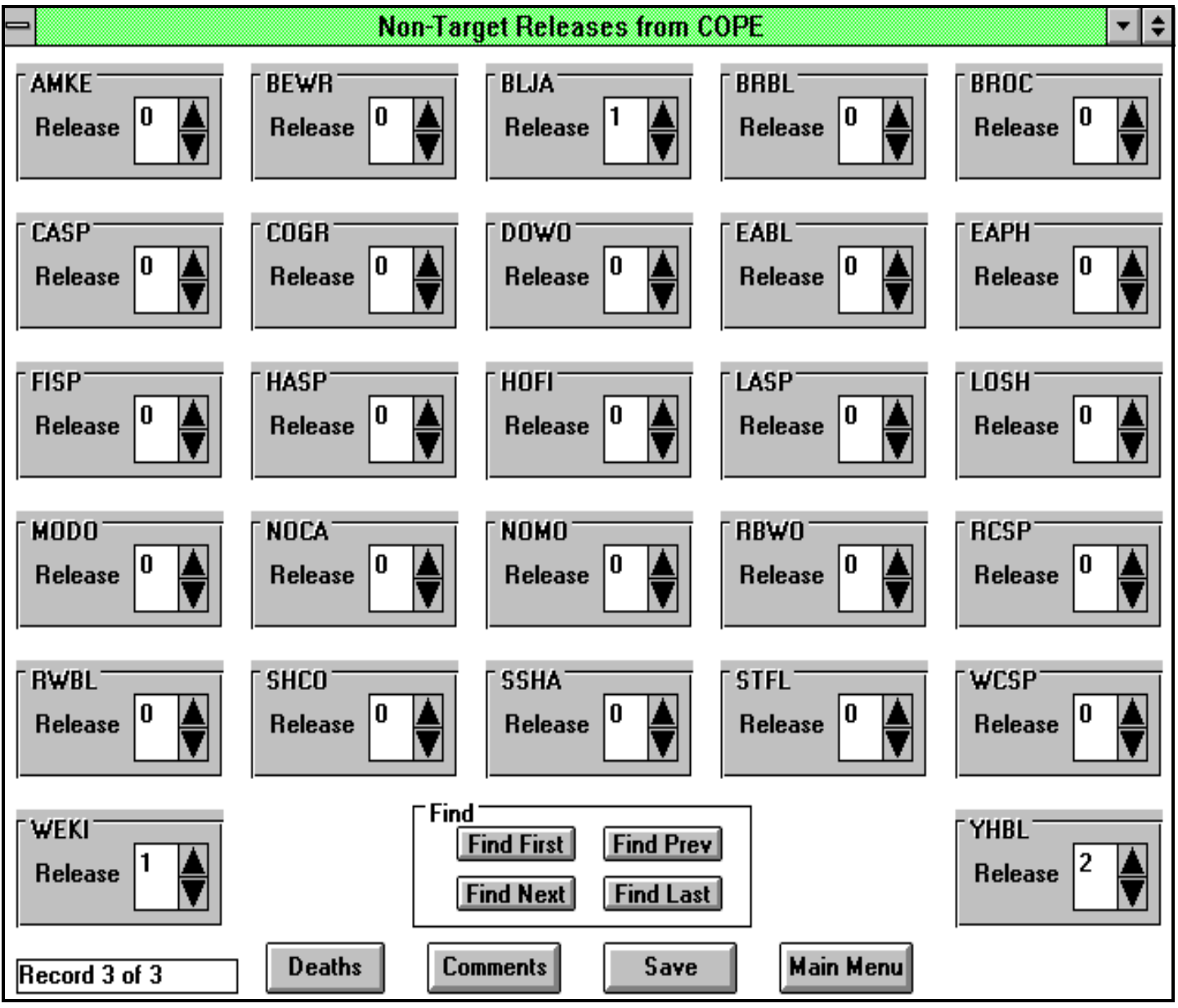

Figure 31. Non-target species edit form.

target deaths or tap No if you want to edit non-target releases. Tap Cancel if you wish to return to the main menu. The resulting edit form is shown in Figure 31.

The same edit form is used for non-target deaths as well as non-target releases. The only difference is the labels. Tap Releases or Deaths to toggle between both. The text box in the lower left hand corner shows how many records belong to a particular trap. Use the FIND buttons to view and/or edit those records. Tap Save to save your changes to the database. Tap Main Menu to remove the edit form and return to the main menu form.

\section{c. Exit the Program}

Tap Exit from the main menu to exit the program. All files are closed. 


\section{Black-Capped Vireo Survey} (BCVI.MAK)

\subsection{General Description}

The Black-Capped Vireo program records location and nesting data on known BCVI territories. Information can also be recorded for suspected territories where the nest is never found. When you save the data, the data are stored in a DBase IV database file under the path name $\mathrm{C}: \backslash \mathrm{VB} \backslash \mathrm{BCVI} \backslash \mathrm{BCVI} . \mathrm{DBF}$. The field names and descrip-tions of this file are given below. Data types and lengths are given in parentheses.

REC_NUMBER (string) (4) - Number of record in the database.

ID (string) (7) - Unique code for each BCVI territory. Composed of training area and territory. The program automatically inserts ID with every new record.

DATE (string) (8) - Current date.

START (string) (5) - Start time of observation.

STOP (string) (5) - Stop time of observation.

MINUTES (numeric) (8) - The difference between start and stop times in minutes. The program automatically calculates and inserts this field into the record.

OBSERVER (string) (3) - Observer's initials.

REGION (string) (4) - Designated region of Fort Hood. The program will automatically insert the correct region into the record based on your entry in the TR_AREA field.

ORIG_TR_AR (string) (4) - Training area where bird was first banded. 
TR_AREA (string) (4) - Current training area.

TERRITORY (string) (2) - Territory number within a training area.

EASTING (string) (6) - Easting coordinate.

NORTHING (string) (7) - Northing coordinate.

AERIAL (string) (3) - Aerial photo number.

MATED (true/false) (1) - Was the male mated?

M_CONFIRM (true/false) (1) - Was the male visually confirmed?

M_BAND (string) (4) - Band number prefix of male. The program automatically inserts this when band colors are confirmed.

M_NUMBER (string) (5) - Band number suffix of male. The program automatically inserts this when band colors are confirmed.

M_BAND_DAT (string) (8) - Date when male was originally banded. The program automatically inserts this when band colors are confirmed.

M_BAND_AGE (string) (3) - Age when male was originally banded. The program automatically inserts this when band colors are confirmed.

M_CURR_AGE (string) (3) - Current age of male.

MU_LEFT (string) (2) - Color code representing the upper left leg band of a male banded bird.

ML_LEFT (string) (2) - Color code representing the lower left leg band of a male banded bird.

MU_RIGHT (string) (2) - Color code representing the upper right leg band of a male banded bird.

ML_RIGHT (string) (2) - Color code representing the lower right leg band of a male banded bird.

F_CONFIRM (true/false) (1) - Was female visually confirmed? 
F_BAND (string) (4) - Band number prefix of female. The program automatically inserts this when band colors are confirmed.

F_NUMBER (string) (5) - Band number suffix of female. The program automatically inserts this when band colors are confirmed.

F_BAND_DAT (string) (8) - Date when female was originally banded. The program automatically inserts this when band colors are confirmed.

F_BAND_AGE (string) (3) - Age when female was originally banded. The program automatically inserts this when band colors are confirmed.

F_CURR_AGE (string) (3) - Current age of female.

FU_LEFT (string) (2) - Color code representing the upper left leg band of a female banded bird.

FL_LEFT (string) (2) - Color code representing the lower left leg band of a female banded bird.

FU_RIGHT (string) (2) - Color code representing the upper right leg band of a female banded bird.

FL_RIGHT (string) (2) - Color code representing the lower right leg band of a female banded bird.

NO_NEST (True/False) (1) - No nest was observed but nesting evidence was found.

NEST_ATMPT (string) (2) - Number of nest attempt.

NEST_SBSTR (string) (4) - Nest substrate.

NEST_HGT (string) (4) - Nest height.

NEST_STAGE (string) (1) - Current stage of nest.

PARASITIZE (True/False) (1) - Was nest parasitized?

NEST_FATE (string) (2) - Ultimate fate of nest. 
BCVI_EGGS (numeric) (8) - Number of BCVI eggs.

BCVI_NSTLG (numeric) (8) - Number of BCVI nestlings.

BCVI_FLEDG (numeric) (8) - Number of BCVI fledglings.

BHCO_EGGS (numeric) (8) - Number of BHCO eggs.

BHCO_NSTLG (numeric) (8) - Number of BHCO nestlings.

BHCO_FLEDG (numeric) (8) - Number of BHCO fledglings.

EGGS_SHOOK (numeric) (8) - Number of BHCO eggs shook.

EGGS_REMOV (numeric) (8) - Number of BHCO eggs removed.

NSTLG_KILL (numeric) (8) - Number of BHCO nestlings killed.

FLEDG_KILL (numeric) (8) - Number of BHCO fledglings killed.

COMMENTS (string) (150) - Any important notes.

\subsection{Starting the Program}

To start the program, double tap the BCVI icon with the pen. After writing your initials in the box, the main menu form in Figure 32 will appear.

\subsection{Program Flow}

a. Add new territory

To record a new territory, tap the Add Territory button. The main menu form will be removed and the new territory form will appear as shown in Figure 33.

The program will insert default values for current date, observer initials, nest height, and record number. You can increment or decrement the current date by tapping the spin button. You can also change the default initials by double tapping the Observer text box. Write the new initials in the box provided. All subsequent records will contain the new initials. 


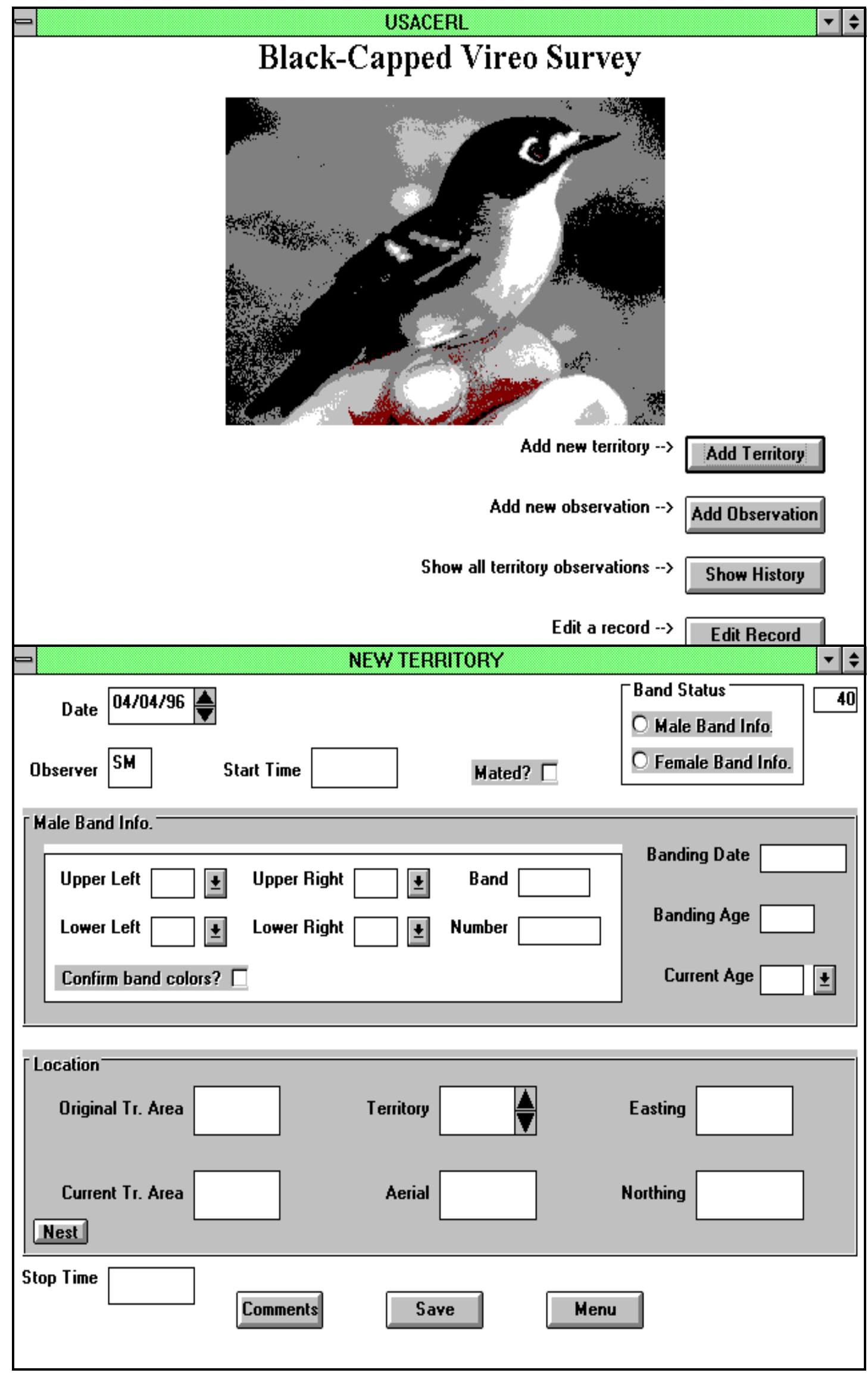

Figure 33. BCVI new territory form. 
In the upper right corner is the Band Status frame, which contains two option buttons. These option buttons control what you see in the band information frame. The default band information frame is Male Band Info. To bring up the Female Band Info frame, tap the Female Band Info. option button. Use both option buttons to record banding information for males and females.

$\underline{\text { Start Time }}$ - Double tap the text box to insert the observation start time or write it in the box.

Mated? - Tap the check box if male is mated.

Upper Left - Lower Right - Choose a color code for each leg band from the combo box.

Confirm band colors? - If you're sure of the band colors, tap the check box. The program will automatically search the BCVI_BND.DBF file for the BCVI matching that band color combination and retrieve the band number, banding age, banding date, and original training area.

$\underline{\text { Current Age }}$ - Choose an age code from the combo box.

Current Tr. Area - Write the current training area in the text box.

Territory - Use the spin button to increment the territory number or write it in the text box.

Aerial - Write the aerial photo number in the text box.

Easting - Write the easting coordinate in the text box.

Northing - Write the northing coordinate in the text box.

Nest - Tap this button to record nesting information. Figure 34 shows an example of the nesting frame. To eliminate the frame, double tap it.

No Nest? - Check this box if evidence of nesting was found but no nest was actually observed.

Nesting Effort - Accept the default nesting effort number or use the spin button to increment the number. From the time you enter a nesting effort 


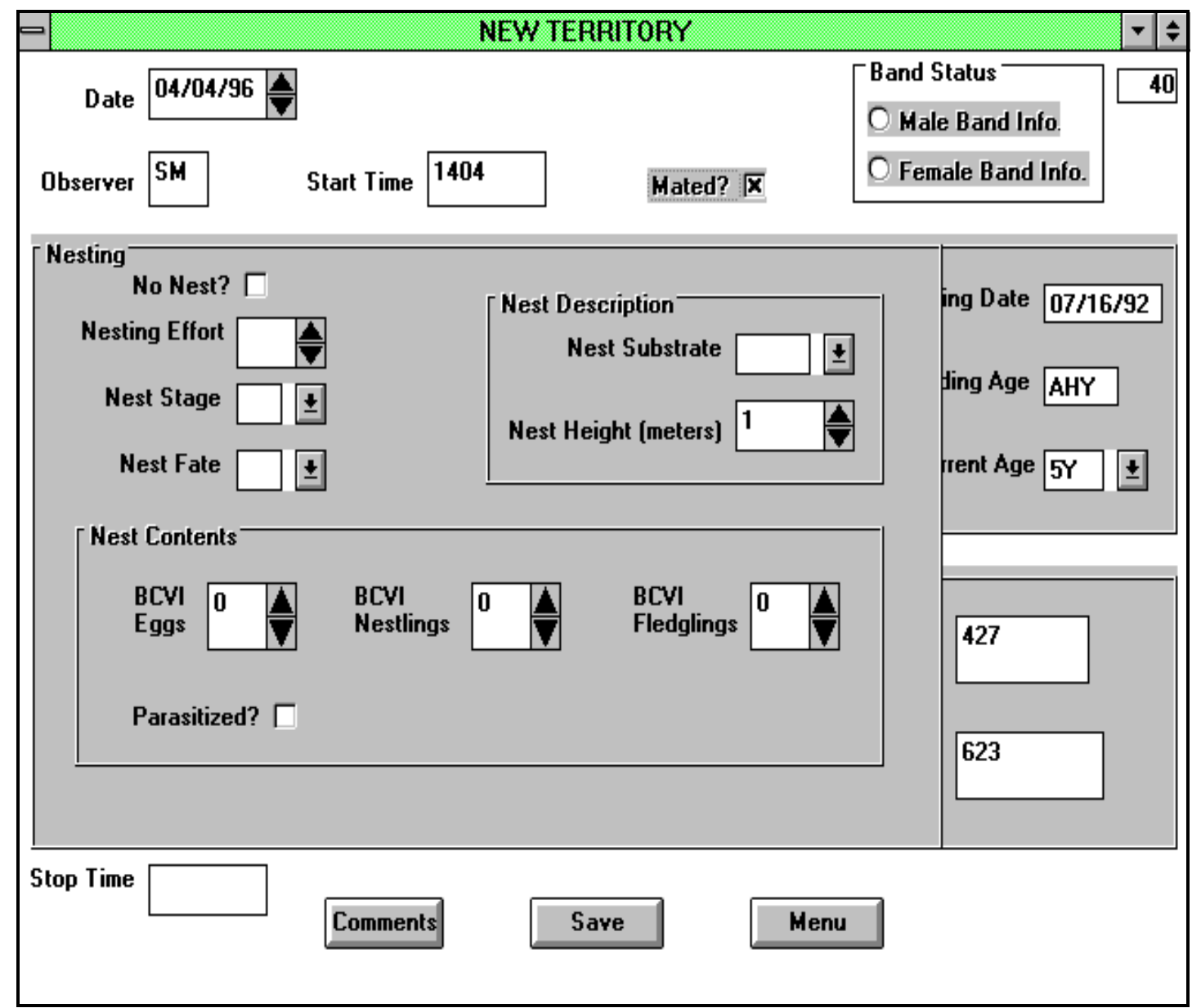

Figure 34. BCVI nesting information frame.

number to the time you enter a nest fate, the program will automatically carry forward the nesting effort number for new observations.

Nest Stage - Choose a code from the combo box.

Nest Substrate - Choose a code from combo box.

Nest Height - Use the spin button to increment or decrement nest height by 0.1 meter or accept the default.

$\underline{\text { Nest Fate }}$ - Choose a code from the combo box.

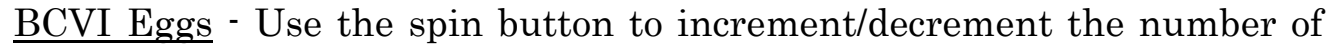
BCVI eggs or write it in the text box.

BCVI Nestlings - Use the spin button to increment/decrement the number of BCVI nestlings or write it in the text box. 
BCVI Fledglings - Use the spin button to increment/decrement the number of BCVI fledglings or write it in the text box.

Parasitized - Check this box if the nest has been parasitized. Once checked, another frame will appear containing text boxes for BHCOs. When finished entering values for them, double tap the frame to make the frame disappear.

BHCO Eggs - Use the spin button to increment/decrement the number of $\mathrm{BHCO}$ eggs or write it in the text box.

BHCO Nestlings - Use the spin button to increment/decrement the number of BHCO nestlings or write it in the text box.

BHCO Fledglings - Use the spin button to increment/decrement the number of BHCO fledglings or write it in the text box.

Eggs Shook - Use the spin button to increment/decrement the number of $\mathrm{BHCO}$ eggs shook or write it in the text box.

Eggs Removed - Use the spin button to increment/decrement the number of BHCO eggs removed or write it in the text box.

Nestlings Removed - Use the spin button to increment/decrement the number of BHCO nestlings removed or write it in the text box.

Fledglings Removed - Use the spin button to increment/decrement the number of BHCO fledglings removed or write it in the text box.

$\underline{\text { Stop Time }}$ - Double tap the text box to insert the observation stop time or write it in the box.

Comments - Tap this button and write any necessary comments in the white space provided. To eliminate the box, double tap it.

When you've completed making entries, verify your start and stop times and tap the Save button. The record will automatically be appended to the end of the database. Tap Menu to remove the new territory form and return to the main menu form.

b. Add new observation 


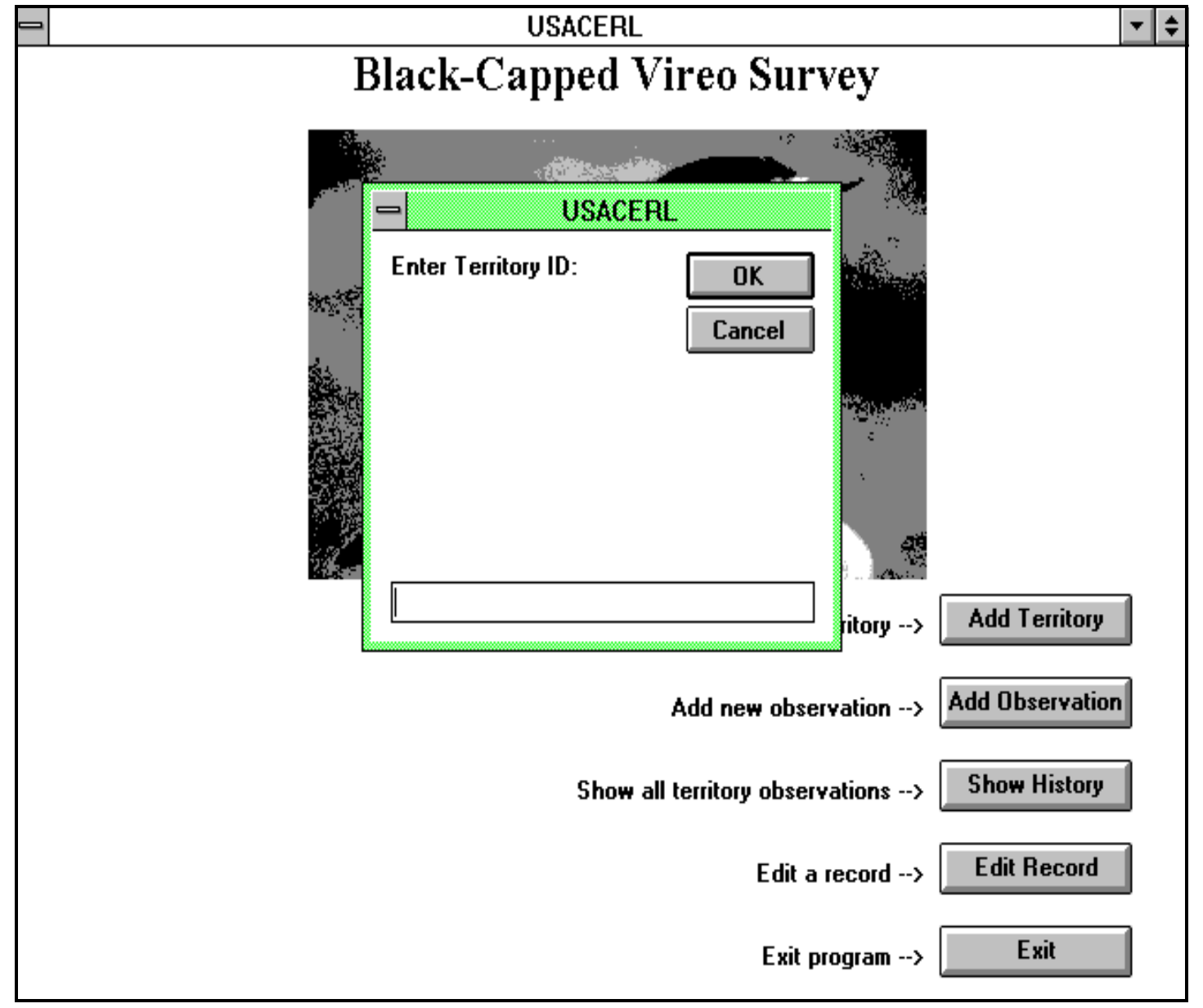

Figure 35. BCVI selection list box.

To add a new observation, tap Add Observation. The program will ask you to enter a territory ID. Figure 35 shows an example.

Write the training area number followed by a "-" and then the territory number (i.e., 12-3) in the box. Tap OK and the new observation form shown in Figure 36 will appear. Tap Cancel to cancel your request.

All fields in this form work exactly the same way as the fields in the new territory form. The only difference is the flashing Confirmed? frame. This frame flashes to emphasize its importance. To stop the flashing, you must tap "Yes" or "No" for the male and also for the female if there is one. You cannot save a record until you've satisfied the Confirmed? requirements.

The date, observer, and record number fields all have default values entered. You can increment/decrement the date by tapping the spin button. The default initials 


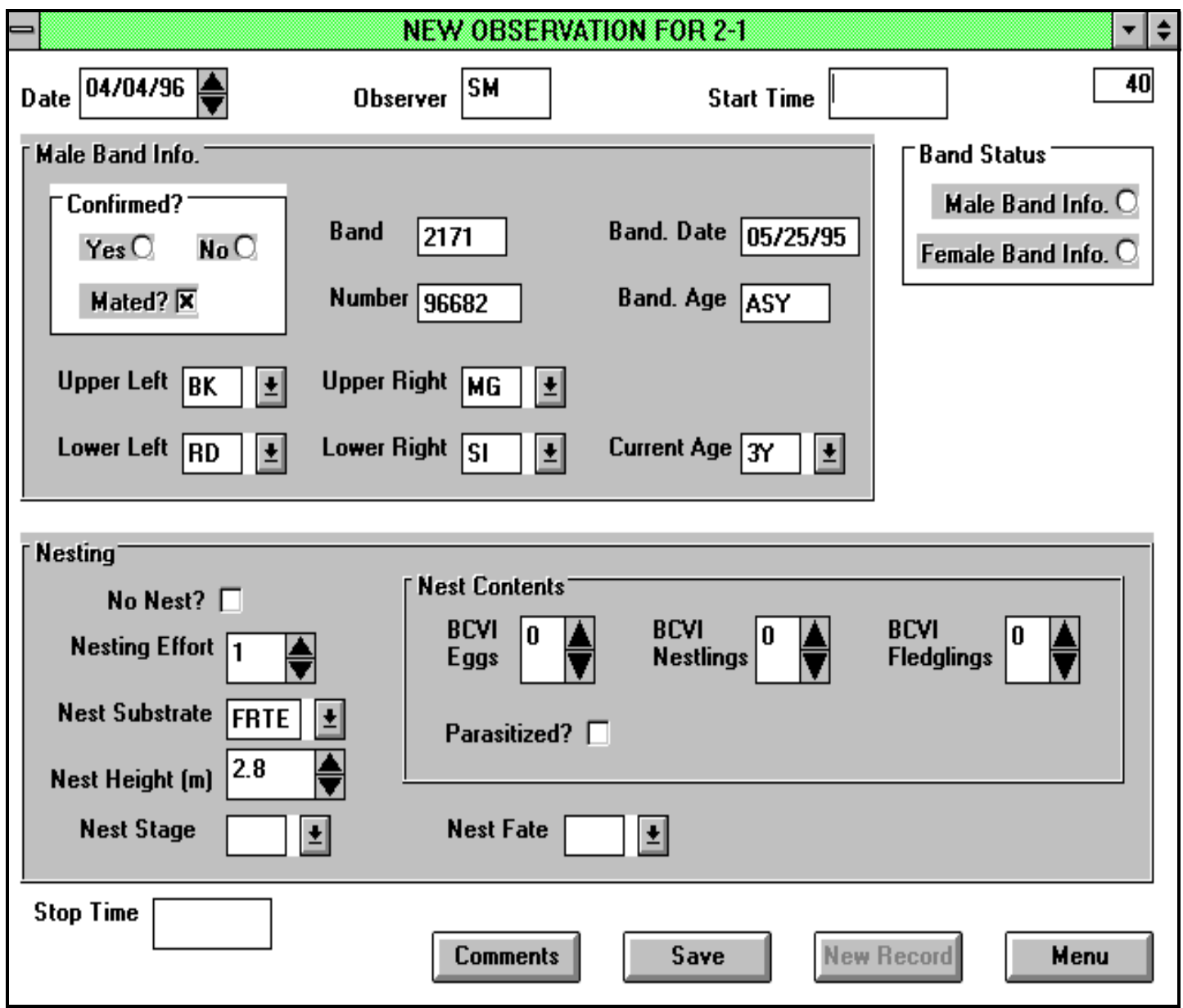

Figure 36. BCVI new observation form.

can be changed by double tapping the Observer text box. Band number, leg bands, banding age, banding date, current age, and nesting effort, substrate, and height are all carried forward from the last occurrence of the ID code in the database. If you are entering leg band colors for the first time, tap "Yes" in the Confirmed? frame to retrieve the corresponding band number, banding age, and banding date from the BCVI_BND.DBF file.

To save the record to the database, verify your start and stop times and tap Save. To add another record for the same Territory ID, tap New Record. To remove the new observation form and return to the main menu, tap Menu.

\section{c. Show History}

To display a report of all observations for a given ID code, tap Show History. The program will ask you to enter a territory ID exactly like adding a new 


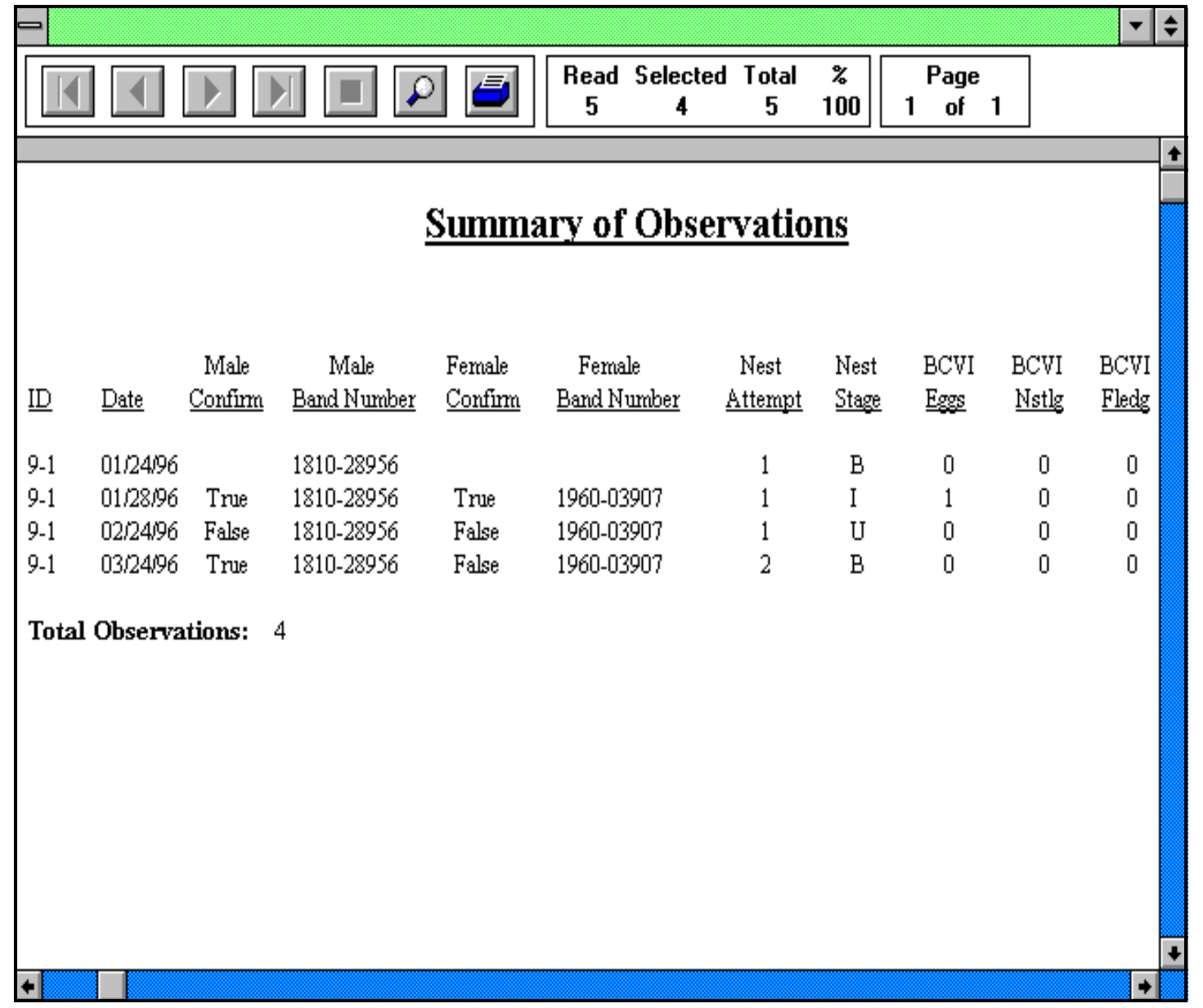

Figure 37. BCVI summary of observations form.

observation. See Figure 35 for an example. Tap Cancel to cancel your request or write the territory ID in the text box and tap OK. The fields displayed include ID code, date, male confirmed, male band number, female confirmed, female band number, nest attempt, nest stage, BCVI eggs, BCVI nestlings, BCVI fledglings, and comments. Figure 37 shows an example.

Use the left and right arrows to view each page and the printer icon to direct the report to the printer. To return to the main menu, tap the control box at the top left hand corner of the screen and tap the "Close" option.

\section{d. Edit a record}

To edit an existing record, tap Edit Record. The program will again ask you to enter the territory ID. If you want to forego the edit process, tap Cancel. Otherwise, write the territory ID in the text box and tap OK. The edit form will 
appear displaying the last record matching that ID code. Figure 38 shows an example.

You now have access to the entire set of records belonging to that ID code. The text box in the lower left corner shows the number of matching records. Use the FIND buttons to view and/or edit those records.

The controls on the edit form work exactly the same way as on the new observation form. Tap Save to save any changes to the database. Tap Cancel to exit out of edit mode and cancel any changes you've made. The FIND buttons will still be available to view matching records. Use Cancel as well to make the nesting frame disappear if you're no longer in edit mode. Tap Menu to remove the edit form and return you to the main menu form. 


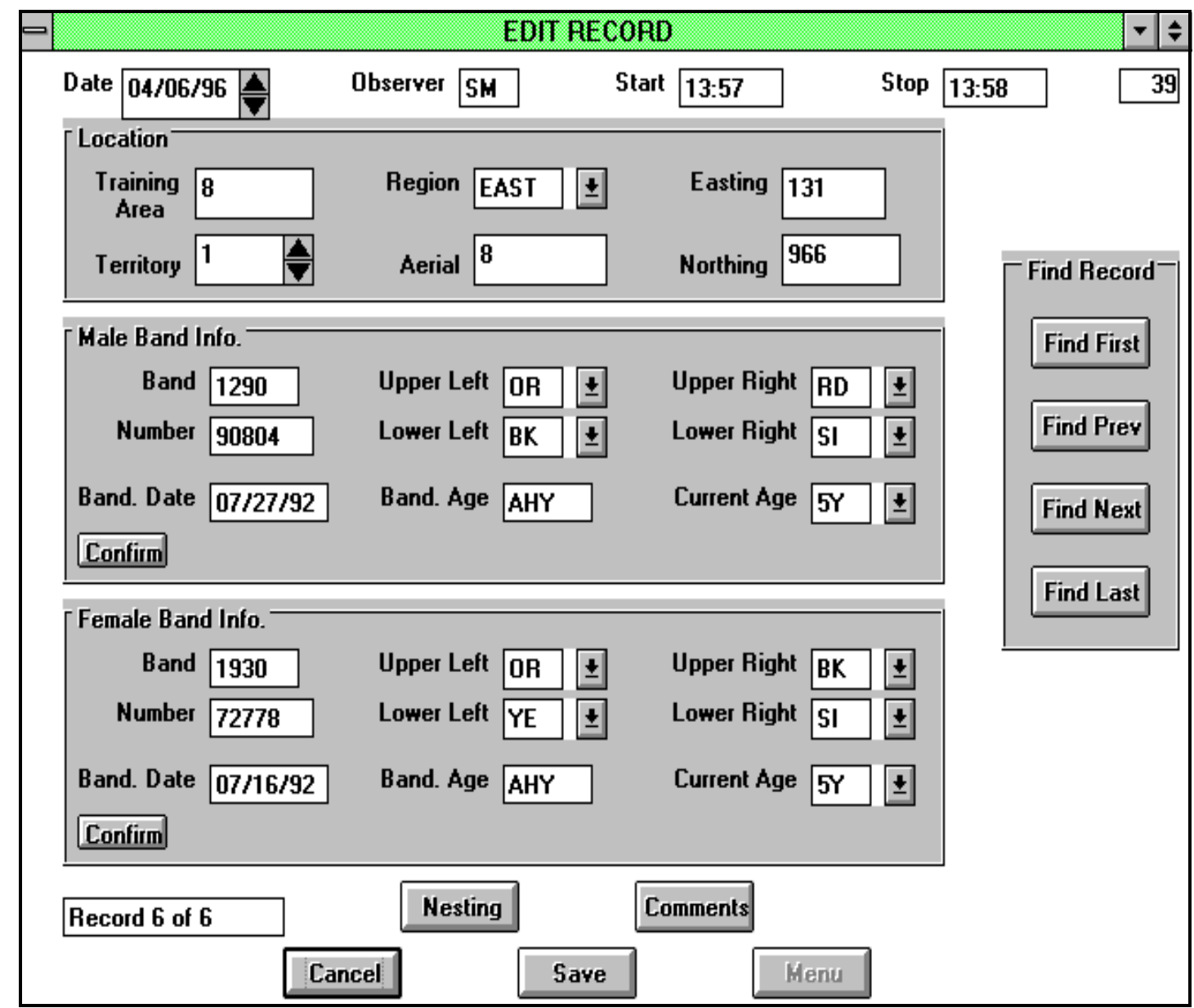

Figure 38. BCVI edit form.

e. Exit the Program

To exit the program, tap Exit from the main menu. All files are closed. 


\section{Golden-Cheeked Warbler Program} (GCWA.MAK)

\subsection{General Description}

The Golden-Cheeked Warbler program records location and nesting data on GCWAs. It can record data from the intensive study area, point counts, and returning birds. However, it doesn't record measurement data. When you save the data, the data are stored in a DBase IV database file under the path name $\mathrm{C}: \backslash \mathrm{VB} \backslash \mathrm{GCWA} \backslash \mathrm{GCWA} . \mathrm{DBF}$. The field names and descriptions of this file are given below. Data types and lengths are given in parentheses.

REC_NUMBER (string) (4) - Number of the record in the database.

DATE (string) (8) - Current date.

START (string) (5) - Start time of observation.

STOP (string) (5) - Stop time of observation.

MINUTES (numeric) (8) - The difference between start and stop times in minutes. The program automatically calculates and inserts this field into the record.

OBSERVER (string) (3) - Observer's initials.

TARG_OBS (true/false) (1) - Was target bird observed?

TARG_BAND (string) (4) - Band number prefix for target bird.

TARG_NUMBR (string) (5) - Band number suffix for target bird.

TU_LEFT (string) (2) - Color code representing the upper left leg band of the target bird. 
TL_LEFT (string) (2) - Color code representing the lower left leg band of the target bird.

TU_RIGHT (string) (2) - Color code representing the upper right leg band of the target bird.

TL_RIGHT (string) (2) - Color code representing the lower right leg band of the target bird.

TARG_EAST (string) (6) - Easting coordinate where target bird was originally banded.

TARG_NORTH (string) (7) - Northing coordinate where target bird was originally banded.

N_TARG_OBS (true/false) (1) - Was a non-target bird observed?

OBS_BAND (string) (4) - Band number prefix for observed bird.

OBS_NUMBER (string) (5) - Band number suffix for observed bird.

BAND_DATE (string) (8) - Date when observed bird was originally banded. The program will automatically insert this field into the record.

OU_LEFT (string) (2) - Color code representing the upper left leg band of the observed bird.

OL_LEFT (string) (2) - Color code representing the lower left leg band of the observed bird.

OU_RIGHT (string) (2) - Color code representing the upper right leg band of the observed bird.

OL_RIGHT (string) (2) - Color code representing the lower right leg band of the observed bird.

OBS_TR_AR (string) (4) - Training area where observed bird was banded originally. The program will automatically insert this field into the record.

OBS_EAST (string) (6) - Easting coordinate where observed bird was banded originally. The program will automatically insert this field into the record. 
OBS_NORTH (string) (7) - Northing coordinate where observed bird was banded originally. The program will automatically insert this field into the record.

BAND_AGE (string) (3) - Age when observed bird was originally banded. The program will automatically insert this field into the record.

MATED (true/false) (1) - Was the observed bird mated?

F_CONFIRM (true/false) (1) - Was female sighting confirmed?

TR_AREA (string) (4) - Current training area of observed bird.

TERRITORY (string) (2) - Current territory of observed bird.

EASTING (string) (6) - Current easting coordinate of observed bird.

NORTHING (string) (7) - Current northing coordinate of observed bird.

NEST_NUMBR (string) (1) - Nest number.

NEST_SBSTR (string) (4) - Nest substrate.

NEST_HGT (string) (4) - Nest height.

NEST_STAGE (string) (1) - Stage of nest.

NEST_FATE (string) (2) - Ultimate fate of nest.

GCWA_EGGS (numeric) (8) - Number of GCWA eggs.

BHCO_EGGS (numeric) (8) - Number of BHCO eggs.

GCWA_NSTLG (numeric) (8) - Number of GCWA nestlings.

BHCO_NSTLG (numeric) (8) - Number of BHCO nestlings.

GCWA_FLEDG (numeric) (8) - Number of GCWA fledglings.

BHCO_FLEDG (numeric) (8) - Number of BHCO fledglings. 
NSLG_CONFM (true/false) (1) - Were nestlings confirmed?

HY_BIRD_AG (string) (2) - Estimated age of hatching year birds.

FLDG_DATE1 (string) (8) - Estimated fledging date for first group of nestlings.

FLDG_DATE2 (string) (8) - Estimated fledging date for second group of nestlings.

COMMENTS (string) (200) - Any important notes.

\subsection{Starting the Program}

To start the program, double tap the GCWA icon with the pen. After writing your initials in the box, the data entry form will appear as in Figure 39.

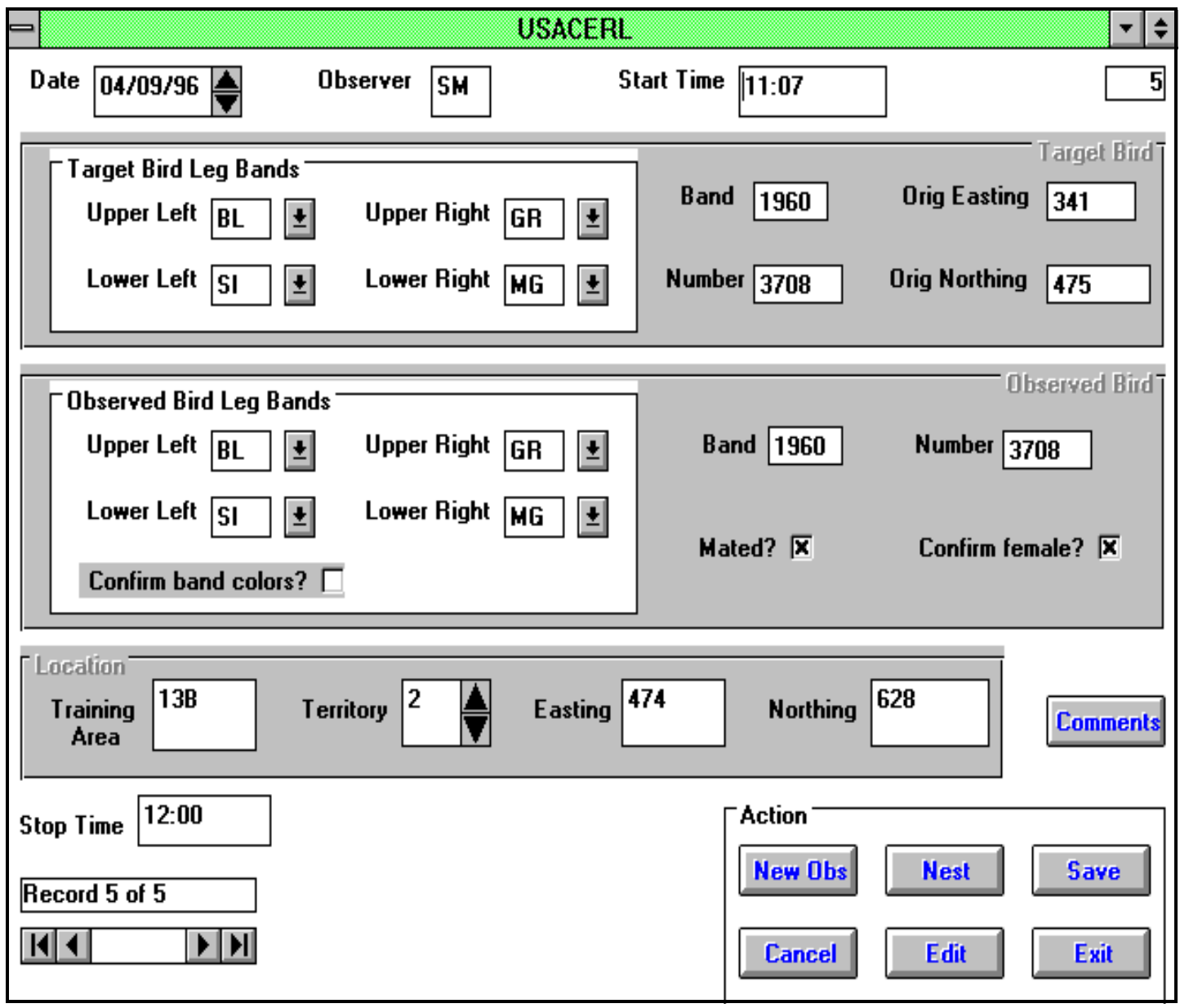

Figure 39. BCVI data entry form. 
The information displayed on the form (assuming the database is not empty) is the last record in the database. The total number of records in the database is shown at the bottom left corner of the form. The number at the top right corner indicates the number of the individual record in the database. From here, you can add, edit, or view any record in the database.

\subsection{Program Flow}

\section{a. Add new record}

To add a new record, tap the New Obs button. The program will respond by asking if you're looking for a particular bird. Tap Cancel to cancel your request. Tap No if you're not looking for a particular bird but wish to enter data. Tap Yes to bring up the target bird selection form shown in Figure 40.

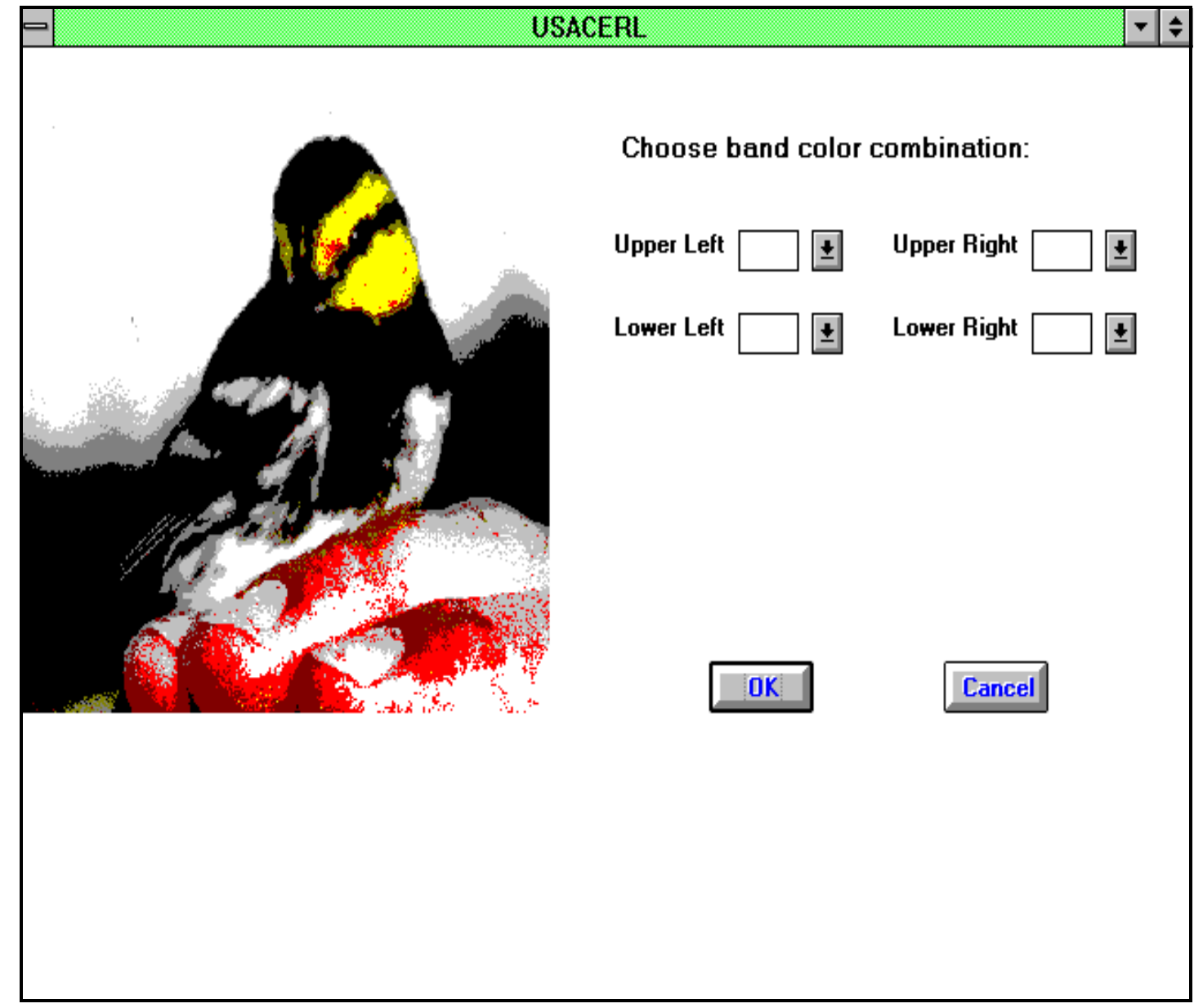

Figure 40. Target bird selection form. 
Tap Cancel to cancel your request or choose a leg band color from each combo box. Tap OK and the target bird selection form will disappear while the data entry screen will reappear. The program will clear all fields but retrieve the band colors, and original easting and northing coordinates from the GCWA_BND.DBF file and insert them into the Target Bird frame.

Whether or not you're looking for a target bird, selecting either Yes or No will always place default values in the date, observer, training area, nest height, and record number fields. You can increment or decrement the date by tapping the spin button. You can change the default initials as well by double tapping the Observer text box and writing the new initials in the box provided. All subsequent records will contain the new initials.

Start Time - Double tap the text box to insert the observation start time or write it in the box.

Upper Left - Lower Right - Choose a color code for each leg band from the combo box.

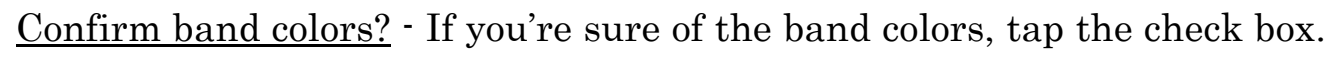
The program will automatically search the GCWA_BND.DBF file for the GCWA matching that band color combination and retrieve the band number. It will also retrieve the original banding date, age, training area, easting, and northing coordinates to save for later.

Mated? - Tap the check box if the bird was mated.

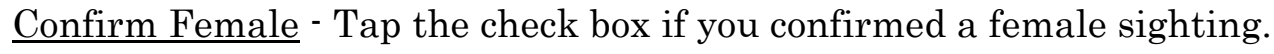

Training Area - Write the training area in the text box or accept $13 \mathrm{~B}$ as the default.

Territory - Use the spin button to increment/decrement the territory or write it in the text box.

Easting - Write the easting coordinate in the text box.

Northing - Write the northing coordinate in the text box. 


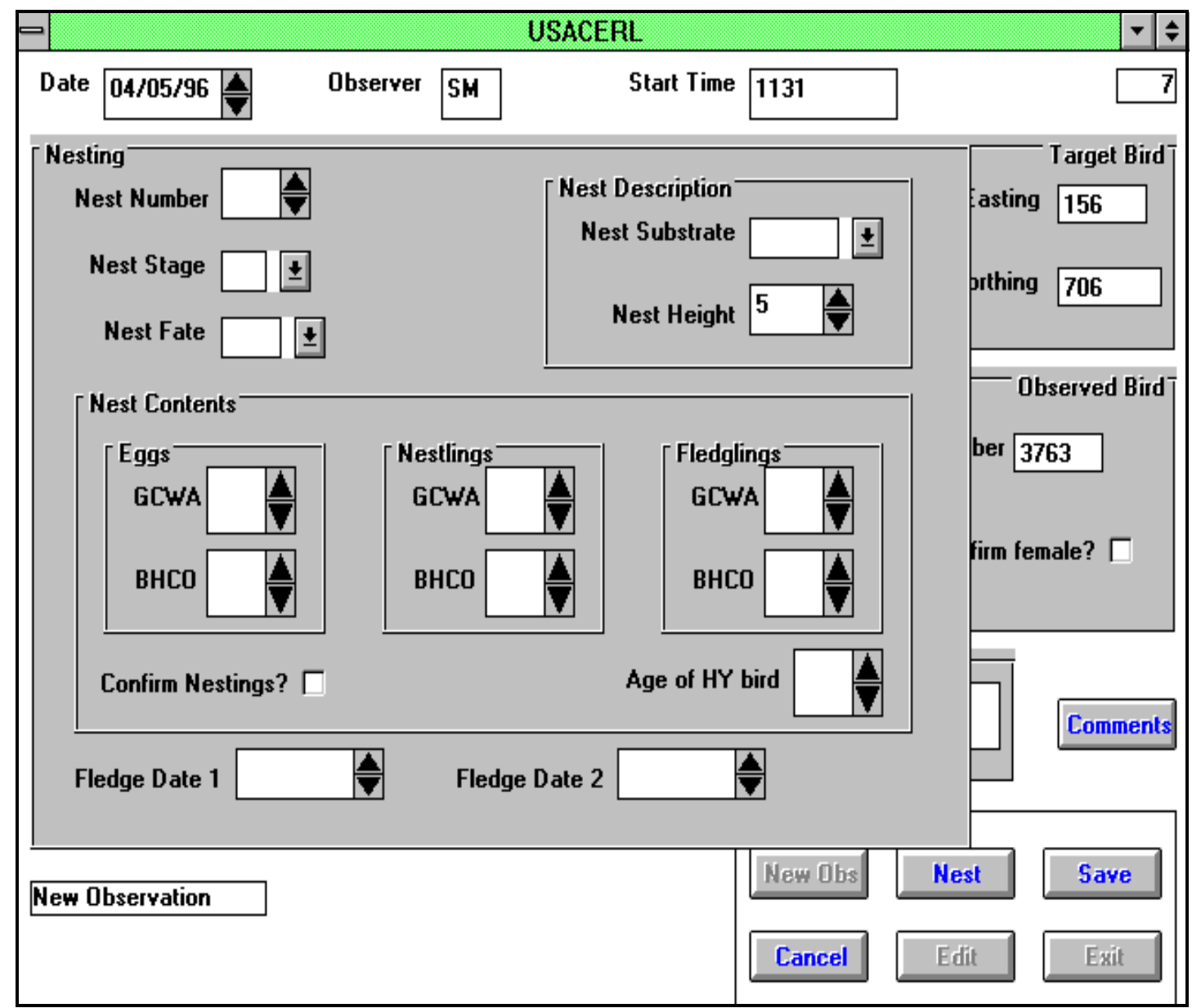

Figure 41. GCWA nesting data frame.

Nest - Tap this button to record nesting data. Figure 41 shows an example of the nesting frame. To eliminate the frame, double tap it.

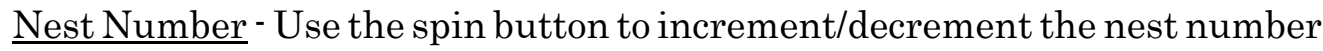
or write it in the text box.

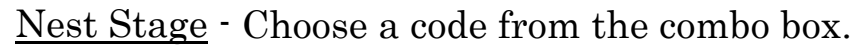

$\underline{\text { Nest Fate }}$ - Choose a code from the combo box.

$\underline{\text { Nest Substrate }}$ - Choose a code from the combo box.

Nest Height - Use the spin button to increment or decrement nest height by 0.1 meter or accept the default. 
GCWA Eggs - Use the spin button to increment/decrement the number of GCWA eggs or write it in the text box.

BHCO Eggs - Use the spin button to increment/decrement the number of BHCO eggs or write it in the text box.

GCWA Nestlings - Use the spin button to increment/decrement the number of GCWA nestlings or write it in the text box.

$\underline{\mathrm{BHCO} N e s t l i n g s}$ - Use the spin button to increment/decrement the number of $\mathrm{BHCO}$ nestlings or write it in the text box.

GCWA Fledglings - Use the spin button to increment/decrement the number of GCWA fledglings or write it in the text box.

BHCO Fledglings - Use the spin button to increment/decrement the number of BHCO fledglings or write it in the text box.

Confirm Fledglings - Tap the check box if you've confirmed fledglings.

Age of HY Bird - Use the spin button to increment/decrement the estimated age of the GCWA fledglings or write it in the text box.

Fledge Date 1 - Double tap the text box to insert the current date. Use the spin button to increment/decrement the date.

Fledge Date 2 - Double tap the text box to insert the current date Use the spin button to increment/decrement the date.

Comments - Tap this button and write any necessary comments in the white space provided. To eliminate the screen, double tap it.

$\underline{\text { Stop Time }}$ - Double tap the text box to insert the observation stop time or write it in the box.

b. Edit a record

To edit a record, tap the Edit button. The same target bird selection form shown in Figure 40 will appear. If you want to forego the edit process, tap Cancel and return to the original form. Otherwise, enter all the leg band colors and tap OK. 
The data entry form will reappear and you will have access to the entire set of records matching that color band combination. Use the FIND buttons to view and/or edit those records.

c. Cancel an action

Tap Cancel to break out of any action. If you're adding a new record, the fields are cleared and the database pointer will point to the last record in the database. If you're editing a record, all changes will be disregarded and you will no longer be in edit mode. The database pointer will still point to the current record.

If you are scrolling through the database examining the comments or nesting data of a particular record, tapping Cancel will make the comments box or nesting frame disappear, double tapping will not.

d. Save a record

To save a new record or one that has been edited, tap the Save button. A new record will be appended to the end of the database. An edited record will retain its position in the database.

e. Exit the program

To exit the program, tap Exit. All files are closed. 


\section{Database Backup Program}

(BACKUPDB.MAK)

\subsection{General Description}

The Database Backup program is a very simple and straightforward program that does exactly what its name implies. It will backup any database you choose to a floppy disk. The name of the file will be the same except the extension will be.BAK instead of .DBF. The purpose of database backup is twofold: (1) it is saved on different media separate from the computer itself, and (2) it can be merged with another like database into a separate computer, creating a master database.

\subsection{Starting the Program}

To start the program, double tap the DB_Backup icon with the pen. The form shown in Figure 42 will appear.

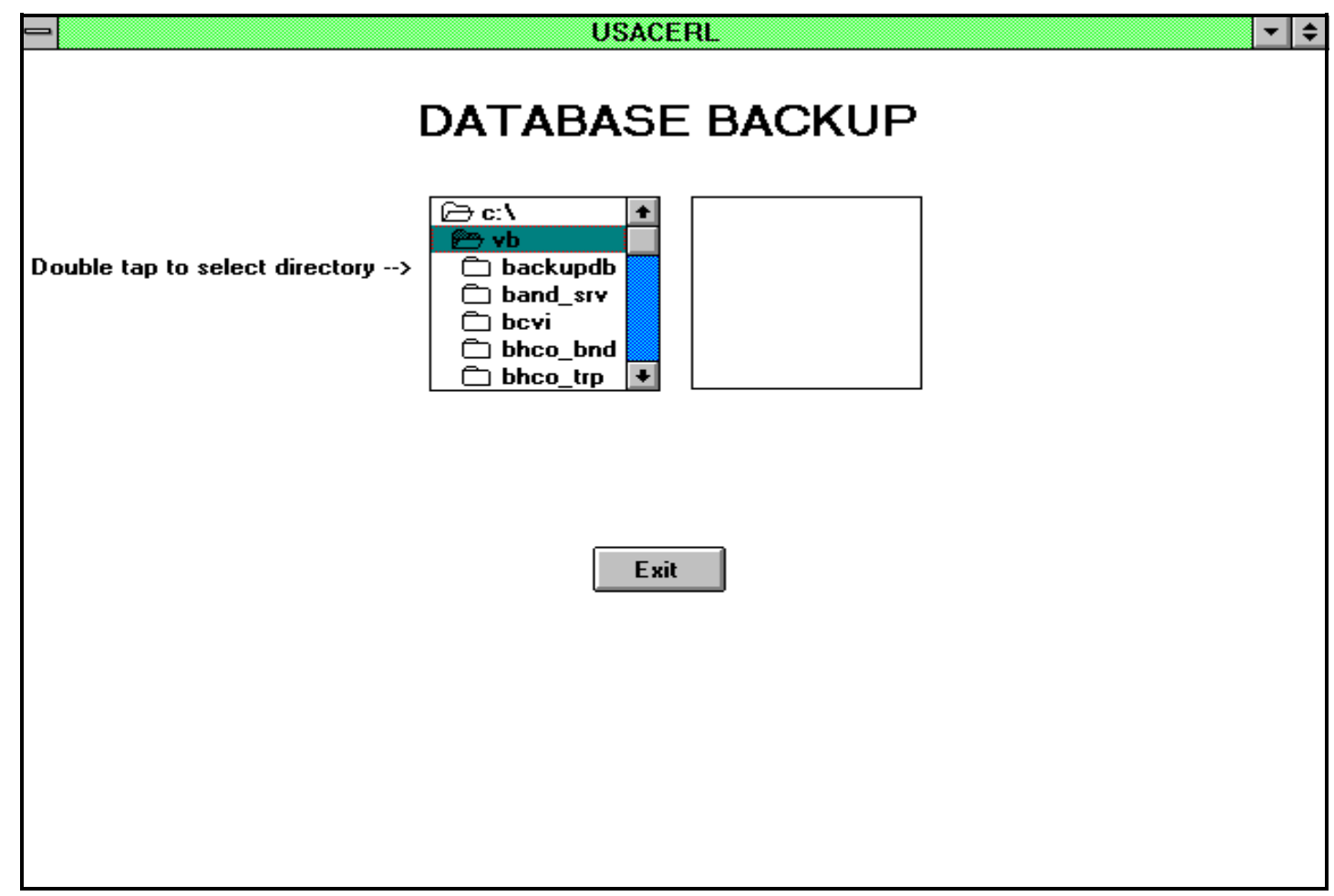

Figure 42. Database backup form. 


\subsection{Program Flow}

Use the scroll arrows to view the subdirectories under $\mathrm{C}: \backslash V B$. Double tap your chosen subdirectory and the list box will display all databases under that subdirectory. Tap the database name you wish to back up and the program will ask you to verify it. From this point, tap Cancel if you want to exit the program. Tap No to return to the beginning and start again. Tap Yes and the program will continue the backup process by asking you to select either the "A:" or "B:" drive to place your disk into. Write "A" or "B" in the text box, insert the appropriate disk, and tap OK. When the back up is complete, the program will issue a message.

\subsection{Exit the program}

To exit the program, tap Exit. All files are closed. 


\section{Data Analysis}

To expedite data analysis, macros written in Microsoft Excel 5.0 were used to analyze the raw data. Macros are nothing more than programs written in the Excel programming language. All macros should be loaded in the directory $\mathrm{C}: \backslash \mathrm{MSOFFICE} \backslash \mathrm{EXCEL} \backslash \mathrm{XLSTART}$ and can be executed by calling them up and selecting 'RUN' from Excel's menu bar. However, to simplify matters, these macros have all been assigned to custom buttons. To run any macro, start Microsoft Excel 5.0 and make sure none of the database files are open. Look for the custom button corresponding to the program you want to run on the custom tool bar. Click the button and the code will automatically execute and an output table will be created.

Sixteen macros are currently available, all of which generate summary tables or lists. Nine macros analyze data on black-capped vireos, five analyze data on goldencheeked warblers, and one each analyze data for brown-headed cowbirds and nontarget birds.

\subsection{BCVI Territory Summary}

This macro called BCVI_TER.XLS uses BCVI.DBF to generate a summary table of BCVI territories per region and training area. The output consists of one Excel sheet with the summary table. Figure 43 shows an example.

\subsection{BCVI Nest Fates and Success Rates}

BCVI_NF.XLS uses BCVI.DBF to generate a summary table of nest fates and success rates per region. The output consists of three Excel sheets. The first two sheets are intermediate tables used during processing. Sheet 3 is the output table summarizing the nest fate totals of all regions plus an added column showing percent success. Figure 44 shows an example. 


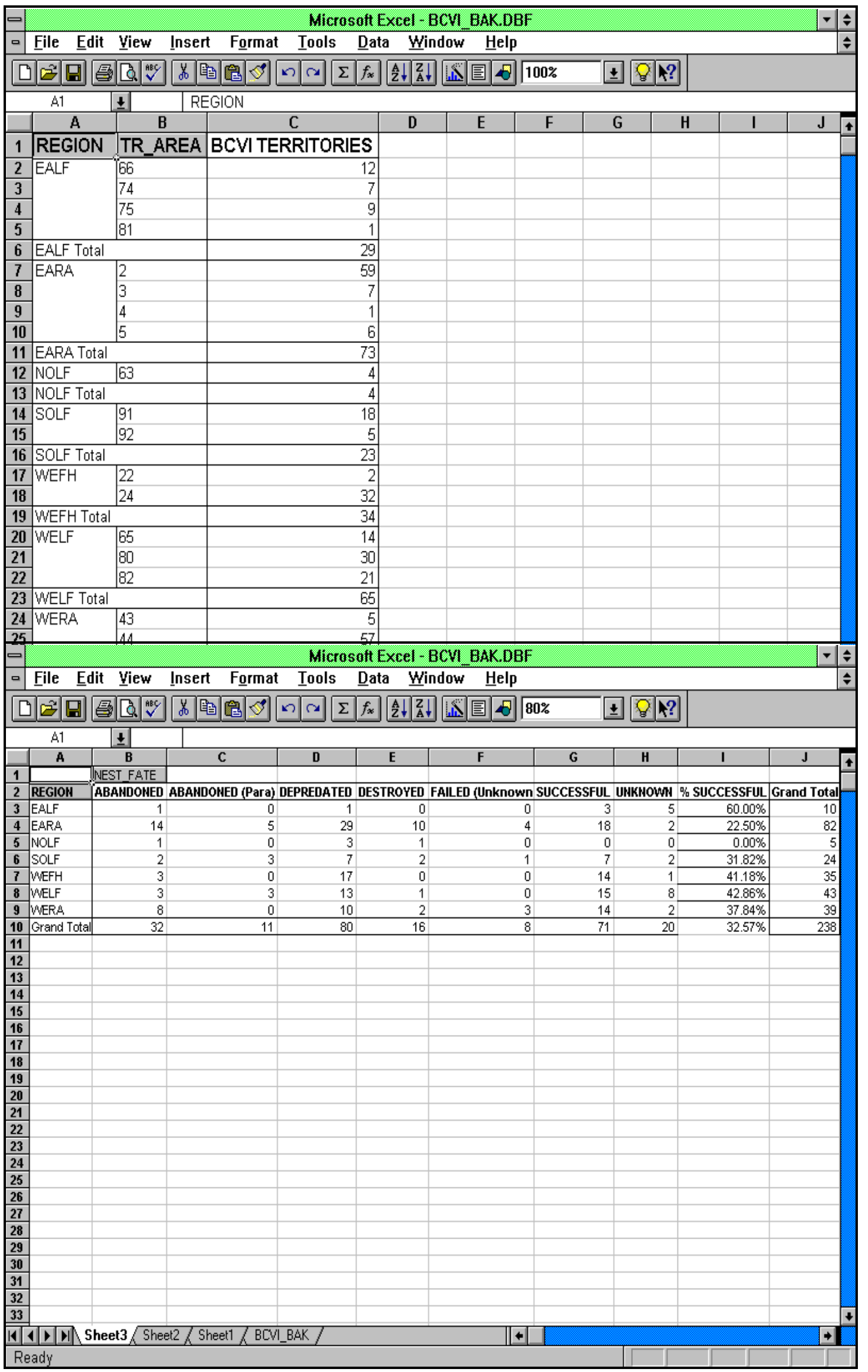

Figure 44. BCVI nest fates and success rates. 


\subsection{BCVI Nest Fates and Success Rates (monitored $>3$ dates)}

BCVI_NF3.XLS is basically the same as the previous macro except that it excludes all territories that were not monitored at least three times. The output will consist of four Excel sheets. The first three sheets are intermediate tables used during processing. Sheet 4 is the output table and has the same format as Figure 44 .

\subsection{BCVI Productivity and Pair Success of Successful Territories}

BCVI_PR.XLS uses BCVI.DBF to generate a summary table of productivity and pair success per region for all territories. The output consists of four Excel sheets. The first three sheets are intermediate tables used during processing. Sheet 4 is the output table summarizing the total number of pairs, successful pairs, and young fledged. Two additional columns show productivity for all pairs and productivity for successful pairs. Figure 45 shows an example.

\subsection{BCVI Productivity and Pair Success of Successful Territories (monitored $>3$ dates)}

BCVI_PR3.XLS is basically the same as the previous macro except that it only includes territories that were monitored three or more times. The output consists

\begin{tabular}{|c|c|c|c|c|c|c|c|}
\hline$=1$ & \multicolumn{6}{|c|}{ Microsoft Excel - BCVI.DBF } & \multirow{2}{*}{\begin{tabular}{c|c}
-15 \\
5
\end{tabular}} \\
\hline - & File Edit & View & Insert Format & Data $\underline{\underline{W}}$ & indow Help & & \\
\hline & 回回耪 & B. & 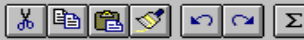 & \begin{tabular}{|lll|l}
$\Sigma$ & $f_{x}$ & $\mathrm{~A} \downarrow$ \\
$\mathrm{Z}$
\end{tabular} & † 正国 & $\pm A ?$ & \\
\hline & $\mathrm{A1}$ & \multicolumn{6}{|c|}{ REGION } \\
\hline & $\mathrm{A}$ & B & $\mathrm{C}$ & D & $E$ & $\frac{\mathrm{F}}{\mathrm{F}}$ & G \\
\hline 1 & REGION & PAIRS & SUCCESSFUL PAIRS & S YOUNG & PROD. FOR ALL & PROD. FOR SUCC. PAIRS & \\
\hline 2 & $\overline{\mathrm{EALF}}$ & 28 & & $\begin{array}{cc}2 & 5 \\
\end{array}$ & 0.178571429 & \multirow{2}{*}{$\begin{array}{r}2.5 \\
2.066666667\end{array}$} & \\
\hline 3 & EARA & 73 & & 15 & 0.424657534 & & \\
\hline 4 & NOLF & 4 & & 0 & 0 & \#DIV/O! & \\
\hline 5 & SOLF & 22 & & 16 & 0.727272727 & $\begin{array}{r}3.2 \\
2769230769\end{array}$ & \\
\hline 6 & WEFH & 34 & & 13 & 1.058823529 & \multirow{2}{*}{$\begin{array}{r}2.769230769 \\
2\end{array}$} & \\
\hline 7 & WELF & 65 & & 12 & 0.369230769 & & \\
\hline 8 & WERA & 62 & & 12 & 0.483870968 & 2.5 & \\
\hline 9 & Grand Total & 288 & & 142 & 0.493055556 & \multirow{2}{*}{2.406779661} & \\
\hline 10 & & \\
\hline 11 & & & & & & & \\
\hline \multicolumn{8}{|l|}{12} \\
\hline \multicolumn{8}{|c|}{13} \\
\hline \multirow{2}{*}{\multicolumn{8}{|c|}{14}} \\
\hline & & & & & & & \\
\hline \multicolumn{7}{|c|}{16} & \\
\hline \multicolumn{8}{|c|}{17} \\
\hline \multirow{2}{*}{\multicolumn{8}{|c|}{$\frac{18}{10}$}} \\
\hline \multirow{2}{*}{\multicolumn{8}{|c|}{$\frac{19}{20}$}} \\
\hline & & & & & & & \\
\hline \multicolumn{8}{|c|}{21} \\
\hline \multicolumn{8}{|c|}{22} \\
\hline 23 & & & & & & & \\
\hline \multicolumn{6}{|c|}{24} & & \\
\hline \multicolumn{8}{|c|}{25} \\
\hline \multicolumn{8}{|c|}{$\frac{26}{27}$} \\
\hline \multicolumn{8}{|c|}{ et4 Sheet3 / Sheet2 / Sheet1 / BCVI / } \\
\hline $\mathrm{R}$ & ady & & & & & [ & $\Gamma$ \\
\hline
\end{tabular}

Figure 45. BCVI productivity and pair success. 
of four Excel sheets. The first three sheets are intermediate tables used during processing. Sheet 4 is the output table and has the same format as Figure 45.

\subsection{BCVI Productivity and Pair Success of All Territories}

BCVI_PRD.XLS uses BCVI.DBF to generate a summary table of productivity and pair success for all pairs of BCVIs with or without nests for each region. The output consists of one Excel sheet summarizing the total number of pairs, young fledged, and productivity. Figure 46 shows an example.

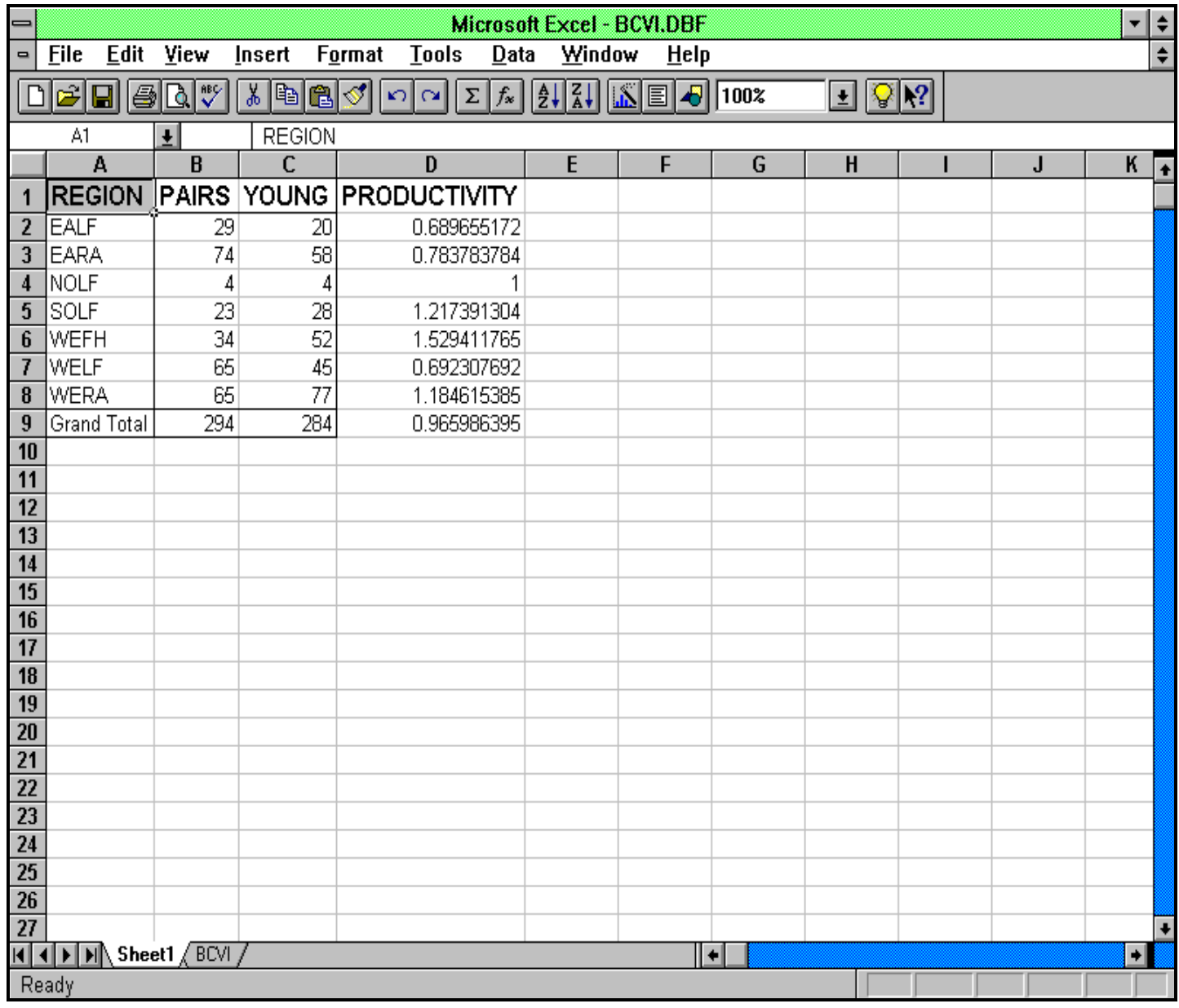

Figure 46. BCVI productivity and pair success for all BCVI pairs.

\subsection{Age Structures for Banded BCVls}

BCVI_AGE uses BCVI.DBF and BCVI_BND.DBF to generate three summary tables of age structures for all banded adult BCVIs. The output consists of three Excel sheets. Sheets 1 and 2 contain age structure summaries for all adult males and females observed. Sheet 3 contains an age structure summary for all male and 


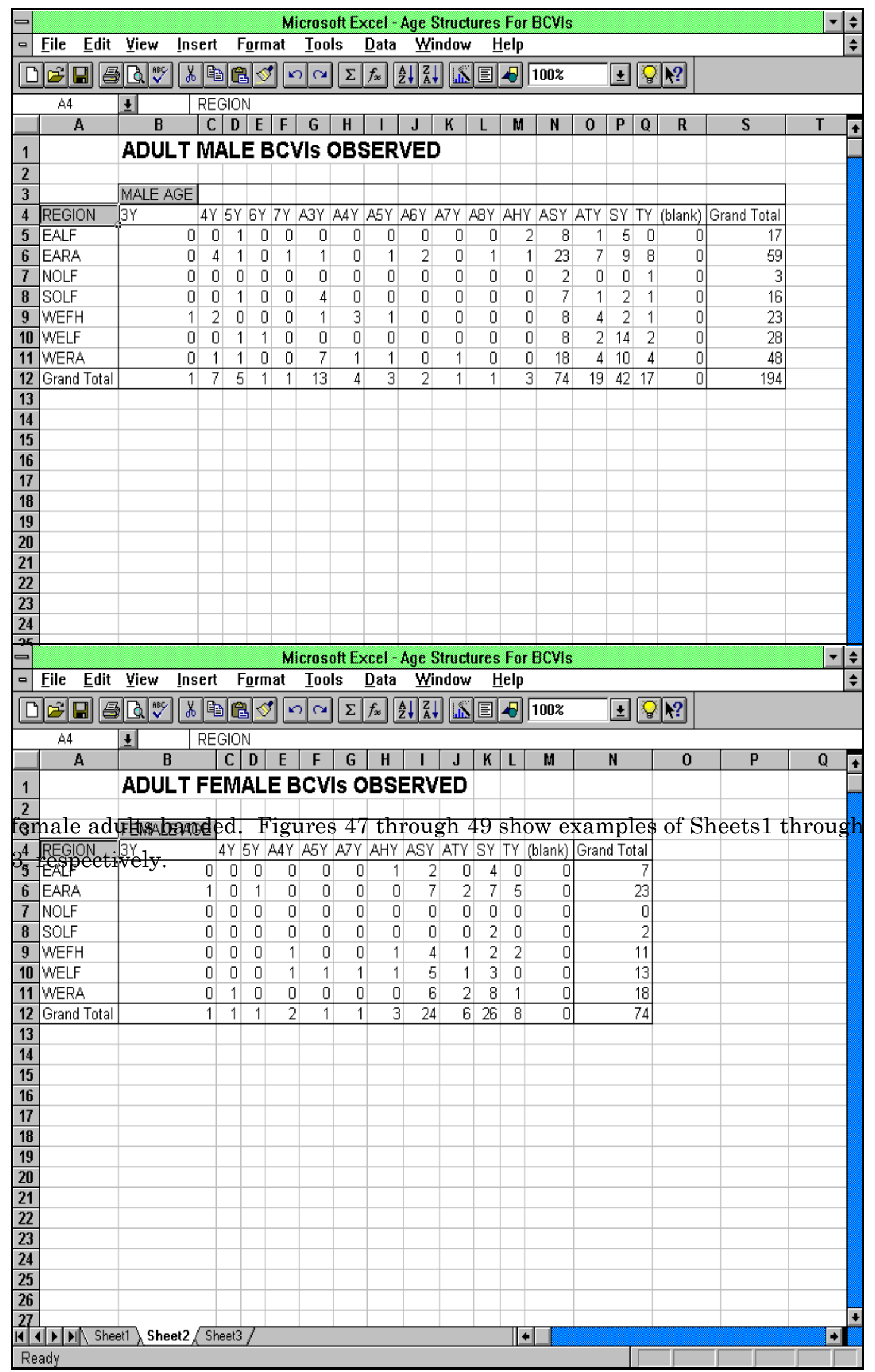

Figure 48. Age structures for adult female BCVI. 


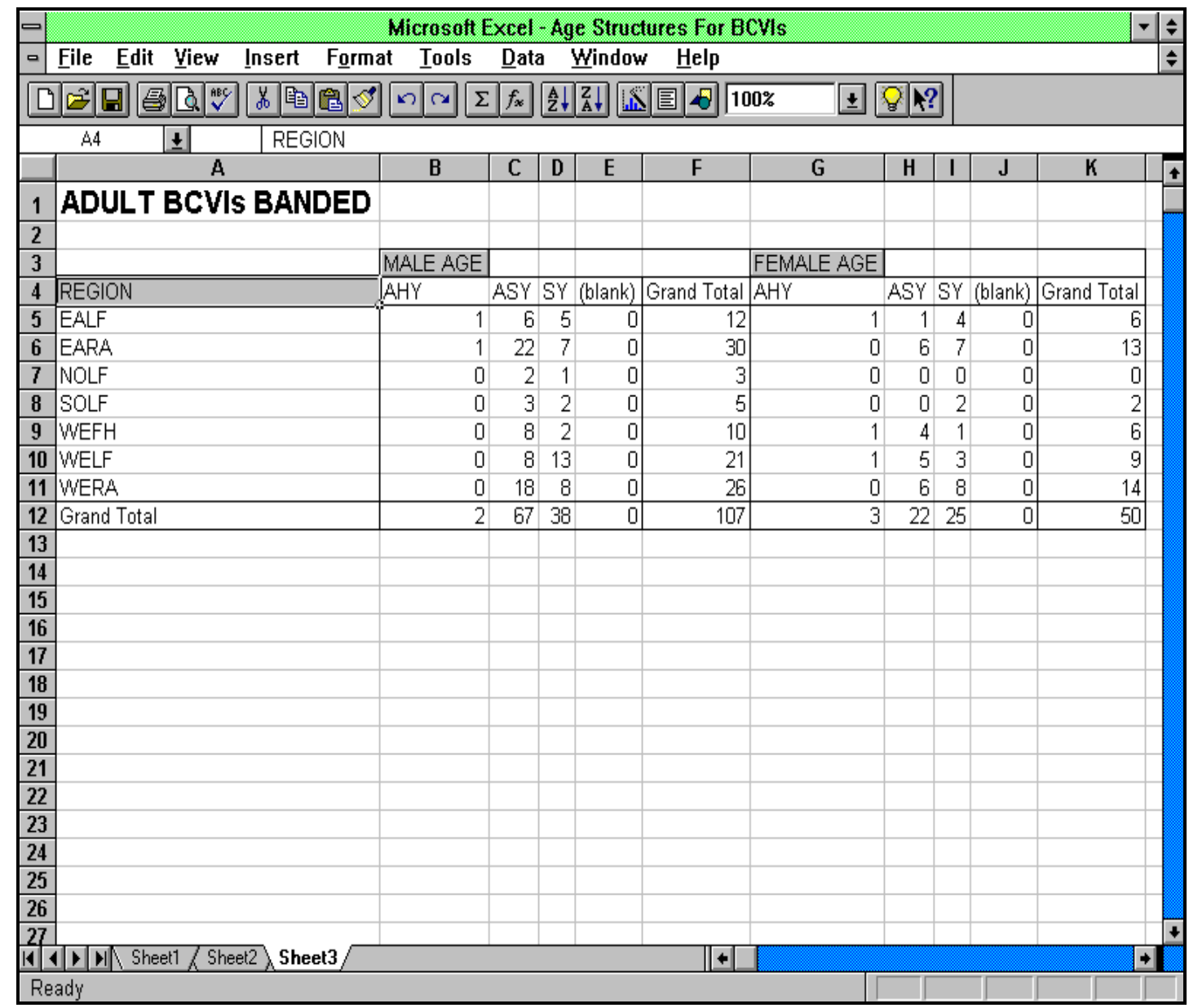

Figure 49. Age structures for banded adult BCVI.

\subsection{BCVI Dispersal Distance}

This macro uses SI_RECAP.DBF to generate a summary table of dispersal distances for returning BCVIs. The output consists of two Excel sheets. Sheet 1 is an intermediate table used during processing. Sheet 2 is the output table summarizing the total number of returning BCVIs, the average dispersal distance, and the number of BCVIs whose dispersal distance was less than 500 meters. Figure 50 shows an example of Sheet 2.

\subsection{BHCO Parasitism Rates of BCVI Nests}

BHCO_PAR.XLS uses BCVI.DBF to generate a summary table of parasitism rates of BCVIs by BHCOs. The output consists of three Excel sheets. The first two sheets are intermediate tables used during processing. Sheet 3 is the output table 


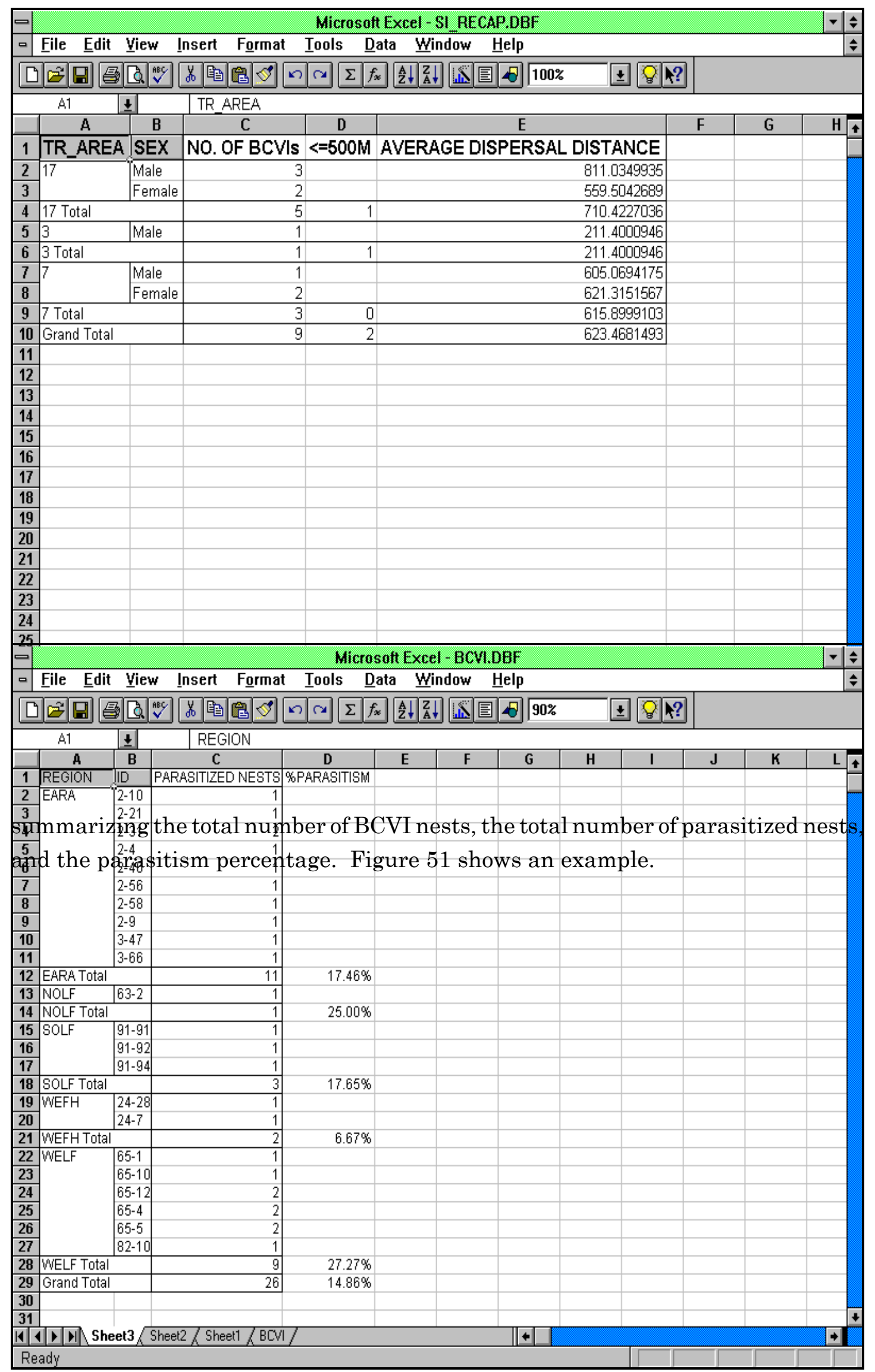

Figure 51. BHCO parasitism rates of BCVI. 


\subsection{BHCO and Non-Target Species Trap Deaths}

BHCO_NTG.XLS uses BHCO_TRP.DBF to generate a summary table of BHCO deaths and incidental trap deaths of non-target species per month. The output consists of one Excel sheet summarizing the total number of male and female cowbirds deaths and incidental non-target deaths. Figure 52 shows an example.

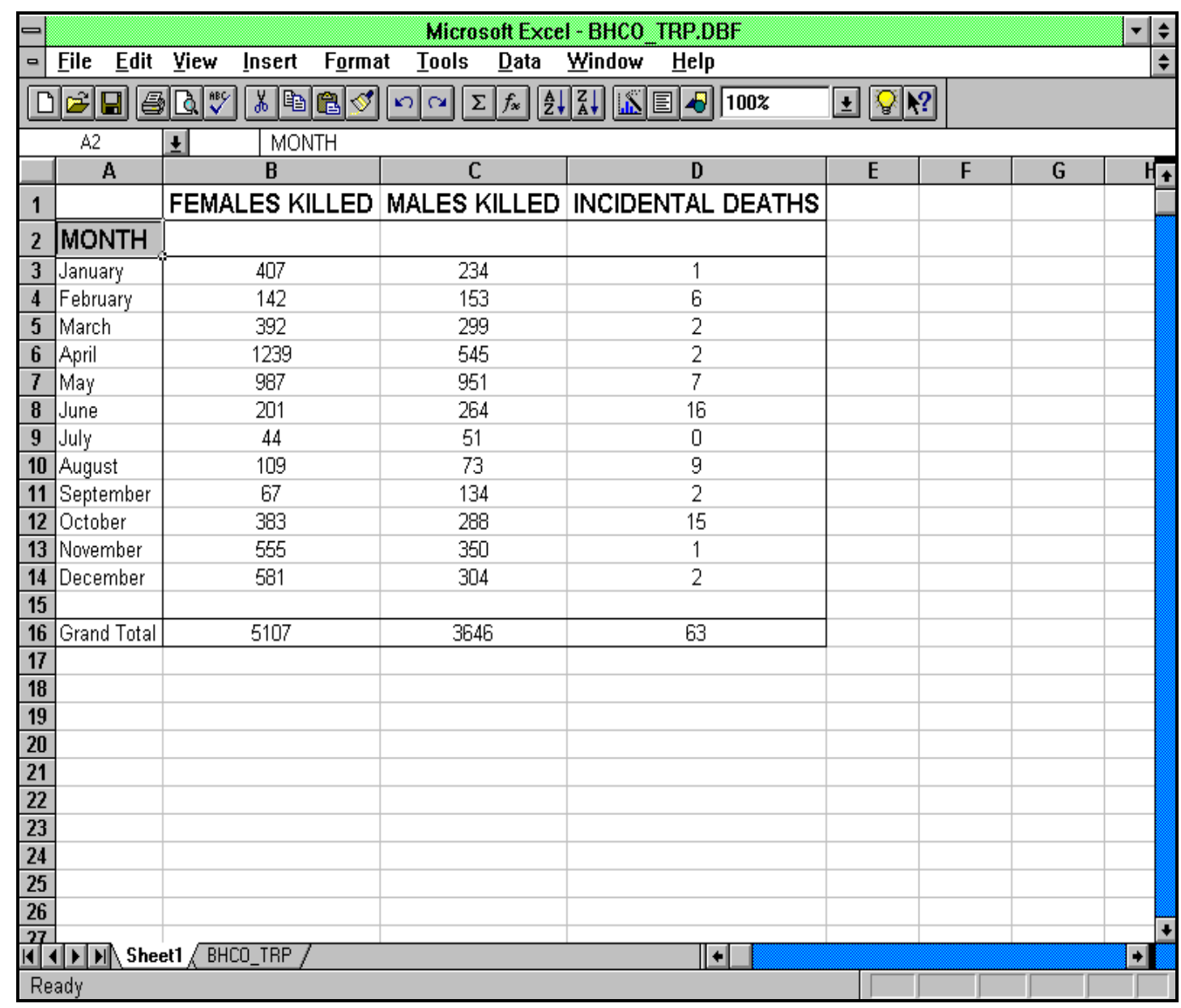

Figure 52. BHCO and non-target species deaths.

\subsection{Breakdown of Non-Target Species Deaths}

NTG_DEAD.XLS uses NON_TARG.DBF to generate a summary table of the different non-target species that were accidentally killed within BHCO traps. The output consists of one Excel sheet containing a breakdown of the number of nontarget deaths per month. Figure 53 shows an example. 


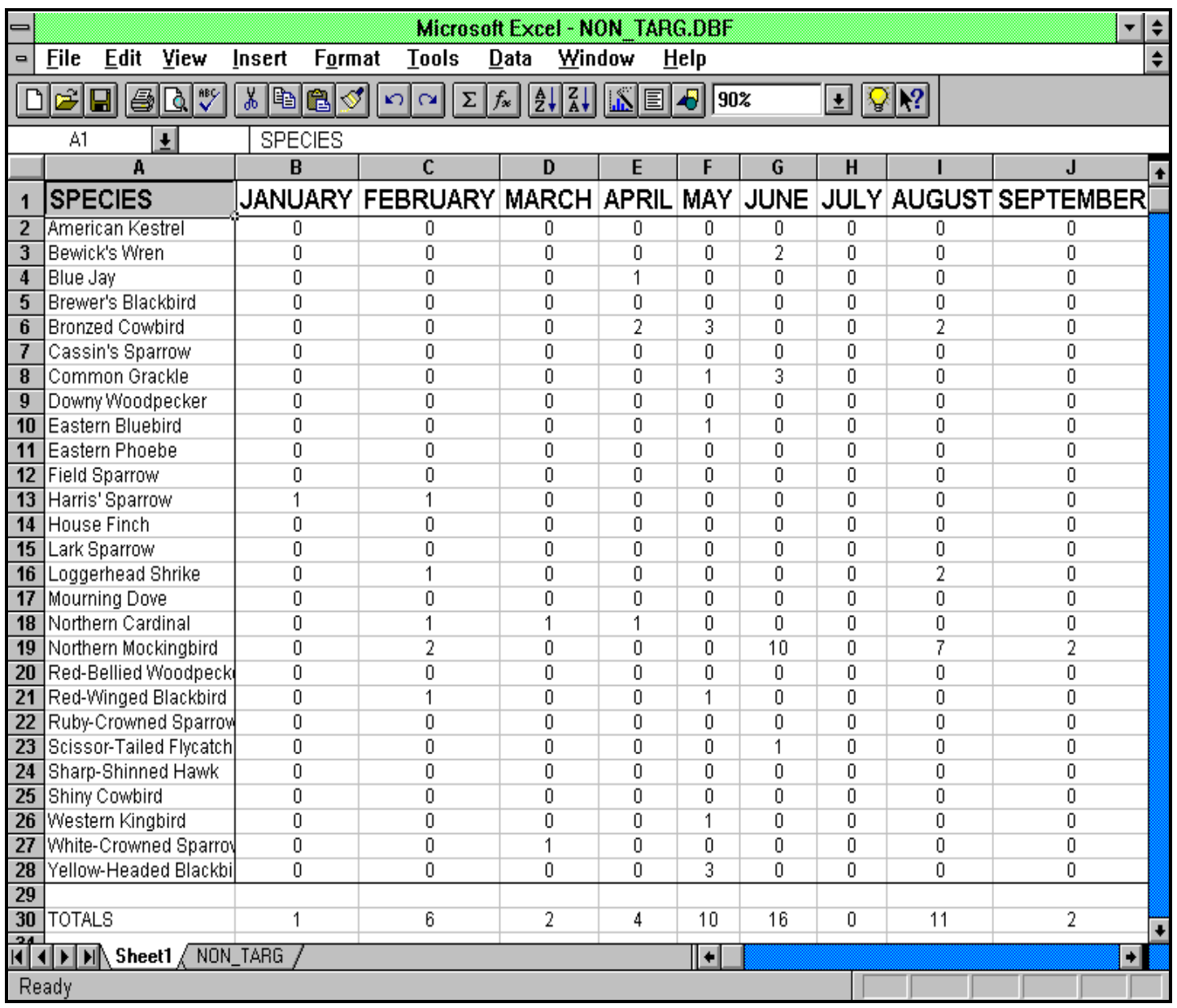

Figure 53. Breakdown of non-target species deaths.

\subsection{Summary of GCWAs Captured}

GCWA_1.XLS uses GCWA_BND.DBF to generate a summary of all GCWAs captured throughout the field season. The output consists of four Excel sheets. Sheet 1 is an intermediate sheet used during processing. Sheets 2 through 4 each contain a different summary analysis. Sheet 2 contains a table of captured GCWAs divided by sex and age. Sheet 3 contains a table of captured GCWAs divided by sex, region, and training area. Sheet 4 contains a table of captured male GCWAs divided by age and training area. Figures 54 through 56 show Sheets 2 through 4 , respectively.

\subsection{Male GCWAs Searched for and Found}

GCWA_2.XLS uses GCWA.DBF to generate a summary of all male GCWAs searched for and found. The output consists of one Excel sheet containing a list of 


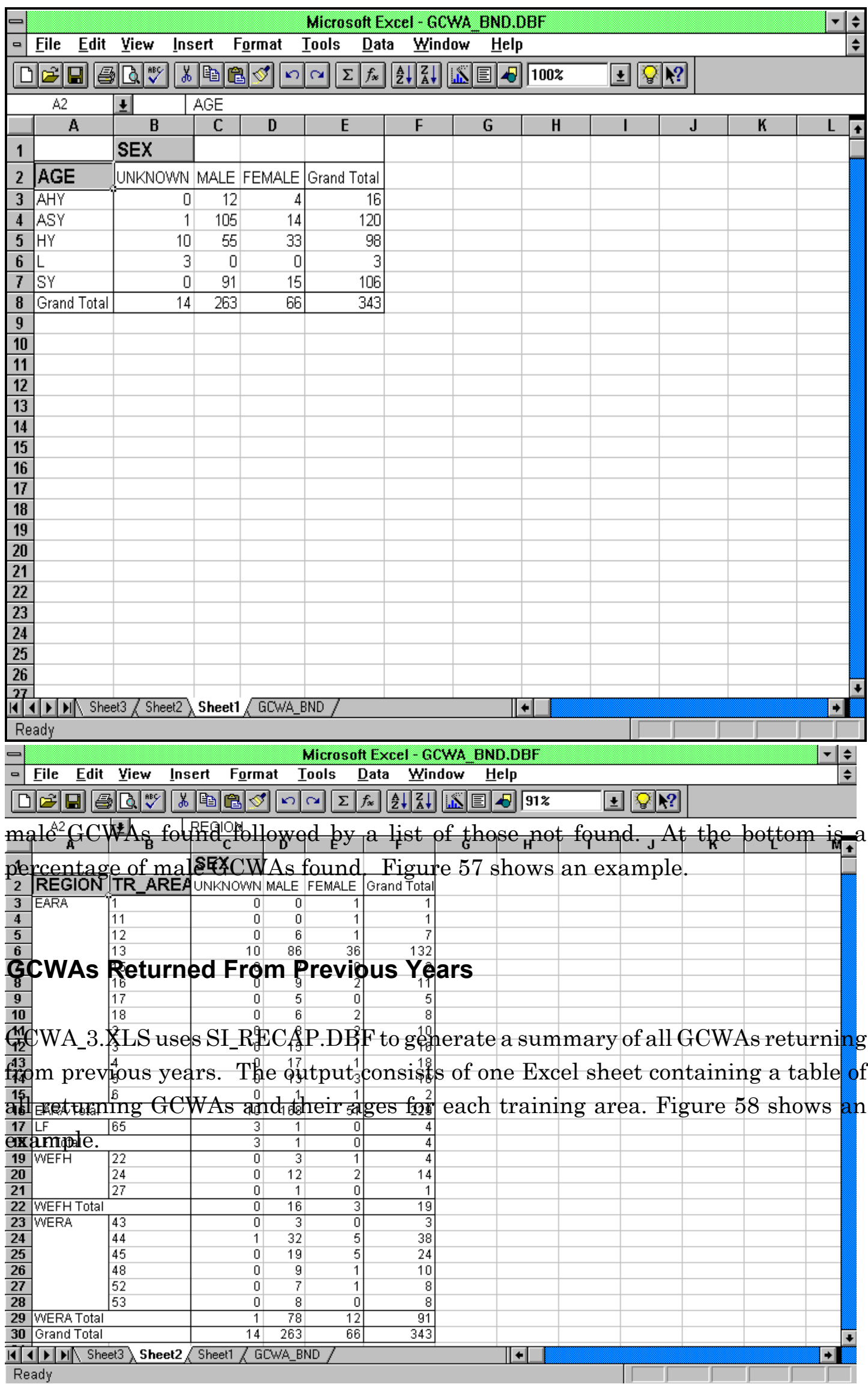

Figure 55. Captured GCWAs by sex, region, and training area. 


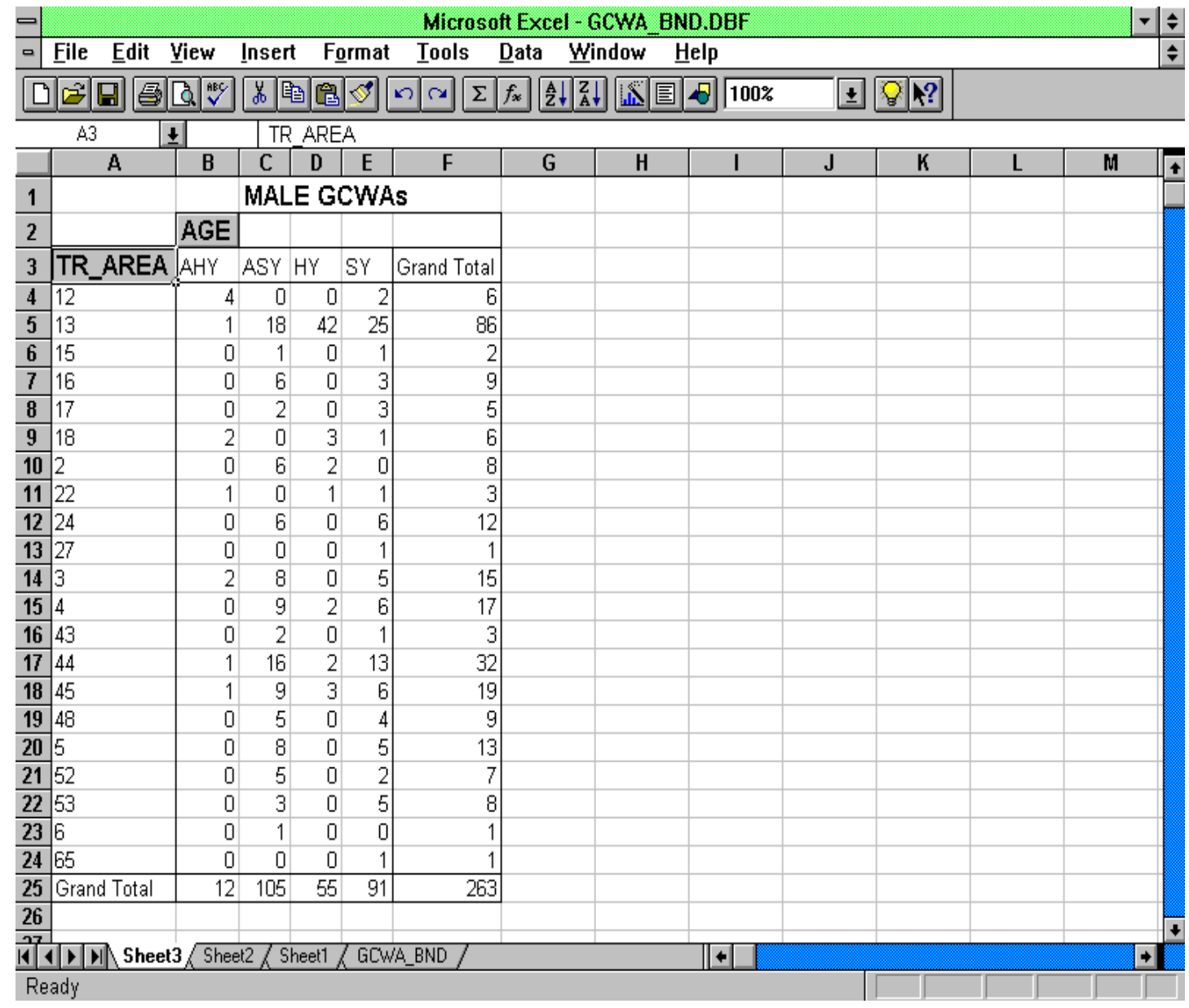

Figure 56. Male GCWAs by age and training area. 


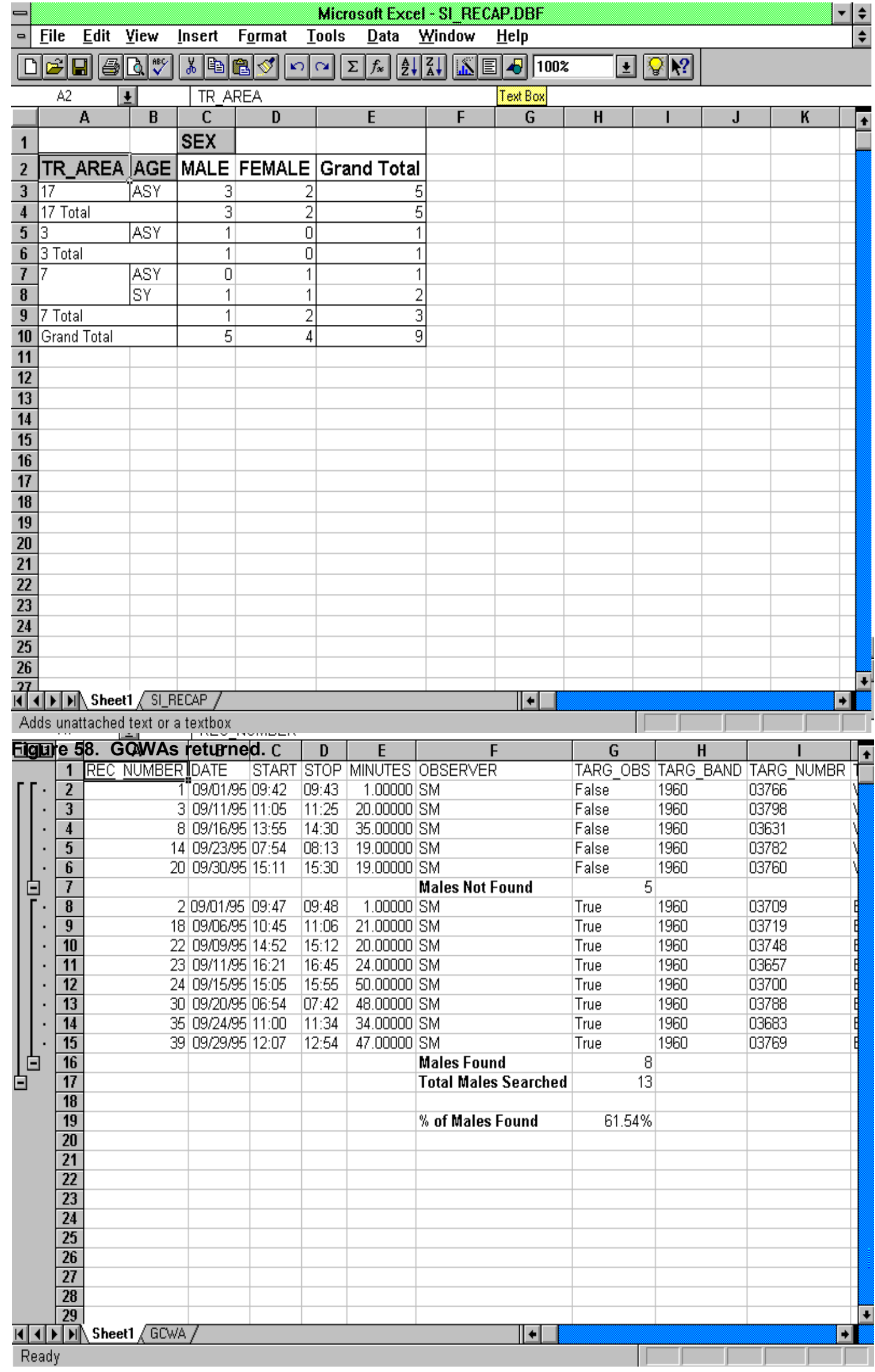

Figure 57. Male GCWAs searched for and found. 


\subsection{GCWA Dispersal Distance}

GCWA_4.XLS uses SI_RECAP.DBF to generate a summary of average dispersal distances for all GCWAs returning from previous years. The output consists of three Excel sheets. Sheets 1-2 are intermediate tables used during processing. Sheet 3 contains a table of all returning GCWAs, how many dispersal distances were less than 500 meters, and average dispersal distance. Figure 59 shows an example of Sheet 3 .

\subsection{GCWAs Detected on Point Counts}

GCWA_5.XLS uses BIRD_CNT.DBF to generate summary tables of GCWAs detected during point counts. The output consists of four Excel sheets. Sheet 1 is a simple table showing how many training areas had GCWAs in them. Sheet 2 is a table of all GCWAs seen per training area. Sheet 3 is a table of all GCWAs heard per training area. Sheet 4 is a table of all GCWAs seen and heard at each point. Figures 60 through 63 show examples of Sheets 1 through 4, respectively. 

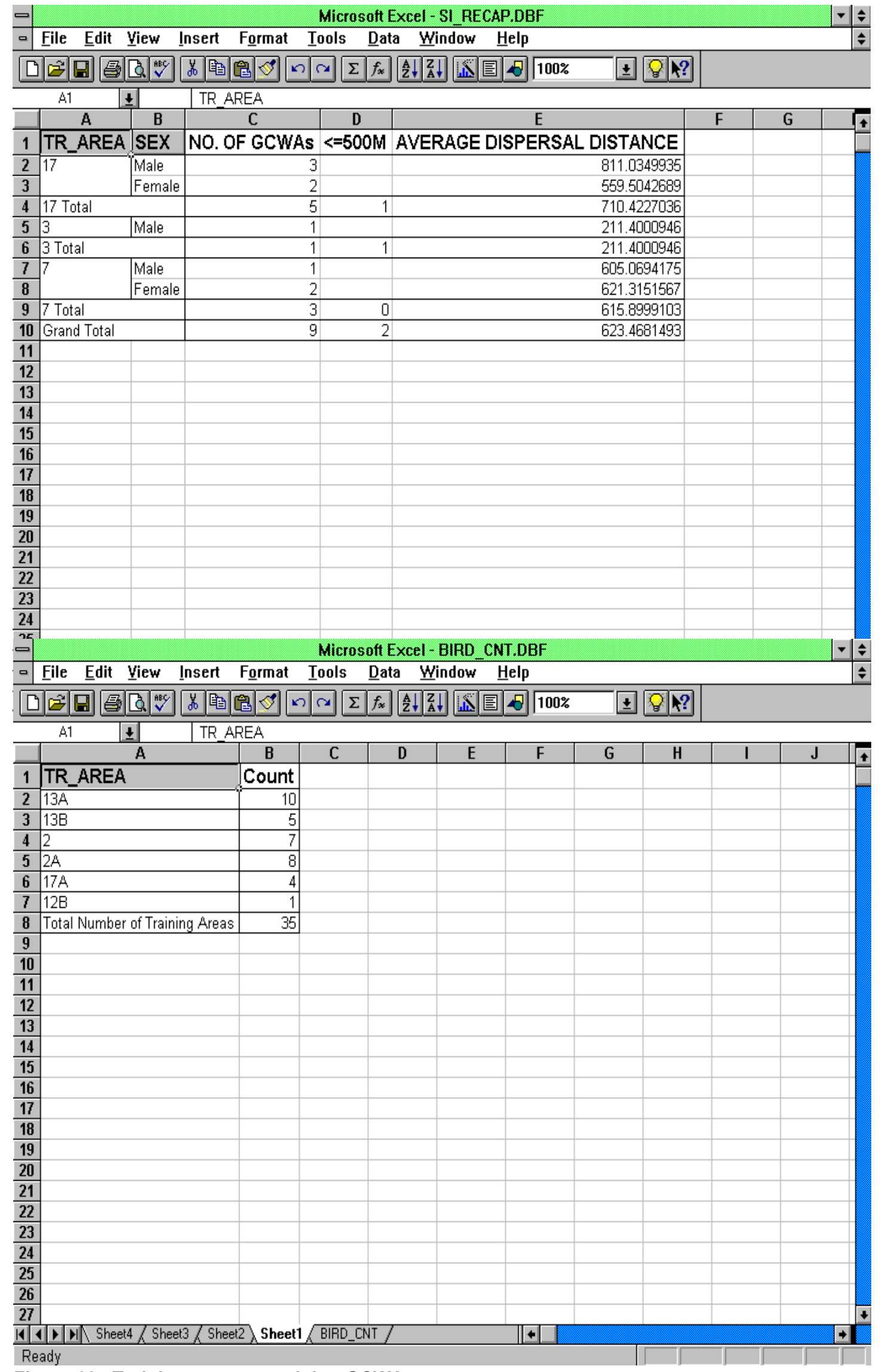

Figure 60. Training areas containing GCWAs. 


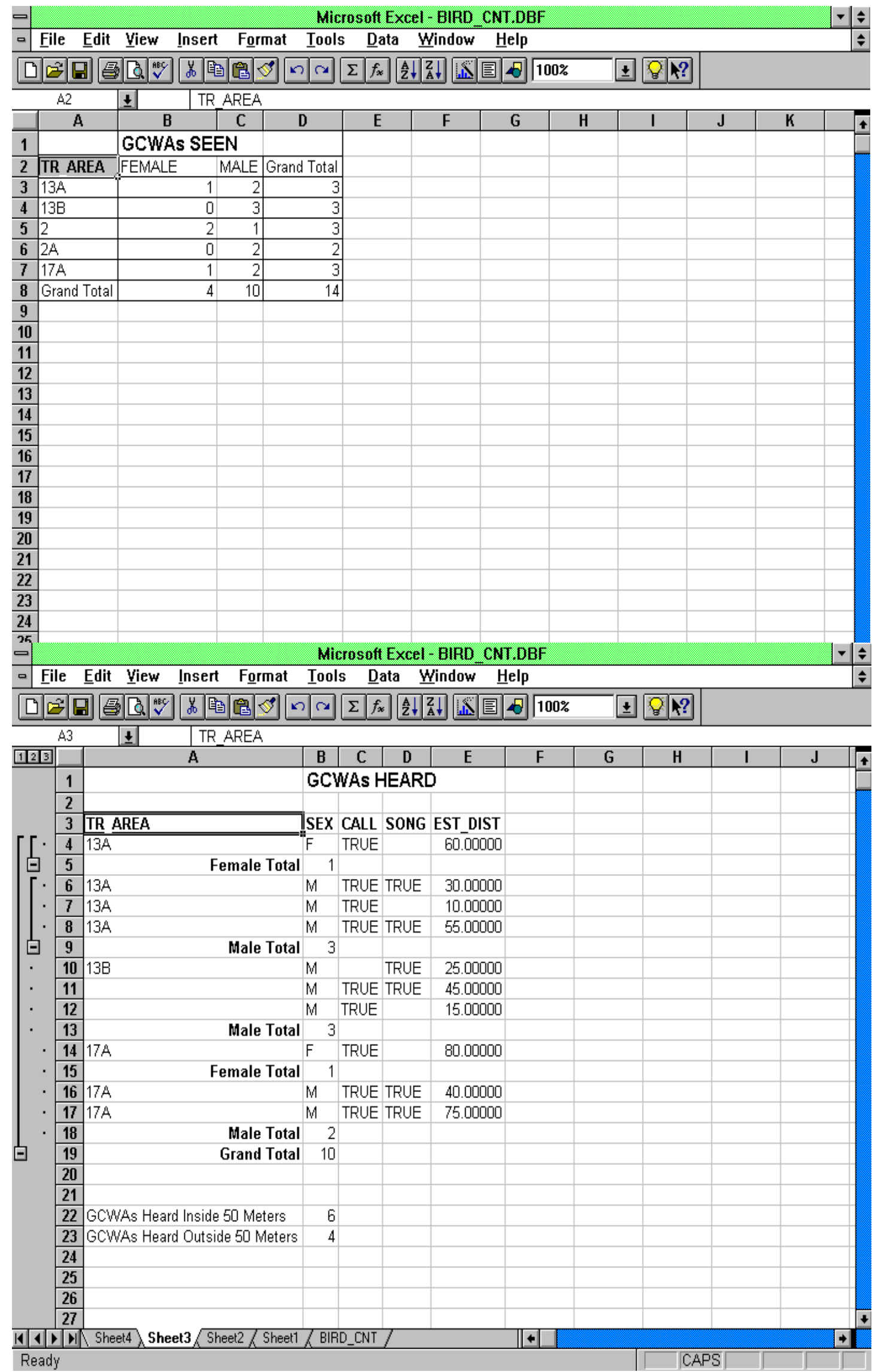

Figure 62. GCWAs heard. 


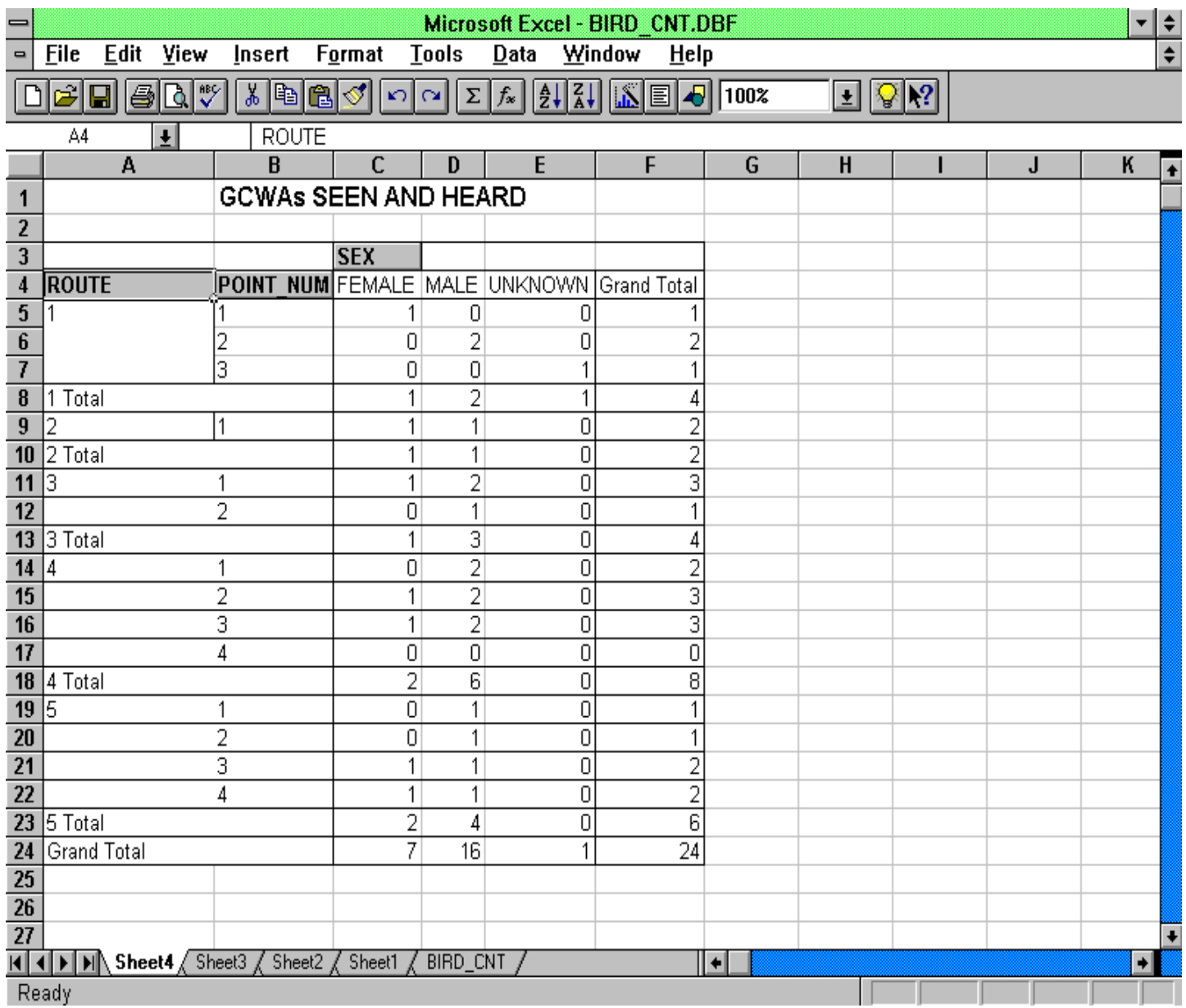

Figure 63. GCWAs seen and heard. 